\title{
Asymmetric and Nonlinear Inter-relations of US Stock Indices
}

\begin{tabular}{|r|l|}
\hline Journal: & International Journal of Managerial Finance \\
\hline Manuscript ID & IJMF-02-2017-0018.R1 \\
\hline Manuscript Type: & Research Paper \\
\hline Keywords: & Inter-relations, Non-linear, Stock markets, Crises \\
\hline \multicolumn{3}{|c}{} \\
\multicolumn{3}{c}{ SCHOLARONE } \\
\\
\multicolumn{3}{c}{ Manuscripts } \\
\end{tabular}




\title{
Asymmetric and Nonlinear Inter-relations of US Stock Indices
}

\author{
June 22, 2017
}

\begin{abstract}
Purpose-This paper will examine the inter-relations among the US stock indices.

Design/methodology/approach-Data of nine US stock indices spanning a period of sixteen years (20002015) are employed. Asymmetries are examined via an error correction model (ECM). Non-linear interrelations are researched via Breitung's nonlinear cointegration, an M-G nonlinear causality model, shocks to the forecast error variance, a shock spillover index and an asymmetric VAR-GARCH (VAR-ABEKK) approach.

Findings-The inter-relations are significant. Our results are robust across all types of inter-relations. They are highest in the Lehman Brothers sub-period. Higher stability after the EU debt crisis enhances the independence and growth of the US stock indices.

Originality/value-To the best of our knowledge, this is the first study to examine the inter-relations of US stock indices. Most studies on inter-relations concentrate on portfolio analysis to reveal diversification benefits among various asset markets internationally. Hence, this study contributes to the literature on the inter-relations of a specific asset market (stock) and in a specific nation (United States). The evident inter-relations support the notion of diversification benefits in the US stock markets.
\end{abstract}

Keywords: Inter-relations; Non-linear; Stock markets; Crises.

JEl Classification: G01; G11. 


\section{Introduction}

The increased inter-relationship of international financial markets and their gradual integration towards a global financial system leaves little space for diversification benefits to pass to the market participants (Gagnon, Power and Toupin, 2016; Mimouni, Charfeddine and Al-Azzam, 2016; among others). Investors favor countries whose returns are more correlated with home assets. This preference for familiarity makes international diversification less effective (Bergin and Pyun, 2016). In addition, the recent US (2008) and EU (2013) financial crises have revealed that the financial markets are heavily interrelated (Gagnon, Power and Toupin, 2016). The US and EU markets affected each other in these crises. The literature has also extensively studied the international impact of these two market failures on the rest of the world (Jin and An, 2016; and, Oztek and Ocal, 2016). The choice of the US stock market is motivated by the important role that this market plays in the world's financial environment. A huge number of studies have deal with the impact of the US financial crisis and EU crisis at the cross market level but few have examined the relative economic phenomena within the same market. We believe that this investigation should have added value to our knowledge. In addition, diversification is a crucial issue: the construction of a "national" portfolio may not be so dangerous if one considers that both systemic and currency risks are absent. These possible strategies are also beneficial to explore.

There are few diversification benefits among the international markets. The main reason for this is their strong interrelation, as mentioned previously. International interrelations are not affected by the geographical distances among international stock markets because all equity markets trade electronically and internationally. Interrelations are also revealed by the extensive use of algorithmic trading internationally (Yang et al.,2015). Most of the transactions in stock markets are implemented with algorithms, without the physical presence of a trader. Time lag also has no influence on algorithmic trading. There may, however, be diversification opportunities within the geographical boundaries of a national market. The main reason for such benefits is the invalid assumption that the indices of the same national market are almost identical and have the same informational content. The recent financial crises, the more expensive cost of external financing and the increased efficiency of internal (national) capital markets (because of increased importance of regulations and corporate governance) increased the diversification benefits in national markets (Mazur and Zhang, 2015). The present study examines the diversification benefits of the national stock markets for the United States. If evidence is found for the most efficient (highly liquid and regulated) equity market, then many more diversification benefits will exist in other less developed or emerging stock markets. The informational content allowing diversification benefits is further enriched by its asymmetric nature, if existent (Kyle, 1985). The importance of asymmetries in portfolio diversification is evident in the very recent literature (e.g. Zhou and Nicholson, 2015; and, Low, Faff and Aas, 2016).

In this paper, several methodological approaches are employed to investigate the long- and short-run dynamic linkages among the most known stock indices in the US stock market. First, an asymmetric error correction model (ECM) is implemented to detect the asymmetric relationships across US stock indices, as 
developed by Apergis and Miller (2006) and recently empirically employed by Koulakiotis (2015). Second, US stock indices are tested for non-linear cointegration relationships, as in Breitung (2001). This non-linear cointegration methodology is primarily used to detect linear relationships among variables and then to test the nature of the non-linear cointegration, and has recently been employed by Choudhry and Osoble (2015). Third, the non-linear causality for US stock indices is investigated via the bivariate noisy M-G model for nonlinear Granger causality, as also recently employed in Choudhry and Osoble (2015). Fourth, the interrelations among US stock indices are detected via the forecast error variance and spillover index, as introduced by Diebold and Yilmaz (2009 and 2012) and suggested by Narayan (2015). Finally, the asymmetric bivriate VAR-GARCH (VAR-ABEKK) model of Kroner and $\mathrm{Ng}$ (1998) has also been implemented to investigate the return and volatility spillover effects among the US indices.

We propose to add to the literature in a number of ways. First, an important number of studies in the empirical literature focus on the interrelations and the diversification benefits in international financial markets but the interconnectedness structures in a geographically integrated market are underestimated in terms of research papers, mainly for the US stock market, in contrast to the euro zone area where there is a comparatively higher number of studies on this issue. Second, a number of methodological approaches are used for the first time, individually or in combination for this issue. Finally, the research questions of this paper are of particular research interest, particularly at a time of political upheaval for the US economy. The upcoming trade protectionism may significantly influence the international trade relations in corporate, investing and financing terms. In its turn, this will drive US investors to look for diversification benefits domestically in the US stock markets.

The analysed US stock indices are the S\&P Dow Jones, NYSE Global and Russell indices groups of indices in the period of 2000-2015. The causal relations change among sub-periods, revealing the importance of the US and EU crises to the interrelations. The most important evidence of strongest interrelations is found during the Lehman Brothers crisis sub-period, which is consistent with Boubaker et al.(2016). Another important result is that the causal interrelations have changed during the crisis and in the post-crisis sub-periods. These results are consistent with those of Alexakis and Siriopoulos (1999), and Sander and Kleimeir (2003) for the Asian crisis in 1997. Similar results are obtained from our cointegration analysis in that the most significant cointegrated relationships are detected during crises sub-periods, and particularly in the Lehman Brothers crisis sub-period. These cointegration results are in line with Sander and Kleimeir (2003), and Ramlall (2009). The asymmetric behavior of the interrelations is evident in financial markets (Vortelinos, 2016). Potential asymmetric response indicates that negative news of one index has a negative effect on the other index; while, positive news does not have any effect. This behavioural aspect of interrelations is evident in our results and is more intense during crisis sub-periods, especially in the Lehman Brothers crisis sub-period. This result is better explained by the literature of behavioural finance. When investors are fearful because of a turbulent environment, they search for negative events because their impact is expected to be more significant. As they react only and more intensively to negative events, they feed the turbulent environment that made them 
fearful. Such investing behaviour creates a vicious circle of negative expectations. This effect of bad news is also identified by the ABEKK model. This result is in the line with that of Philippas and Siriopoulos (2013), who point out that international portfolios should account that dynamic correlation between the Eurozone countries is driven not only by their macroeconomics and fiscal performances but is also influenced by behavioural reasons.

The impact of the recent financial crises in the interrelations has been important to financial markets (Kuppuswamy and Villalonga, 2016). Returns shocks are relatively more important during the two crises, particularly in the Lehman Brother sub-period. This is evident because the increased risk aggravated the detected interdependences. In the post-crisis period, the effects are limited to the forecast error variances of the indices. The spillover index results show that there are greater spillover returns and volatility effects during the post-crisis sub-period compared to other sub-periods. In addition, the investing behavior of market participants became short- rather than long-term oriented because of the crises. The increased and institutional uncertainty in the United States and EU made financial markets more intense in their reactions. The high intention of the market reactions made them less interdependent, particularly in the long run when the reaction effect dies out quicker than before. This explains why our results indicate less intense interrelations in the post-crisis period. Heterogeneity may affect the interrelations (Caccioli et al., 2015; and, Vortelinos, 2016). This is examined via the forecast error variance method, which refers to whether index returns shocks have different magnitudes of impacts on explaining the forecast error variance of other indexes. We found that US stock indexes respond heterogeneously to other indexes return shocks in both crises and post-crises sub-periods, this result is confirmed by implementing ABEKK model.

The rest of this paper is structured as follows. Section 2 reviews the literature. Section 3 describes the data. Section 4 researches the asymmetries among US stock indices. Section 5 examines their dynamic interdependence. Section 6 investigates the importance of US stock index return or volatility shocks in explaining the forecast error variance of other US stock indices. Section 7 examines the volatility transmission mechanism among the US stock indices via a VAR-ABEKK approach. Section 7 draws a conclusion.

\section{Literature review}

The behavior of the financial markets, especially during crises periods, is a crucial issue for investors who are interested in portfolio diversification, risk assessment and management. Many studies have been conducted for this purpose and their common result is that the transmission of shocks from one market to another increase in times of crises (for example Forbes and Rigobon, 2002; Dungey et al.2015, Barunik et al.2016). In addition, the empirical research shows that the recent US and EU financial crises indicate that the financial markets are heavily interrelated (Gagnon, Power and Toupin, 2016). In particular, the US and EU markets affected each other in these crises. The literature has also extensively studied the international impact of these two market failures to the rest of the word (Jin and An, 2016; and, Oztek and Ocal, 2016). 
The term interrelations has been employed in the literature as contagion, interdependence, cointegration, spillover or co-movements. Contagion is defined as the significant increase in the correlation among markets, causing a crisis, which passes to all the other markets (Masson, 1998; Pesaran and Pick, 2003; Corsetti et al., 2005). However, Forbes and Rigobon (2002) noticed that an increase in cross-market correlation during crises may not necessarily indicate contagion because of heteroskedasticity, which can cause cross-market correlations to increase after a crisis, even if there is no increase in the underlying correlations. Therefore, Forbes and Rigobon (2002) propose a method of correcting the heteroskedasticity by adjusting cross-market correlation coefficients. They find no contagion during the Asian crisis of 1997 when the adjusted correlation coefficient is used while they notice that the high level of cross-market correlation coefficient after a crisis only reflects a continuation of strong cross-market linkages. Their conclusion is that there is no contagion, only interdependence. However, Mollah et al.(2016) implemented an unrestricted vector auto regression (VAR), which was originally developed by Forbes and Rigobon (2002), found contagion effects between the US and other either emerging or developed markets during both Lehman Brothers and Eurozone crisis. Boubaker et al.(2016) show similar results. Interdependence has been recently researched by Hon et al.(2004), Chiang et al.(2007), Kenourgios (2014), Luchtenberg and Viet Vu (2015),Tabak et al.(2016),Wang et al.(2017) reporting results similar to contagion literature.

Another part of the literature reveals the importance of interdependence to shock transmissions internationally. Morales and Callaghan (2012 and 2014) underline that the global financial crisis was an event that triggered the problems of the Asian financial market. Furthermore, they indicate that global financial crisis has been differently affecting the world's economic regions. They argue that there is no evidence that supports contagion effects, neither across world market nor across regional market. Meanwhile, their results indicate that instead of contagion the markets suffered mostly from spillover effects, originating from the US economy, and that they were transmitted by some key countries into the different regions (Singapore in Asia and the UK in Europe). In addition, Flavin and Shenan (2015) testing for contagion from the US subprime mortgage-backed securities market to other sectors of the US financial system during the recent crisis find little or no evidence of contagion and they highlight that cross-market interdependencies are central to the transmission of the initial subprime-mortgage market shock across the US financial system. Furthermore, Zhang et al. (2017) investigate 27 markets from Asia, America, and Europe during the period 2006-2015 and find that markets from different continents have strong correlations at specific time shifts. They indicate that a strong linkage is observed both at the same day and of one day delay, especially between Asia-Europe and Asia-America, while they also observe that the time-varying influence strength has abnormal changes during the financial crisis. Previous studies also indicate similar results, for example Wang and Xie (2015) and Kumar and Deo (2012).

Notable parts of empirical research study the dependence and the degree of integration of international financial markets by means of cointegration analysis. However, there are no conclusive results about the specific nature of the dependence of international financial markets. Kasa (1992) uses monthly and quarterly 
data for the period 1974-1990 and examines the stock markets in the United States, Japan, the United Kingdom, Germany, and Canada. His results indicate the presence of a single common trend driving these countries' stock markets. On the other hand, Pascual (2003) does not identify cointegration relationship among French, German, and United Kingdom stock markets for the period 1960-1999. However, time series that are not found to be cointegrated in a period sample cannot be cointegrated in a subsample (Kasa, 1992). Huang et al.(2000) using daily data of the stock markets in China, Hong Kong, Taiwan, Japan and the United States from October 1992 to June 1997, find that there was no cointegration relationship between the Chinese stock market and other markets. Similarly, Zhang and Li (2014) do not find strong cointegration relationships between the Chinese and US stock markets for the period between January 2000 and January 2012. Lucey and Voronkiva (2008) examine the relationships between Russian, EMU Countries, United Kingdom, United States, Japan, Hungary, Czech Republic and Poland, over the period of 1995-2004 and conclude that international markets do not effect on the Russian equity market in the long run while the crisis in 1998 did not change the nature of the long-run relationships. On the other hand, Guidi and Ugur (2014) investigate the degree of integration of South-Eastern Europe (Bulgaria, Croatia, Romania, Slovenia and Turkey) with the market of Germany, the UK and the USA and find that the South-Eastern European markets are cointegrated with the Germany and the UK markets over the period 2000?2013, but not with the USA market over the period of 2000-2013 while they notice the effect of financial crisis. More recently, Al Nasser and Hajille (2016) examine stock market integration among five emerging stock markets (Brazil, China, Mexico, Russia and Turkey) and developed markets of the United States, United Kingdom and Germany. Their results show evidence of short-run integration among markets while the long-run coefficients for stock market returns in all emerging countries show a significant relationship only with German stock market return. Furthermore, Yang, Kolari, and Min (2003) and more recently Gagnon, Power and Toupin (2016) indicate that cointegration relationships among markets is strengthened due to financial crises.

The issue of interdependencies is also examined through modeling the mean and volatility spillovers that exists in financial markets. Volatility spillovers across markets are larger when interdependences among markets are high. Market returns tend to be more correlated when volatility increases while the periods of high volatility are associated with crisis (Wu, 2001). Also, Gamba -Santamaria et al. (2017) indicates that total spillover varies considerably over time while in crisis higher spillovers are detected. Diebold and Yilmaz (2009, 2012, and 2014) introduce a volatility spillover measure based on forecast error variance decompositions from an underlying vector autoregressions model. This framework not only measures previous and current crises but it also measures spillovers at levels outside of the pairwise level through system-wide spillovers. Diebold and Yilmaz (2012) find that the volatility fluctuations among US stock, bond, foreign exchange and commodities markets are quite limited until the global financial crisis. As the crisis intensified, the same happens with volatility spillovers, with particularly important spillovers from the stock market to other markets taking place after the collapse of the Lehman Brothers. In addition, Kumar (2013) analyses the volatility spillovers between exchange rates and stock price in the IBSA nations implementing the model of 


\section{Data}

\subsection{Data description}

Our dataset begins on 3 January 2000 and ends on 28 July 2015, for a common sample total of 3,916 training days. All US stock indices are expressed in US dollars. ${ }^{1}$ All of the US stock indices have the same length of the time-series data with the same start and end date, and they also have their prices deployed for the same dates across the entire sample. The US indices that we studied are the most liquid and well documented internationally. These indices can be classified into their publishers and are as follows: (i) S\&P Dow Jones indices, including S\&P 500 (SPX), S\&P 100 (OEX), Dow Jones Composite (DJA) and Dow Jones Industrial Average (DJI); (ii) NYSE Global index group, including NYSE Composite (NYE) and NYSE AMEX Composite (XAX); and (iii) Russell indices, including Russell 1000 (RUI), Russell 2000 (RUT) and Russell 3000 (RUA). The data were obtained from Datastream.

\subsubsection{S\&P Dow Jones indices group}

The S\&P Dow Jones indices group is a joint venture that is majority-owned by McGraw Hill Financial. From all of the S\&P Dow Jones Indices published, the present paper researches the S\&P 500, S\&P 100, Dow Jones Composite (DJA) and Dow Jones Industrial Average (DJI).

The S\&P 100 (OEX) is a sub-set of the S\&P 500 and measures the performance of large cap companies in the United States. The index includes 100 major, blue chip companies across multiple industry groups. The stocks in the S\&P 100 tend to be the largest and most established companies in the S\&P 500. The average market capitalisation (weighted by market capitalisation) of the S\&P 100 is about twice that of the $\mathrm{S} \& \mathrm{P} 500$

\footnotetext{
${ }^{1}$ The abbreviations of the stock indices are as indicated in the literature.
} 
( $\$ 142$ bn vs. $\$ 68$ bn as of April 2014). So it is larger than a large-cap index.

The S\&P 500 (SPX) index is a US stock market index that is based on the market capitalisations of 500 large companies having common stock listed on the NYSE or NASDAQ.

The Dow Jones Composite (DJA) index is a composite index that measures changes within the 65 companies that make up the three Dow Jones averages: the 30 stocks that form the Dow Jones Industrial Average (DJIA), the 20 stocks that make up the Dow Jones Transportation Average (DJTA) and the 15 stocks of the Dow Jones Utility Average (DJUA). The Dow Jones 65 Composite, like the other three sub-indexes, is price-weighted.

The Dow Jones Industrial Average (DJI) index shows how 30 large publicly owned companies based in the United States have traded during a standard trading session in the stock market. It is the second oldest US market index. It is the sum of the component prices divided by a divisor, which changes whenever one of the component stocks has a stock split or stock dividend.

\subsubsection{NYSE Global index group}

The NYSE Global index group includes the NYSE Composite (NYE) and NYSE AMEX Composite (XAX) index. These indices are published by the New York Stock Exchange (established in 1792).

The AMEX Composite (XAX) index is a capitalisation weighted index that maps all the stocks, ADRs, Closed End investment vehicles. REITs and limited partnerships listed on the American Stock Exchange. It is weighted by its market value (as of the start of the day) as a percent of the total market value for all components. The level of the AMEX Composite is not altered by stock splits, stock dividends or trading halts, nor is it affected by new listings, additional issuances, delistings, or suspensions.

The NYSE Composite (NYE) index is a stock market index that covers all of the common stocks listed on the New York Stock Exchange. Over 2,000 stocks are covered in the index, of which over 1,600 are from US corporations and over 360 are foreign listings. It uses free-float market cap weighting.

\subsubsection{Russell indices group}

The Russell indices group includes the Russell 1000, Russell 2000 and Russell 3000 . The Russell's US indexes cover $98 \%$ of the US equity investable universe and include companies determined to be part of the US equity market according to Russell's robust country classification methodology.

The Russell 1000 index measures the performance of the large-cap segment of the US equity universe. It is a subset of the Russell 3000 Index and it includes approximately 1,000 of the largest securities based on a combination of their market cap and current index membership. The Russell 1000 represents approximately 92\% of the US market. The Russell 1000 Index is constructed to provide a comprehensive and unbiased barometer for the large-cap segment and it is completely reconstituted annually to ensure that new and growing equities are reflected.

The Russell 2000 index measures the performance of the small-cap segment of the US equity universe. 
The Russell 2000 Index is a subset of the Russell 3000@ Index, representing approximately $10 \%$ of the total market capitalisation of that index. It includes approximately 2,000 of the smallest securities based on a combination of their market cap and current index membership. The Russell 2000 is constructed to provide a comprehensive and unbiased small-cap barometer and it is completely reconstituted annually to ensure that larger stocks do not distort the performance and characteristics of the true small-cap opportunity set.

The Russell 3000 index measures the performance of the largest 3,000 US companies representing approximately $98 \%$ of the investable US equity market. The Russell 3000 Index is constructed to provide a comprehensive, unbiased and stable barometer of the broad market and it is completely reconstituted annually to ensure that new and growing equities are reflected.

\subsection{Subsamples (robustness)}

As suggested by Narayan (2015), the robustness of the results in such a study needs research in different subsamples. Consequently, in the present paper, the following three subsamples are employed:

(1) Lehman Brothers crisis sub-sample: 1 September 2008-7 December 2010. This period starts with the expansion of the FED and ECB balance sheet because of the liquidity issues that seized financial markets following the collapse of Lehman Brothers (Cukierman, 2013).

(2) EU crisis sub-sample: 8 December 2010-31 March 2012. This period starts with the beginning of the EU debt crisis and ends with the completion of the Greek sovereign crisis (Cukierman, 2013).

(3) Post-crisis sub-sample: 1 April 2012-28 July 2015. This period starts after the end of the Greek sovereign crisis up to the end of the sample. It can be considered as the ex-post-crisis period, for the purposes of the present study.

\subsection{Preliminary data analysis}

\subsubsection{Descriptive statistics}

Descriptive statistics for all indices are depicted in Tables $1 \mathrm{~A}$ and 1B, concerning full sample and sub-periods, respectively. Standard deviations are close to zero, indicating low dispersion from the mean. The highest standard deviation was observed in the Russell 2000 (0.0158) while the lowest was observed in the Amex Composite (AMEX) index (0.0114). Among the sub-periods, we observe higher standard deviation in Lehman Brothers and EU crises sub-periods, while they decrease in post-crisis sub-period. This result refers to all indices because of the financial crises. The skewness metric is used in order to examine the asymmetry threshold effect. We observe that skewness is negative for all indices, which means that the distribution of returns is skewed to left and is thicker in the lower tail. Greater asymmetries are observed in EU crisis subperiod than the other sub-periods. Kurtosis is quite high for all indices, which means that their distribution is heavy tailed. In addition, kurtosis is lower in the sub-periods rather than the full sample. Jarque-Bera and Ljung-Box tests for normality are conducted to test whether the series are normally distributed. The results 
indicate that the series of all indices are not normally distributed because the null hypothesis of normality is rejected at a 5\% significance level. We also observe that series has interdependence through Ljung-Box test because the null hypothesis states that the data are independently distributed, which is rejected at a $5 \%$ significance level.

[Insert Table $1 \mathrm{~A}$ about here]

[Insert Table 1B about here]

\subsection{Asymmetries in the relationship across US stock indices}

Following Koulakiotis et al. (2015) and as suggested Apergis and Miller (2006), an ECM with four dummy variables is employed to magnify the asymmetric response of exchange rates to stock market news:

$$
\begin{gathered}
E C=\text { Index }_{1}-a_{0}-a_{1} \cdot \text { Index }_{2} \\
\Delta E R=a_{0}+\beta_{1} \cdot \Delta E R_{i}+\beta_{2} \cdot \Delta s^{-}+\beta_{3} \cdot \Delta s^{+}+\beta_{4} \cdot \Delta s^{s}+\beta_{5} \cdot \Delta s^{l}+\beta_{6} \cdot E C+\nu
\end{gathered}
$$

where $\triangle E R$ is the first difference of Index $_{1}$ that when lagged (by $i$ AIC lags) becomes one of the explanatory variables; $\beta_{1}$ indicates the effect of long-term lagged Index 1 returns difference; $\beta_{2}$ and $\beta_{3}$ indicates the effect of short-term negative and positive news on Index 1 difference; $\beta_{4}$ and $\beta_{5}$ measures the effect of short-term small and large news on Index 1 difference, respectively; $\beta_{6}$ is the effect of long-term lagged error correction term; $\sigma$ is the standard deviation of the Index $\operatorname{return}_{2} s^{S}$ is the dummy variable whether $\Delta s$ equals to or less than $-\sigma\left(\Delta s^{S}=1\right)$ or not $(0) ; \Delta s^{-}$is the dummy variable whether $\Delta s$ equals to or less than $0\left(\Delta s^{-}=1\right)$ or not $(0) ; \Delta s^{+}$is the dummy variable whether $\Delta s$ is greater than $0\left(\Delta s^{+}=1\right)$ or not (0); and, $\Delta s^{l}$ is the dummy variable whether $\Delta s$ equals to or greater than $\sigma\left(\Delta s^{l}=1\right)$ or not $(0)$. The short-term positive/negative effect is compared to the short-term small/large effect ( $F_{1}$ test); null hypothesis $H_{0}: \beta_{2}+\beta_{3}=\beta_{4}+\beta_{5}$. The positive or negative short-term effect is tested using another F-test $\left(F_{2}\right.$ test $)$; null hypothesis $H_{0}: \beta_{2}=\beta_{3}$. The small or large short-term effect is tested using $F_{3}$ test; null hypothesis $H_{0}$ : $\beta_{4}=\beta_{5}$. A $T$-test is employed to test the difference between the small and negative effect $\left(\beta_{2}-\beta_{3}\right)\left(T_{1}\right.$ test $)$; as well as the difference between positive and negative effect $\left(\beta_{4}-\beta_{5}\right)\left(T_{2}\right.$ test). Finally, the long-term effects are summarised in the $\beta_{6}$ coefficient of the error correction $(E C)$.

This sub-section refers to the potential asymmetric response of one index to any other index's news. Results for the full sample as well as the Lehman Brothers crisis, EU crisis and post-crisis sub-periods are presented in Tables $2 \mathrm{~A}-2 \mathrm{D}$, respectively. The coefficient of $\Delta E R$ indicates the effect of long-term lagged index return difference. In the full sample results (Table $2 \mathrm{~A}$ ), there is a strong negative effect of long-term lagged index return difference for most of US stock indices. There are fewer indices in the Lehman Brothers crisis sub-period and even fewer in the EU crisis sub-period with a significant effect of long-term lagged index return difference when compared to the full sample (Tables $2 \mathrm{~B}-2 \mathrm{C}$ ). The post-crisis sub-period (Table 2D) is 
the sub-period with the lowest effects of long-term lagged index return difference, among full sample and all sub-sample periods. It is also important to note the only indices that affected in long term are RUI and the S\&P Dow Jones Group indices. Next, the results of the asymmetric effects are provided in detail.

[Insert Table 2A about here]

[Insert Table 2B about here]

[Insert Table 2C about here]

[Insert Table 2D about here]

First, the asymmetries are examined in terms of news direction. Concerning the full sample (Table 2A), the impact of negative news is higher in absolute terms than the one of positive news; these results are as expected. The former is negative and the latter positive, while the former is higher than the latter in absolute terms. For example, the positive news effect is positive for the effect of RUI on XAX (0.6250), NYE (0.3570), SPX (0.4578), OEX (0.5978) and DJI (0.3610), while the negative news of RUA and NYE indices effect on DJA is negative (-6.73 and -5.55) and higher in absolute terms. In the Lehman Brothers sub-period (Table 2B), the EU crisis sub-period (Table 2C) and the post-crisis sub-period (Table 2D), there is evidence that the negative news of one index is statistically significantly and negatively affects another index; however, the positive news does not have a statistically significance effect. These results are similar to those in the full sample period but here they hold for more US stock indices. Comparing the results across sub-periods, for the effect of negative and positive news it is obvious that markets react to negative news while positive news does not seem to be so important. This result is in line with Apergis and Miller (2006).

Second, the asymmetries are examined in terms of the size of the news effect. In most of the cases, the small news effects on indices are higher than the large news effects. In addition, the F3-test is employed to test the differences between the small and large short-term effect $\left(H_{0}: \beta_{4}=\beta_{5}\right)$. The results show that the small news effects are different to large news effects, at a $1 \%$ significance level, in all cases and for all periods.

Third, the asymmetries are examined in terms of the duration of the news effect. The short-run effects on indices are positive, while the long-run effects are negative. The results are consistent in full sample and all sub-sample periods. The short-run effects are higher (sign dependently) than long-run effects. This is a robust result across full sample and sub-sample periods. It is also consistent with Koulakiotis et al.(2015). In addition, the long-run effects are time dependent because of their dispersion across sub-sample periods. The major result is that the short-run effects are higher than the long-run effects, which is stronger in the crises sub-periods. This can be attributed to the changed investing behavior of market participants in crises. The degree of their risk aversion increases and they look for a higher compensation for the increased market uncertainty. As far as the news effect is higher in the short-run, asset allocation is better to happen in the long-run in order for the overall portfolio variance to be minimised.

Fourth, the reason of asymmetric effects is further assessed. We examined whether the size or direction asymmetric effect is more significant. The short-term positive/negative effect is compared to the short-term small/large effect (F1 test). The null hypothesis $\left(H_{0}: \beta_{2}+\beta_{3}=\beta_{4}+\beta_{5}\right)$ is rejected at a $1 \%$ significance level 
for most indices in the full sample (Table 5A) and sub-sample periods (Tables 2B-2D); however, there are few cases in the crises sub-sample periods that the null hypothesis is accepted.

Fifth, the significance of the difference between positive and negative short-term effects is tested using the F2-test $\left(H_{0}: \beta_{2}=\beta_{3}\right)$. The results indicate that positive effects are statistically different to negative effects in all cases.

Finally, a t-test is employed to examine the difference between negative and positive effect $\left.\beta_{2}-\beta_{3}\right)\left(T_{1}\right.$ and the difference between small and large effect $\left.\beta_{4}-\beta_{5}\right)\left(T_{2}\right.$. In all cases, both t-tests indicate a statistically significant difference. This means that the effect of positive (small) news of one index is significantly different to the negative (large) news of another, respectively.

In summary, the crises have changed the interrelations of US stock indices and they have created new prospects in asset allocation. Long-term relations seem to diminish in the post-crisis sub-period. This happens because the market conditions change dramatically after crises periods. We found that the impact of one index to another is time dependent. So, the interdependence, and particularly in the after crises periods, should be further examined.

\section{Dynamic interdependence across US stock indices}

The present section researches Breitung's non-linear cointegration relationships and the M-G non-linear causality model across US stock indices, as recently studied in Choudhry and Osoble (2015).

\subsection{Breitung's non-linear cointegration}

Breitung (2001) indicates two statistics for linear cointegration relationships in the bivariate tests and provides another test (score) statistic to distinguish linear from non-linear using the rank statistics. Tables 3A and 3B present the results of these test statistics, both correlation adjusted and unadjusted. Table $3 \mathrm{~A}$ presents the results for the full sample and Lehman crisis sub-sample periods, while Table 3B presents the results for the EU crisis and the post-crisis sub-periods. Cointegration relationships exist between all pairwise indices as the rank test statistics reject the null hypothesis of no cointegration at the $1 \%$ significance level. $\kappa$ and $\xi$ refer to the case of the unadjusted version of the test, while $\kappa^{* *}$ and $\xi^{* *}$ refer to the corrected high correlation version of the test.

[Insert Table 3A about here]

[Insert Table 3B about here]

According to Table $3 \mathrm{~A}$ and regarding the full sample period, there is evidence of significant cointegrations among most of the US stock indices. Regarding the Lehman Brothers crisis sub-period, most indices are significantly cointegrated. However, there are some discrepancies between the two tests. The correction adjusted version of the test indicates less cointegrating relationships than the unadjusted for both full sample and Lehman Brothers crisis sub-period. In particular, both $\kappa^{*}$ and $\xi^{* *}$ tests have their null hypothesis of no 


\subsection{M-G non-linear causality model}

Table 4 reports results for the non-linear Granger causality relationships from M-G model between indices. In the full sample the results indicate strong interactive causality relationships among indices because the null hypothesis that one index's returns do not cause another index's returns is rejected at $1 \%$ significance level. The only exception is that the XAX Index does not detect any causal relation in any index. The absence of XAX causality with other indexes has also been found in the Granger causality test. XAX's behavior should be taken into account by fund managers and portfolio managers, who may use it for diversification purposes. In the Lehman Brothers sub-period, the results indicate similar causal relations to full sample period. However, it is worth mentioning that some pairwise indices seem to have lost their strength of causality compared to the full sample causalities. Such pairwise indices are NYE with DJA, DJI and SPX. In addition, the interactive causal relationship between RUI and NYE is less strong because the null hypothesis is rejected at significance level 5\%. In EU crisis sub-period, the results show interactive causal relationships but these are less strong than both full sample and Lehman Brothers sub-sample periods. In this sub-sample period, no causal relation between NYE with DJA, DJI and SPX is detected, which is in contrast to the Lehman Brothers sub-period and full sample sub-period where it is observed in a strong degree. In addition, the XAX index seems to affect some indices. In the post-crisis sub-period, it is obvious that the relations are changed, with the single exception of RUI. The strong and interactive causal relations do not exist, this result is consistent with the linear Granger causality test and is also consistent with Sander and Kleimeier (2003), who found a changed causality relation from the pre- to post-Asian crisis (1997) period.

[Insert Table 4 about here]

In summary, the M-G model of non-linear (symmetric) causality test indicates strong non-linear Granger 
causality relationships among US stock indices in the full sample and Lehman Brothers sub-sample periods, while less evidence in favor of causality is indicated in the EU crisis sub-period and there is almost no nonlinear causality in the post-crisis sub-period. Many differences in the results between traditional Granger Causality and M-G non-linear model are found; such as the strong causal relationships between DJI with Russell group indices in full sample that was found by the non-linear causality test and not found by the linear test. The two (linear and non-linear) methodologies converge to the fact that there are more and stronger causal relationships in the Lehman Brothers crisis, fewer in the EU crisis and much less (close to non-existent) in the post-crisis sub-period. This result reveals the possible importance of the locality in financial markets. Specifically, a market is more heavily affected by a crisis that took place in its geographical boundaries than anywhere else. Such an effect is revealed by stronger interrelations of the market constituents. Moreover, Alexakis and Siriopoulos (1999), who conduct linear and non-linear causality tests, indicate that research should consider non-linear mechanisms when evaluating models of the relationships between stock exchanges because the non-linear approach to causality testing can detect non-linear causal dependence. However, they note that a non-linear approach provides no guidance regarding the source of non-linear dependence. In addition, Choudhry and Osoble (2015) point out that non-linear information might not be fully uncovered by the traditional linear Granger causality test. In the view of these conclusions we conduct both approacheslinear and non-liner causality tests-and evaluate the results in conjunction.

\section{US stock index return shocks in explaining the forecast error vari- ance of other US stock indices}

The forecast error variance and spillover index, as introduced by Diebold and Yilmaz (2009 and 2012) and suggested by Narayan (2015), are employed to the relationship between US stock indices. Both forecast error variance and spillover effects are based on a generalised VAR (GVAR) model. In the present paper, there are two variables (two US stock indices from a different index group). Following Narayan (2015), these variables are denoted as $Z_{t}=\left[R_{t}^{1}, R_{t}^{2}\right]$. As suggested by Pesaran and Shin (1998) and implemented by Narayan (2015), a GVAR (instead of VAR) model is needed to ensure Cholesky variance decomposition. In such a model, correlated shocks are modelled by the distribution of the realised errors. The sum of the contribution to the variance of the forecast error is one with GVAR. The 1-step(day)-ahead forecast can be denoted as, and the respective 1-step(day)-ahead error vector can be denoted as:

$$
k_{t+1}=Z_{t+1}-Z_{t+1, t}=b_{0} \eta_{t+1}=\left[\begin{array}{ll}
b_{0,11} & b_{0,12} \\
b_{0,21} & b_{0,22}
\end{array}\right]\left[\begin{array}{c}
\eta_{1, t+1} \\
\eta_{2, t+1}
\end{array}\right]
$$

with $E\left(k_{t+1, t} k_{t+1, t}^{\prime}\right)=B_{0} B_{0}^{\prime}$ covariance matrix. The variance of the 1-step-ahead error in forecasting $R_{t}^{1}$ is $b_{0,11}^{2}+b_{0,12}^{2}$ and the variance of the 1-step-ahead error variance in forecasting $R_{t}^{2}$ is $b_{0,21}^{2}+b_{0,22}^{2}$. As implemented in Narayan (2015), such a forecast error variance analysis (with the forecast error variance and 
spillover index measures alike) is implemented for both return and volatility series. Instead of the Schwert volatility that Narayan (2015) employed, here a volatility series is estimated via the Parkinson (1980) range estimator.

$$
\operatorname{Par}_{t}=\frac{1}{4 \ln 2} \cdot\left[\ln \left(P_{h, t} / P_{l, t}\right)^{2}\right]
$$

where $P_{h, t}$ and $P_{l, t}$ denote the high and low daily prices. Recently, the range estimator properties have been examined in Louzis, Xanthopoulos-Sisinis and Refenes (2013).

\subsection{Forecast error variance}

The total forecast error variance $(\mathrm{TFEV})$ is

$$
T F E V=b_{0,11}^{2}+b_{0,12}^{2}+b_{0,21}^{2}+b_{0,22}^{2}
$$

[Insert Table 5 about here]

Table 5 reports results of the contribution of US stock index shocks to the forecast error variance of another US stock index's returns, in both the full-sample and all sub-sample periods. It also reports the results on how much of the forecast error variance of an index returns is explained by shocks to the volatility of another index's returns. The results are based on a 30-day-ahead forecast error, while the optimal lag length in the VAR model is chosen by the Schwarz information criterion. In the full sample period, the contribution of an index return shocks to the forecast error variance of another index is heterogeneous and small. In most of the cases, an index's return shocks explain less than $1 \%$ of the forecast error variance of another index's returns. There are, however, two exceptions: the contribution of SPX index to RUA, and RUA to SPX with contributions being $1.28 \%$ and $1.01 \%$, respectively. The SPX, RUA, and RUI indices have an interactive contribution, which is approximately equal. This steady relation among these indices is consistent with the results of the previous sub-sections. However, the too small contribution of RUT to DJI and this of RUT to DJA is an unexpected result. It should be noted that the results change in the sub-sample periods. In the Lehman Brothers sub-sample period, the contribution of an index returns shocks to the forecast error variance of another is for all indices higher than in the full sample. Indicatively, the contribution of SPX return shocks to the forecast error variance of RUA is $7.65 \%$, in contrast with the respective $1.28 \%$ contribution in the full sample period. In the EU crisis sub-period, the contributions are smaller than in the Lehman Brothers crisis sub-period, while they differ in some cases. Most of the contributions of Russell Group indices return shocks to the forecast error variance of NYSE Group indices and, vice versa, are in the EU crisis than the Lehman Brothers crisis sub-period. The significant interactive contributions among SPX, RUA and RUI also hold in the EU crisis sub-period. In the post-crisis sub-period, most of the contributions decrease compared to the other periods, to contribution vales of less than $1 \%$. The only exceptions are the contribution of RUI index return shock to the forecast error variance of OEX (1\%) and SPX (1.09\%), and the contribution of SPX index returns shock to the forecast error variance of RUI (1.01\%) and RUA (1.02\%). 
The contribution of an index volatility (instead of return) shocks to the forecast error variance of another index is also reported in Table 5. In the full sample period, the volatility shocks of an index explain the forecast error variance of another index by less than $1 \%$ in most of the cases. The highest such contribution is RUI volatility shocks to SPX volatility (1.29\%), while the lowest is for the contribution of SPX volatility shocks to the forecast error variance of RUI. The same asymmetric relation exists for the one between SPX and RUA. However, the results differ among sub-periods. In the Lehman Brothers crisis sub-period, the contributions of the volatility shocks to the forecast error variance are higher than in the full sample period. The largest contribution is DJI shocks of return volatility to the forecast error variance of XAX (1.25\%), while the smallest is the contribution of RUA return volatility to the forecast error variance of OEX $(0.3618 \%)$. In the EU crisis period, contributions are less than both the full sample and Lehman Brothers crisis sub-sample periods. The largest contribution is the SPX shocks of return volatility to the forecast error variance of RUA $(1.25 \%)$, while the smallest is the contribution of DJA return volatility to the forecast error variance of RUI $(0.3262 \%)$. The contributions in the post-crisis sub-period are the smallest among all periods. All contribution values are less than $1 \%$, and the contributions of RUI return volatility to the forecast error variances of OEX $(1.09 \%)$ and SPX $(1.15 \%)$ are the only exceptions.

In summary, the magnitude of contributions varies heavily among indices and periods. The highest effect is the one of SPX on the forecast error variance of RUI and RUA. In addition, most of the indices respond heterogeneously to other indices' volatility shocks among different periods. The Lehman Brothers crisis has the highest effects, while the full sample period comes second, and the EU crisis period third and the post-crisis period were last. This result is in line with the results of the previous sub-sections.

\subsection{Spillover index}

Diebold and Yilmaz (2012) proposed the spillover index (SOI), which is the total spillover relative to the total forecast error variance (TFEV).

$$
S O I=\frac{b_{0,21}^{2}+b_{0,22}^{2}}{b_{0,11}^{2}+b_{0,12}^{2}+b_{0,21}^{2}+b_{0,22}^{2}} \times 100
$$

[Insert Table 6 about here]

Table 6 reports the total shock spillover index (\%) from a US stock index return to another US stock index return. The results concerning the spillover from a US stock index return volatility to another US stock index return are also reported. In the full sample period, the results vary considerably among different indices. For example, the total shock spillover index (\%) between DJI and NYE returns is $9.81 \%$, while the total shock spillover index (\%) between DJI and RUT returns is as low as $0.0509 \%$. The results in the sub-periods are different to the full sample period and are also heterogeneous among sub-periods. Most of the total shock spillovers are reduced from the full sample period to the Lehman Bothers crisis sub-period, and then are also reduced from Lehman Brothers crisis to EU crisis, and they are then finally further reduced from the EU 


\section{Bivariate spillover effects among the US stock indices}

In this section, we employ a bivariate $\operatorname{VAR}(\mathrm{k})$ - $\operatorname{ABEKK}(\mathrm{p}, \mathrm{q}, \mathrm{g})$ (asymmetric BEKK) model to assess the return and volatility spillover effects among the US indices (k, p, q and $\mathrm{g}$ refer to number of order in the VAR, ARCH, GARCH and asymmetric BEKK order). The conditional mean specification of a VAR(1)$\operatorname{ABEKK}(1,1,1)$ system of equations that accommodates the returns of each US index is described as follows:

$$
\left[\begin{array}{c}
\Delta E R_{1, t} \\
\Delta E R_{2, t}
\end{array}\right]=\left[\begin{array}{c}
C_{1} \\
C_{2}
\end{array}\right]+\left[\begin{array}{cc}
\Phi_{11} & \Phi_{12} \\
\Phi_{21} & \Phi_{22}
\end{array}\right] \cdot\left[\begin{array}{c}
\Delta E R_{1, t-1} \\
\Delta E R_{2, t-1}
\end{array}\right]+\left[\begin{array}{c}
\varepsilon_{1, t} \\
\varepsilon_{2, t}
\end{array}\right]
$$

where $\Delta E R_{t}$ is a nx1 vector of first difference of Index 1 and Index ${ }_{2}, C_{j}$ is a nx1 vector of constant term $(\mathrm{i}=1,2)$. The mean spillovers are measured by the estimates of matrix $\Phi_{i j}$, which is a $2 \times 2$ matrix 
that represents the parameters of the vector autoregressive term. Finally, $\varepsilon_{t}=\sqrt{h_{t} \eta_{t}}$ is the residual term or conditionally heteroskedastic for each index of the mean equations and $\eta_{t} \sim N(0,1)$ is an iid random process, which is a nx1 vector that represents the shock term. The number of lags are selected by AIC.

The bivariate ABEKK(1,1,1) of Kroner and Ng (1998) based on the standard BEKK of Engle and Kroner (1995) provides the cross-market effects in the variance covariance matrix and allows the asymmetric response of volatility. The bivariate $\operatorname{ABEKK}(1,1,1)$ is described as follows:

$$
h_{t}=C^{\prime} C+A^{\prime} \varepsilon_{t-1}^{\prime} \varepsilon_{t-1} A+B^{\prime} h_{t-1} B+G^{\prime} u_{t-1}^{\prime} u_{t-1} G
$$

where $C$ is a $2 \times 2$ lower upper triangular matrix of constant term, $A$ and $B$ are the $2 \times 2$ matrices, where the diagonal parameters are the response of own past innovations and past volatility of Index $i$, respectively, while the off-diagonal parameters are the cross-market effects of stock and volatility, respectively. The offdiagonal parameters of matrices $A$ and $B$ measure the volatility spillover effect. The $2 \times 2$ matrix $G$ represent the diagonal parameters of the asymmetric effect of Index $i$ to its own past negative innovations, while the off-diagonal parameters are the cross-market asymmetric response of indices to the negative shocks of another index. Finally $u_{t}=\min \left(\varepsilon_{t}, 0\right)=(1 / 2)\left\{\varepsilon_{t}-\left|\varepsilon_{t}\right|\right\}^{2}$.

[Insert Table 7A about here] [Insert Table 7B about here]

Tables 7A \& 7B reports the results of the return and volatility spillovers among the US indices implementing the bivariate $\operatorname{VAR}(1)$ - $\operatorname{ABEKK}(1,1,1)$ model. Each parameter on the tables indicates a specific effect. More specifically, diagonal parameters $\Phi_{11}$ and $\Phi_{22}$ indicate that the past returns of an index effect on its own returns. The off diagonal parameters $\Phi_{12}$ and $\Phi_{21}$ show that past returns of each index effect on returns to the other index. The diagonal parameters $A_{11}$ and $A_{22}$ measure the effect of a past innovation of the each index to its own volatility, while the off diagonal $A_{12}$ and $A_{21}$ indicate the cross-index effect of past innovation of one index to another index. $B_{11}$ and $B_{22}$ denote the effect of a past volatility of the each index to its own volatility and the off diagonal $B_{12}$ and $B_{21}$ the cross-index impact of past innovation of one index to the other index volatility. End $G_{i j}$ suggest the asymmetric responses. Namely, the diagonal parameters $G_{11}$ and $G_{12}$ measure the asymmetric response of each index to its own past negative shock, while off-diagonal parameters $G_{12}$ and $G_{21}$ indicate the cross-index asymmetric responses of each index to another index past negative.

The results indicate that mean and volatility spillovers are time varying and that spillovers are unevenly spread across sub-periods. For example, compared with spillovers between OEX and all other indices, there is a significant evolution of the spillovers between them that changes from one sub-period to the next. Exception is the bivariate model of RUA-NYE which no such effect has been detected both the full sample and subperiods.

Furthermore, out of the 26 bivariate systems of indices that we examined, we have detected four pairwise indices that indicate both strong spillover effects and asymmetric responses during full sample period while in sub-periods they do not detected such strong effect. The four pairwise are: RUI - DJI, RUI-OEX, RUI

\footnotetext{
${ }^{2}$ See Kroner and Ng (1998).
} 
-SPX and RUI-NYE. For example, in the pairwise OEX-RUI, the diagonal parameters $\Phi_{11}$ and $\Phi_{22}$ indicate the past returns of the index OEX effect on the returns of $\operatorname{OEX}\left(\Phi_{11}\right)$, and the past returns of RUI also effect the RUI's returns $\left(\Phi_{22}\right)$, suggesting that each has its own spillover over time, at significant level $1 \%$. In addition, there is a strong bidirectional mean spillover effect between the two indices, at $1 \%$ significant level. The effect from RUI to OEX is positive (0.2279), while the effect from OEX to RUI is negative $(-0.2866)$. This behavior/effect is detected during EU crisis and post-crisis sub-periods but is not detected during the Lehman Brothers crisis.

In the same example, the diagonal parameters $A_{11}$ and $A_{22}$ measure the effect of a past innovation of the OEX to its own volatility and a past innovation of RUI to its own volatility, respectively. The full sample period results show that there is a strong effect of a past shock of each index to its own volatility. The off-diagonal parameters $A_{12}$ and $A_{21}$ indicate the cross-index effect of past innovation of RUI index to the OEX volatility and the effect of past innovation of OEX index to the RUI volatility. The results show that there is a strong positive and bidirectional mean spillover effect between these indices, at $1 \%$ significant level. On the other hand, during two crisis, and especially during the EU crisis, the spillovers are limited.

The parameters $B_{11}$ and $B_{22}$ indicate the effect of a past volatility of the OEX on its own volatility and the effect of RUI on its own volatility, respectively. During full sample period, the past volatility of OEX has a strong effect on the volatility of the index, at significance level 1\%, while no effect is detected for RUI. $B_{12}$ and $B_{21}$ measure the cross index past volatility of one index to another index's volatility. We found that there is a strong bidirectional volatility spillover effect between the two indices, at $1 \%$ significant level. The volatility spillover effect from RUI to OEX is positive (0.9541), while the effect from OEX to RUI is negative $(-0.2487)$. In contrast, no volatility spillover is detected during two crises, with the exception of the EU crisis, whose diagonal parameter $B_{11}$ equal to 0.0339 , which indicates that the past volatility of the OEX effect on its own volatility is significant at a level of 1

The diagonal parameters $G_{11}$ and $G_{22}$ measure the asymmetric response of the index (OEX and RUI, respectively) to its own past negative shock, while off-diagonal parameters indicate the cross-index asymmetric responses. More specifically, a past negative shock of OEX has a strong effect on the volatility of the OEX, at significance level 1\%. The same is applied for RUI. In addition, there is a strong bidirectional asymmetric response between the two indices, at $1 \%$ significant level. The asymmetric response from RUI to OEX is positive (1.7799) while these effect from OEX to RUI is negative (-1.2772). In contrast to full period results, in sub-periods the pattern is changed dramatically. The only asymmetric response that is found is from OEX to RUI $\left(G_{12}\right.$, which equals 1.0451) at significant level 1\%, during the Lehman Brothers sub-periods while in EU crisis not effect is found. In the post-crisis sub-period, a past negative shock of RUI is found to have a strong effect on the volatility of RUI ( $G_{22}$ equal to 0.6317$)$, and an asymmetric response from OEX to RUI $\left(G_{21}\right.$ equal to 0.7929$)$ at significant level $1 \%$.

The examination of the sub-sample periods indicates some interesting points. First, it is pointed that in crisis higher spillovers are detected. During the Lehman Brothers sub-period we found effects that during 
other sub-periods do not exist. For example, examining the bivariate model of SPX-RUA, both diagonal and off diagonal parameters indicate mean spillovers and volatility spillovers in statistical significance $1 \%$, during Lehman Brothers sub-period but the relevant results during the other two sub-periods show that there is no such effect. The bivariate model of SPX-NYE has similar results. Second, the EU crisis period is a sequence of Lehman Brothers crisis; however, the results show that the US market is resistant to external shocks. In contrast to Lehman Brothers, few effects are observed, mainly in diagonal parameters and in volatility terms. This suggests that an external event could create pressures but these are limited in cross index level (for example see the bivariate model DJI-NYE, DJI-XAX). In summary, the post-crisis period seems to show that the market is changed. Both asymmetric responses and spillovers are developed again, indicating a perspective of consecutive crisis. In other words, investors assess the market with attention and keep in their minds the possibility of a crisis.

A similar result to the results of the previous unit 3.4 is also highlighted in relation to the effect of bad news. The parameters $G_{i j}$ are statistically significant and in the majority of cases both diagonal and off diagonal elements act independently of the existence of spillovers effects. This issue indicates the important role of market sentiment while it is implied that the choices about diversification benefits are limited in bad news periods. An indicative example is the case of DJA-RUA, while the results do not indicate the existence of returns or volatility spillover effects, the asymmetric responses of one index to the other or to its own past negative shock are strong during full sample period. The same finding appears among sub-periods, the asymmetric responses are more frequent than the other effects. Specifically, we have detected asymmetric responses in almost all cases during the US crisis sub-period, while in the EU crisis sub-period the spillover effects are too few but the cases of asymmetric responses are more (see bivariate model DJI-RUI and RUADJI, indicatively ). Another conclusion is that the volatility spillovers are more frequent and stronger than the return spillovers. Volatility is a source of uncertainty in financial markets and investors are stepping up the degree of diversification of their portfolios. This means that the investors act to create interactions on the whole market behavior, which are more pronounced within the geographic boundaries of the same market. This result is in the line of volatility clustering concept in financial markets (see, among others, Engle, 1993; Gaunersdorfer et al., 2008; He et al., 2016).

Summarising the results, we conclude that patterns do not exist. The spillover effect in terms of return and volatility is not constant but changes over time and according to the conditions of the market while in crisis higher spillovers are detected. This result is consistent with the result of the previous subsections 5.1 and 5.2, and with the current literature (Gamba-Santamaria et al., 2017). Because of the different evolution of the spillovers among indices, investors should adjust their allocation as time passes and conditions change. In other words, long-run benefits are not expected but in the short-run investors can gain. In addition, consistent to the previous results, the asymmetric response analysis indicates that market discounts more quickly the bad news than any other shock, so policy makers should rethink before making any announcements or similar acts that could have a negative effect on the market, while risk managers have to pay attention to how markets 
assess the news each time. Finally, the cross-market effects capturing return linkage and transmission of shocks and volatility from one index to another, which implies that the market is not efficient because the investors can surpass the market by analysing historic returns and volatility information.

\section{Conclusions}

This paper examines the inter-relations of the US stock indices. Many methods are employed for robustness purposes. Asymmetries, interdependences, non-linear cointegrations, non-linear causalities, the effects of an index return or volatility shocks to the forecast error variance of another index, as well as return and volatility spillovers are all highest in the Lehman Brothers sub-period, while second comes the EU crisis and last is the post-crisis sub-period. This result is consistent with the results in all of the other papers. It is also consistent with Sander et al. (2003) and Ramlall (2009). It is also quite rational because the Lehman Brothers crisis at that time affected the US markets more than any other nation's markets. Moreover, the EU crisis mostly affected the European markets and was felt to a lesser extent in the United States. The post-crisis period had no shock to affect the inter-relations among the US stock indices. It is also theoretically sound because more intense interrelations are expected in the crisis periods. Higher uncertainty, as a result of crises, triggers stronger ties across indices. When investors are fearful because of the turbulent environment they tend to search for negative events because their impact is expected to be more significant. Given that they react only and more intensively to negative events, they feed the turbulent environment that made them fearful. Such investing behavior creates a vicious circle of negative expectations. Higher stability in calmer periods, like the post-crisis sub-period of the present study, enhances independence and growth for the constituents of each index and the indices per se. This reveals the major contribution of this paper: the inclusion of US stock indices in a portfolio, because of their low quality interrelations, can increase portfolio diversification benefits in the post-crisis period.

Portfolio and fund managers should take this result into consideration when they allocate assets in the post-crisis period. Such diversification effects may be enforced by the recent Brexit decision as well as the new US presidency. More and more investing opportunities in the US stock markets may be in need of international investors. The insights of this study are important for risk managers and policy makers from many perspectives. First, we provide a deeper knowledge on the field of interdependencies and how the transmission mechanisms operate through different types of methodologies (i.e. causality, cointegration, covariance and variance), this issue that is related to portfolio diversification. In addition, evaluating the markets interactions contributes to the detection and monitoring of crises, adjusting the risk exposures of portfolios each time. Third, we propose portfolio strategies that can identify how the market reacts to an internal and external event, such as the US crisis and EU crisis for the investigated market. Furthermore, policy makers should build mechanisms of disconnections among markets in order to limit possible harmful effects passing from one market to another. In addition, policy makers should take into account the results of 
this study in relation to the market's reaction during crisis periods in order to take preventive measures that discourage or prevent such effects. Finally, attention must be taken in the architecture of the indices with a view to secure the market's structural aspects.

Future research can extend the present study's contribution by researching whether the EU crisis has an important impact on the interrelations of the respective EU stock markets. Research can also be further extended to the specific EU crises related to the respective EU states (e.g. Greece, Spain, Ireland, etc.) and the corresponding EU national stock markets. 


\section{References}

[1] Al Nasser, O.M. and Hajilee, M. (2016), "Integration of emerging stock markets with global stock markets", Research in International Business and Finance, Vol. 36, pp. 1-12.

[2] Alexakis, P. and Siriopoulos, C. (1997), "The international stock market crisis of 1997 and the dynamic relationships between Asian stock markets: linear and non-linear Granger causality tests", Managerial Finance, Vol. 25 No. 8, pp. 22-38.

[3] Apergis, N. and Miller, S.M. (2006), "Consumption asymmetry ad the stock market: Empirical evidence", Economics Letters, Vol. 93 No. 3, pp. 337-342.

[4] Barunik J., Ko?enda E. and Vïœcha L.,(2016), "Asymmetric connectedness on the US stock market: Bad and good volatility spillovers", Journal of Financial Markets, Vol. 27, pp. 55-78.

[5] Bekaert, G., Ehrmann, M., Fratzscher, M. and Mehl, A. (2014), "The global crisis and equity market Ccntagion", Journal of Finance, Vol. 69 No. 6, pp. 2597-2649.

[6] Bergin, P.R. and Pyun, J.H. (2016), "International portfolio diversification and multilateral effects of correlations", Journal of International Money and Finance, Vol. 62, pp. 52-71.

[7] Boubaker S., Jouini J. and Lahiani, A. (2016), "Financial contagion between the US and selected developedand emerging countries: The case of the subprime crisis", The Quarterly Review of Economics and Finance, Vol. 61, pp. 14-28.

[8] Breitung, J. (2001), "Rank tests for nonlinear cointegration", Journal of Business and Economics Statistics, Vol. 19, pp. 331-340.

[9] Caccioli, F., Farmer, J.D., Foti, N. and Rockmore, D. (2015), "Overlapping portfolios, contagion, and financial stability", Journal of Economic Dynamics and Control, Vol. 51, pp. 50-63.

[10] Chiang, T.C., Jeon, B.N. and Li, H. (2007), "Dynamic correlation analysis of financial contagion: evidence from Asian markets", Journal of International Money and Finance, Vol. 26, pp. 1206-1228.

[11] Corsetti, G., Pericoli, M., and Sbracia, M. (2005), "Some contagion, some interdependence: more pitfalls in tests of financial contagion", Journal of International Money Finance, Vol. 24, pp. 1177-1199.

[12] Choudhry, T. and Osoble, B.N. (2015), "Nonlinear interdependence between the US and emerging markets' industrial stock sectors", International Journal of Finance and Economics, Vol. 20, pp. 61-76.

[13] Cukierman, A. (2013), "Monetary policy and institutions before, during, and after the global financial crisis", Journal of Financial Stability, Vol. 9, pp. 373-384.

[14] Diebold, F.X. and Yilmaz, K. (2009), "Measuring financial asset return and volatility spillovers, with application to global equity markets", The Economic Journal, Vol. 119 No. 534, pp. 158-171. 
[15] Diebold, F.X. and Yilmaz, K. (2012), "Better to give than to receive: Predictive directional measurement of volatility spillovers", International Journal of Forecasting, Vol. 28 No. 1, pp. 57-66.

[16] Engle, R.F. (1993), "Statistical models for financial volatility", Financial Analysts Journal Vol. 49 No. 1, pp. $72-78$.

[17] Engle, R. and Kroner, K. (1995), "Multivariate simultaneous generalised ARCH", Econometric Theory Vol. 11, pp. 122-150.

[18] Fengler, M. R. and Gisler, K. I. (2015), "A variance spillover analysis without covariances: what do we miss?", Journal of International Money and Finance, Vol. 51, pp. 174-195.

[19] Flavin T.J. and Sheenan, L. (2015), "The role of US subprime mortgage-backed assets in propagating the crisis: Contagion or interdependence?", North American Journal of Economics and Finance, Vol. 34, pp. $167-186$.

[20] Forbes, K.J. and Rigobon, R. (2002), "No contagion, only interdependence: measuring stock market co-movements", Journal of Finance, Vol. 57, pp. 2223-2261.

[21] Fujiwara, I. and Takahashi, K. (2012), "Asian financial linkage: Macro-finance dissonance", Pacific Economic Review, Vol. 17 No. 1, pp. 136-159.

[22] Gamba-Santamaria S., Gomez-Gonzalez J.E., Hurtado-Guarin J.L., and Melo-Velandia L.F. (2017), "Stock market volatility spillovers: Evidence for Latin America", Finance Research Letters, Vol. 20, pp. 207-216.

[23] Gaunersdorfer, A., Hommes, C. and Wagener, F. (2008), "Bifurcation routes to volatility clustering under evolutionary learning", Journal of Economic Behavior and Organization, Vol. 67, pp. 27-47.

[24] Gagnon, M.-H., Power, G.J. and Toupin, D. (2016), "International stock market cointegration under the risk-neutral measure", International Review of Financial Analysis, Vol. 47, pp. 243-255.

[25] Guidi, F. and Ugur, M. (2014), "An analysis of South-Eastern European stock markets: Evidence on cointegration and portfolio diversification benefits", Journal of International Financial Markets, Institutions and Money, Vol. 30, pp. 119-136.

[26] He, X.Z., Li, K., and Wang, C., (2016), "Volatility clustering: A nonlinear theoretical approach", Journal of Economic Behavior $\&$ Organization, Vol. 130, pp. 274-297.

[27] Hon, M.T., Strauss, J. and Yong, S.K. (2004), "Contagion in financial markets after September 11: Myth or reality?", Journal of Financial Research, Vol. 26, pp. 95-114.

[28] Huang, B.-N., Yang, C.-W. and Hu, J.W.-S. (2000), "Causality and cointegration of stock market among the United States, Japan, and the South China Growth Triangle", International Review of Financial Analysis, Vol. 9 No. 3, pp. 281-297. 
[29] Jin, X. and An, X. (2016), "Global financial crisis and emerging stock market contagion: A volatility impulse response function approach", Research in International Business and Finance, Vol. 36, pp. 179195 .

[30] Johansen, S. and Juselius, K. (1990), "Maximum likelihood estimation and inference on cointegrationwith applications to the demand for money", Oxford Bulletin of Economics and Statistics, Vol. 52, pp. $169-210$.

[31] Jozef Barunï¿œk, J., , Ko?enda, E., and Vïœœcha, L. (2016), "Asymmetric connectedness on the US stock market: Bad and good volatility spillovers", Journal of Financial Markets, Vol. 27, pp. 55-78.

[32] Kasa, K. (1992), "Common stochastic trends in international stock markets", Journal of Monetary Economics, Vol. 29, pp. 95-124.

[33] Kenourgios, D. (2014), "On financial contagion and implied market volatility", International Review of Financial Analysis, Vol. 34, pp. 21-30.

[34] Koulakiotis, A., Kiohos, A. and Babalos, V. (2015), "Exploring the interaction between stock price index and exchange rates: An asymmetric threshold approach", Applied Economics, Vol. 47 No. 13, pp. $1273-1285$.

[35] Kroner, K., Ng, V., (1998), "Modelling asymmetric comovements of asset returns", The Review of Financial Studies, Vol. 11 No. 4, pp. 817-844.

[36] Kumar S., N. Deo, (2012), "Correlation and network analysis of global financial indices", Physics. Review, E, Vol. 86 No. 2, 026101.

[37] Kumar, M. (2013), "Returns and volatility spillover between stock prices and exchange rates: Empirical evidence from IBSA countries", International Journal of Emerging Markets, Vol. 8 No. 2, pp. 108-128.

[38] Kuppuswamy, V. and Villalonga, B. (2016), "Does diversification create value? In the presence of external financing constraints? Evidence from the 2007-2009 financial crisis", Management Science, Vol. 62 No. 4, pp. 905-923.

[39] Kyle, A.S. (1985), "Continuous auctions and insider trading", Econometrica, Vol. 53, pp. 1315-1335.

[40] Masson, P. (1998), "Contagion: macroeconomic models with multiple equilibria", Journal of International Money Finance, Vol. 18, pp. 587-602.

[41] Mazur, M. and Zhang, S. (2015), "Diversification discount over the long run: New perspectives", Finance Research Letters, Vol. 15, pp. 93-98.

[42] Mimouni, K., Charfeddine, L. and Al-Azzam, M. (2016), "Do oil producing countries offer international diversification benefits? Evidence from GCC countries", Economic Modelling, Vol. 57, pp. 263-280. 
[43] Mollah S., Shahiduzzaman Quoreshi, A.M.M. and Zafirov, G. (2016), "Equity market contagion during global financial and Eurozone crises: Evidence from a dynamic correlation analysis", Journal of International Financial Markets, Institutions and Money, Vol. 41, pp. 151-167.

[44] Morales, L. and Andreosso-O'Callaghan, B. (2012), "The current global financial crisis: Do Asian stock markets show contagious or interdependency effects", Journal of Asian Economics, Vol. 23 No. 6, pp. 616-626.

[45] Morales, L. and Andreosso-O'Callaghan, B. (2014), "The global financial crisis: World market or regional contagion effects?", International Review of Economics and Finance, Vol. 29, pp. 108-131.

[46] Narayan, P.K., Sharma, S.S. and Thuraisamy, K.S. (2015), "Can governance quality predict stock market returns? New global evidence", Pacific-Basin Finance Journal, Vol. 35 No. A, pp. 367-380.

[47] Low, R.K.Y., Faff, R. and Aas, K. (2016), "Enhancing mean-variance portfolio selection by modeling distributional properties", Journal of Economics and Business, Vol. 85, pp. 49-72.

[48] Louzis, D.P., Xanthopoulos-Sisinis, S. and Refenes, A.P. (2013), "The role of high-frequency intra-daily data, daily range and implied volatility in multi-period Value-at-Risk forecasting", Journal of Forecasting, Vol. 32, pp. 561-576.

[49] Lucey, B.M. and Voronkova, S. (2008), "Russian equity market linkages before and after the 1998 crisis: Evidence from stochastic and regime-switching cointegration tests", Journal of International Money and Finance, Vol. 27, pp. 1303-1324.

[50] Luchtenberg F.K. and Viet Vu Q., (2015), "The 2008 financial crisis: Stock market contagion and its determinants", Research in International Business and Finance, Vol. 33, pp. 178-203.

[51] Pesaran, H. and Pick, A. (2003), Econometric Issues in the Analysis of Contagion, Mimeo, University of Cambridge.

[52] Pascual, A. G. (2003), “Assessing European stock markets (co)integration”, Economics Letters, Vol. 78, pp. $197-203$.

[53] Philippas, D. and Siropoulos, C. (2013), "Putting the "C" into crisis: Contagion, Correlations and Copulas on EMU bond markets", Journal of International Financial Markets, Institutions and Money, Vol. 27, pp. 161-176.

[54] Oztek, M.F. and Ocal, N. (2016), "Financial crises and the nature of correlation between commodity and stock markets", International Review of Economics and Finance, forthcoming.

[55] Parkinson, M. (1980), "The extreme value method for estimating the variance of the rate of return", Journal of Business, Vol. 53, pp. 6-15. 
[56] Ramlall, I. (2009), "Assessing the impact of US subprime crisis on SEMDEX: In quest for a change in stock market interdependence", International Research Journal of Finance and Economics, Vol. 30, pp. $30-44$.

[57] Sander, H. and Kleimeir, S. (2003), "Contagion and causality: An empirical investigation of four Asian crisis episodes", Journal of International Financial Markets, Institutions and Money, Vol. 13, pp. 171186.

[58] Singh A. and Singh M., (2016), "Inter-linkages and causal relationships between US and BRIC equity markets: An empirical investigation", Arab Economic and Business Journal, Vol. 11 No. 2, pp. 115-145.

[59] Vortelinos, D.I. (2016), "Realized correlation analysis of contagion", The Quarterly Review of Economics and Finance, Vol. 60, pp. 138-148.

[60] Tabak, B.M., de Castro Miranda, R. and da Silva Medeiros, M. (2016), "Contagion in CDS, banking and equity markets", Economic Systems, Vol. 40, pp. 120-134.

[61] Wang G.J., , Xie C.,Lin M. and Stanley H.E. (2017), "Stock market contagion during the global financial crisis: A multiscale approach", Finance Research Letters, (in press), available at: https://doi.org/10.1016/j.frl.2016.12.025.

[62] Wang, G.-J. and Xie, C. (2015), "Correlation structure and dynamics of international real estate securities markets: A network perspective", Physica A:Statistical Mechanics and its Applications, Vol. 424, pp. 176193.

[63] Wu, G. (2001), "The determinants of asymmetric volatility", Review of Financial Studies, Vol. 14 No. 3, pp. 837-859.

[64] Yang, J., Kolari, J., and Min, I. (2003), "Stock market integration and financial crises: The case of Asia", Applied Financial Economics, Vol. 13 No. 7, pp. 477-486.

[65] Yang, S.Y., Qiao, Q., Beling, P.A., Scherer, W.T. and Kirilenko, A.A. (2015), "Gaussian process-based algorithmic trading strategy identification", Quantitative Finance, Vol. 15 No. 10, pp. 1683-1703.

[66] Zhang B. and Li, X.M. (2014), "Has there been any change in the comovement between the Chinese and US stock markets?", International Review of Economics and Finance, Vol. 29, pp. 525-536.

[67] Zhang X., Zheng X. and Zeng D.D.,(2017), "The dynamic interdependence of international financial markets: An empirical study on twenty-seven stock markets", Physica A: Statistical Mechanics and its Applications, Vol. 472, pp. 32-42.

[68] Zhou, J. and Nicholson, J.R. (2015), "Economic value of modeling covariance asymmetry for mixed-asset portfolio diversification", Economic Modelling, Vol. 45, pp. 14-21. 


\section{Tables}

\begin{tabular}{|c|c|c|c|c|c|c|}
\hline & Mean & St. deviation & Skewness & Kurtosis & JB test & $L B_{5}$ \\
\hline & \multicolumn{6}{|c|}{ Panel A. S\&P Dow Jones indices group } \\
\hline Dow Jones Composite & $1.72 \mathrm{e}-4$ & 0.0119 & -0.2264 & 10.11 & $8,292^{* *}$ & $88.48^{* *}$ \\
\hline Dow Jones Industrial Average & $1.13 \mathrm{e}-4$ & 0.0119 & -0.0648 & 11.08 & $10,660^{* *}$ & $109^{* *}$ \\
\hline$S \& P 100$ & $4.13 \mathrm{e}-5$ & 0.0126 & -0.1280 & 10.70 & $9,674^{* *}$ & $116^{* *}$ \\
\hline \multirow[t]{2}{*}{$S \& P 500$} & $9.30 \mathrm{e}-5$ & 0.0127 & -0.1854 & 11.16 & $10,885^{* *}$ & $114^{* *}$ \\
\hline & \multicolumn{6}{|c|}{ Panel B. Russell indices group } \\
\hline Russell 1000 & $1.08 \mathrm{e}-4$ & 0.0128 & -0.2067 & 10.96 & $10,375^{* *}$ & $108^{* *}$ \\
\hline Russell 2000 & $2.31 \mathrm{e}-4$ & 0.0158 & -0.2841 & 7.51 & $3,373^{* *}$ & $84.20^{* *}$ \\
\hline \multirow[t]{2}{*}{ Russell 3000} & $1.18 \mathrm{e}-4$ & 0.0129 & -0.2295 & 10.63 & $9,540 * *$ & $106^{* *}$ \\
\hline & \multicolumn{6}{|c|}{ Panel C. NYSE Global index group } \\
\hline NYSE Composite & $1.19 \mathrm{e}-4$ & 0.0126 & -0.3296 & 12.54 & $14,934^{* *}$ & $101^{* *}$ \\
\hline AMEX Composite & $2.50 \mathrm{e}-4$ & 0.0114 & -0.4383 & 16.20 & $28,570^{* *}$ & $54.12^{* *}$ \\
\hline
\end{tabular}

Notes. Table 1A reports the descriptive statistics for the US stock indices, they split into three indices' groups in panels A-C. Mean, standard deviation, skewness, kurtosis, Jarque-Bera statistic and Ljung-Box test for normality (with 5 lags) statistic $\left(L B_{5}\right)^{3}$ are reported. This table concerns the entire sample period from 3 January 2000 and ends on 28 July 2015. ** indicate Newey-West statistical significance at a 5\% significance level.

\footnotetext{
${ }^{3}$ The critial value for $L B_{5}$ at a $1 \%$ significance level is 15.0863 .
} 


\begin{tabular}{|c|c|c|c|c|c|c|c|c|c|c|c|c|c|c|c|c|c|c|}
\hline \multicolumn{19}{|c|}{ Table 1B. Descriptive statistics of returns (sub-samples) } \\
\hline & \multicolumn{3}{|c|}{ Mean } & \multicolumn{3}{|c|}{ St. deviation } & \multicolumn{3}{|c|}{ Skewness } & \multicolumn{3}{|c|}{ Kurtosis } & \multicolumn{3}{|c|}{ JB test } & \multicolumn{3}{|c|}{$L B_{5}$} \\
\hline & Lehman & $\mathrm{EU}$ & Post & Lehman & $\mathrm{EU}$ & Post & Lehman & $\mathrm{EU}$ & Post & Lehman & $\mathrm{EU}$ & Post & Lehman & $\mathrm{EU}$ & Post & Lehman & $\mathrm{EU}$ & Post \\
\hline & \multicolumn{18}{|c|}{ Panel A. S\&P Dow Jones indices group } \\
\hline Dow Jones Composite & $-8.30 \mathrm{e}-5$ & $3.52 \mathrm{e}-4$ & $3.90 \mathrm{e}-4$ & 0.0191 & 0.0123 & 0.0073 & -0.0858 & -0.7305 & -0.214 & 7.27 & 7.08 & 3.64 & $435^{* *}$ & $259^{* *}$ & $20.82^{* *}$ & $47.74^{* *}$ & $44.97^{* *}$ & $26.15^{* *}$ \\
\hline Dow Jones Industrial Average & $-2.94 \mathrm{e}-5$ & $4.54 \mathrm{e}-4$ & $3.45 \mathrm{e}-4$ & 0.0187 & 0.0118 & 0.0072 & 0.0721 & -0.6167 & -0.152 & 8.74 & 6.71 & 3.76 & $786^{* *}$ & $211^{* *}$ & 23.08 ** & $56.22 * *$ & $44.52^{* *}$ & $19.69^{* *}$ \\
\hline$S \& P 100$ & $-1.27 \mathrm{e}-4$ & $4.66 \mathrm{e}-4$ & $4.44 \mathrm{e}-4$ & 0.0199 & 0.0125 & 0.0074 & -0.1442 & -0.6260 & -0.168 & 8.60 & 7.02 & 3.95 & $749^{* *}$ & $245^{* *}$ & $35.33^{* *}$ & $58.72 * *$ & $53.26 * *$ & $19.42^{* *}$ \\
\hline \multirow[t]{2}{*}{$S \& P 500$} & $-8.37 \mathrm{e}-5$ & $4.24 \mathrm{e}-4$ & $4.77 \mathrm{e}-4$ & 0.0207 & 0.0131 & 0.0075 & -0.1905 & -0.6255 & -0.213 & 8.16 & 7.14 & 3.89 & $639^{* *}$ & $258^{* *}$ & $33.65^{* *}$ & $52.98 * *$ & $52.00^{* *}$ & $23.86^{* *}$ \\
\hline & \multicolumn{18}{|c|}{ Panel B. Russell indices group } \\
\hline Russell 1000 & $-6.26 \mathrm{e}-5$ & $4.17 \mathrm{e}-4$ & $4.80 \mathrm{e}-4$ & 0.0209 & 0.0134 & 0.0076 & -0.2221 & -0.6325 & -0.248 & 7.97 & 7.18 & 3.90 & $593^{* *}$ & $264^{* *}$ & $36.81^{* *}$ & $49.85^{* *}$ & $51.71^{* *}$ & $25.77^{* *}$ \\
\hline Russell 2000 & $5.84 \mathrm{e}-5$ & $2.47 \mathrm{e}-4$ & $4.67 \mathrm{e}-4$ & 0.0253 & 0.0188 & 0.0099 & -0.3129 & -0.3068 & -0.327 & 5.39 & 6.13 & 3.53 & $146^{* *}$ & $140^{* *}$ & $24.88^{* *}$ & $33.04^{* *}$ & $49.23^{* *}$ & $31.51^{* *}$ \\
\hline \multirow[t]{2}{*}{ Russell 3000} & $-5.16 \mathrm{e}-5$ & $4.05 \mathrm{e}-4$ & $4.83 \mathrm{e}-4$ & 0.0211 & 0.0138 & 0.0077 & -0.2445 & -0.6067 & -0.263 & 7.66 & 7.15 & 3.87 & $524^{* *}$ & $257^{* *}$ & $36.25^{* *}$ & $47.99 * *$ & $51.88^{* *}$ & $26.15^{* *}$ \\
\hline & \multicolumn{18}{|c|}{ Panel C. NYSE Global index group } \\
\hline NYSE Composite & $-1.39 \mathrm{e}-4$ & $1.76 \mathrm{e}-4$ & $3.28 \mathrm{e}-4$ & 0.0222 & 0.0139 & 0.0077 & -0.2474 & -0.6482 & -0.249 & 7.42 & 6.76 & 3.91 & $471^{* *}$ & $219^{* *}$ & $37.70^{* *}$ & $42.19^{* *}$ & $42.88^{* *}$ & $28.222^{* *}$ \\
\hline AMEX Composite & $1.63 \mathrm{e}-5$ & $4.11 \mathrm{e}-4$ & $-4.84 \mathrm{e}-5$ & 0.0198 & 0.0128 & 0.0083 & -0.2613 & -0.6446 & -0.366 & 10.43 & 6.36 & 4.16 & $1,323^{* *}$ & $179^{* *}$ & $65.72^{* *}$ & $29.38^{* *}$ & $28.12^{* *}$ & $22.45^{* *}$ \\
\hline
\end{tabular}

Notes. Table 1B reports the descriptive statistics for the US stock indices, they split into three indices' groups in panels A-C. Mean, standard deviation, skewness, kurtosis, Jarque-Bera statistic and Ljung-Box test for normality (with 5 lags) statistic $\left(L B_{5}\right)^{4}$ are reported. This table concerns the three subsamples: Lehman Brothers crisis sub-sample starts from 1 September 2008 and ends at 7 December 2010; EU crisis sub-sample starts from 8 December 2010 and ends at 31 March 2012; and, the post-crisis sub-sample starts from 1 April 2012 and ends at 28 July 2015. ** indicate Newey-West statistical significance at a 5\% significance level.

\footnotetext{
${ }^{4}$ The critial value for $L B_{5}$ at a $1 \%$ significance level is 15.0863 .
} 


\begin{tabular}{|c|c|c|c|c|c|c|c|c|c|c|c|c|c|c|c|}
\hline \multirow[b]{2}{*}{$\theta$} & \multicolumn{6}{|c|}{ Coefficients } & \multicolumn{4}{|c|}{ Model significance tests } & \multicolumn{5}{|c|}{ Tests on asymmetric tests } \\
\hline & $\Delta E R$ & $\Delta s^{-}$ & $\Delta s^{+}$ & $\Delta s^{S}$ & $\Delta s^{l}$ & $E C$ & $F-$ stat & $\operatorname{adj} R^{2}$ & Autocorrelation & Heteroskedasticity & $F_{1}$ & $F_{2}$ & $F_{3}$ & $T_{1}$ & $T_{2}$ \\
\hline$D J A \rightarrow R U I$ & $-0.0366^{* * *}$ & $-29.55^{* * *}$ & 1.18 & $-48.67^{* * *}$ & $42.08^{* * *}$ & $-0.0036^{* * *}$ & $1,031^{* * *}$ & 0.6129 & $38.78^{* * *}$ & $101^{* *}$ & $60.26^{* * *}$ & $77.40^{* * *}$ & $217^{* * *}$ & $49.60^{* * *}$ & $109^{* * *}$ \\
\hline$D J A \leftarrow R U I$ & $-0.0588^{* * *}$ & $-5.72^{* * *}$ & 0.1201 & $-9.96^{* * *}$ & $8.52^{* * *}$ & $-0.0022^{* *}$ & $1,099^{* * *}$ & 0.6280 & $25.41^{* * *}$ & $119^{* *}$ & $60.48^{* * *}$ & $77.92 * * *$ & $245^{* * *}$ & $51.44^{* * *}$ & $123^{* * *}$ \\
\hline$D J A \rightarrow R U T$ & $-0.0358^{* * *}$ & $-28.22^{* * *}$ & 0.1189 & $-45.24^{* *}$ & $39.83^{* *}$ & $-0.0063^{* * *}$ & $864^{* * *}$ & 0.5701 & $4.77^{* * *}$ & $91.23^{* * *}$ & $60.28^{* * *}$ & $58.39 * * *$ & $181^{* * *}$ & $38.27^{* * *}$ & $90.70^{* * *}$ \\
\hline$D J A \leftarrow R U T$ & $-0.0231^{* * *}$ & $-7.25^{* * *}$ & -0.0207 & $-11.92^{* * *}$ & $10.05^{* * *}$ & $-0.0083^{* * *}$ & $984^{* * *}$ & 0.6016 & 0.6757 & $189^{* *}$ & $62.01^{* * *}$ & $73.00^{* * *}$ & $211^{* * *}$ & $49.31^{* * *}$ & $106^{* * *}$ \\
\hline$D J A \rightarrow R U A$ & $-0.0297^{* * *}$ & $-31.64^{* * *}$ & 0.3465 & $-50.77^{* * *}$ & $46.41^{* * *}$ & $-0.0033^{* * *}$ & $1,467^{* * *}$ & 0.6925 & $4.82^{* * *}$ & $24.54^{* * *}$ & $116^{* * *}$ & $104^{* * *}$ & $315^{* * *}$ & $69.02^{* * *}$ & $158^{* * *}$ \\
\hline$D J A \leftarrow R U A$ & $-0.0148^{*}$ & $-6.73^{* * *}$ & $-0.4214^{* *}$ & $-11.31^{* * *}$ & $9.94 * * *$ & $-0.0024^{*}$ & $1,574^{* * *}$ & 0.7074 & $4.44^{* *}$ & $42.53^{* * *}$ & $129^{* * *}$ & $100^{* * *}$ & $357^{* * *}$ & $72.29 * * *$ & $179^{* * *}$ \\
\hline$D J A \rightarrow N Y E$ & $-0.0392^{* * *}$ & $-32.22^{* * *}$ & -0.1875 & $-54.27^{* * *}$ & $50.01^{* * *}$ & $2.68 \mathrm{e}-4$ & $1,628^{* * *}$ & 0.7142 & $3.26^{* *}$ & $19.85^{* * *}$ & $132^{* * *}$ & $116^{* * *}$ & $367^{* * * *}$ & $77.80^{* * *}$ & $367^{* * *}$ \\
\hline$D J A \leftarrow N Y E$ & $-0.0162^{*}$ & $-65.57^{* *}$ & $-4.17^{* *}$ & $-117^{* * *}$ & $99.01^{* * *}$ & $-0.0043^{* * *}$ & $1,529^{* * *}$ & 0.7013 & $4.63^{* * *}$ & $38.45^{* * *}$ & $98.08^{* * *}$ & $91.60^{* * *}$ & $357^{* * *}$ & $65.99 * * *$ & $179^{* * *}$ \\
\hline$D J A \rightarrow X A X$ & $-0.0748^{* * *}$ & $-24.16^{* * *}$ & 0.8949 & $-43.53^{* * *}$ & $31.86^{* * *}$ & $-5.62 \mathrm{e}-4$ & $397^{* * *}$ & 0.3790 & $5.61^{* * *}$ & $25.34^{* * *}$ & $10.26^{* * *}$ & $34.74^{* * *}$ & $85.23^{* * *}$ & $21.42^{* * *}$ & $43.08^{* * *}$ \\
\hline$D J A \leftarrow X A X$ & $0.0249^{* *}$ & $-9.07 * * *$ & 0.5676 & $-22.02^{* * *}$ & $15.53 * * *$ & $-7.26 \mathrm{e}-4$ & $386^{* * *}$ & 0.3719 & 1.22 & $133^{* * *}$ & 1.39 & $20.80^{* * *}$ & $99.03^{* * *}$ & $13.25^{* * *}$ & $50.70^{* * *}$ \\
\hline$D J I \rightarrow R U I$ & -0.0345 & $-89.79^{* * *}$ & -0.5887 & $-150^{* * *}$ & $133^{* * *}$ & $-0.0078^{* * *}$ & $1,183^{* * *}$ & 0.6450 & $33.05^{* * *}$ & $119^{* * *}$ & $83.90^{* * *}$ & $79.37^{* * *}$ & $259^{* * *}$ & $53.20^{* * *}$ & $130^{* * *}$ \\
\hline$D J I \leftarrow R U I$ & $-0.0538^{* * *}$ & $-5.55^{* * *}$ & $0.3610^{*}$ & $-10.04^{* * *}$ & $8.76^{* * *}$ & $-0.0056^{* * *}$ & $1,212^{* * *}$ & 0.6505 & $39.76^{* * *}$ & $130^{* *}$ & $58.22^{* * *}$ & $83.82^{* * *}$ & $274^{* * *}$ & $53.47^{* * *}$ & $138^{* * *}$ \\
\hline$D J I \rightarrow R U T$ & $-0.0392^{* * *}$ & $-86.05^{* * *}$ & -2.04 & $-125^{* * *}$ & $112^{* * *}$ & $-0.0080^{* * *}$ & $735^{* * *}$ & 0.5302 & $4.27^{* *}$ & $127^{* * *}$ & $68.56^{* * *}$ & $52.85^{* * *}$ & $145^{* * *}$ & 35.59 *** & $72.83^{* * *}$ \\
\hline$D J I \leftarrow R U T$ & $-0.0231^{* *}$ & $-7.03^{* * *}$ & 0.0350 & $-10.96^{* * *}$ & $9.62^{* * *}$ & $-0.0043^{* *}$ & $811^{* * *}$ & 0.5547 & 0.6669 & $297^{* * *}$ & $62.66^{* * *}$ & $61.51^{* * *}$ & $169^{* * *}$ & $41.43^{* * *}$ & $84.79^{* * *}$ \\
\hline$D J I \rightarrow R U A$ & $-0.0277^{* * *}$ & $-94.75^{* * *}$ & -2.82 & $-156^{* * *}$ & $145^{* * *}$ & $-0.0065^{* * *}$ & $1,668^{* * *}$ & 0.7191 & 2.26 & $32.79^{* * *}$ & $148 * * *$ & $106^{* * *}$ & $372^{* * *}$ & $73.17^{* * *}$ & $186^{* * *}$ \\
\hline$D J I \leftarrow R U A$ & -0.0102 & $-6.55^{* * *}$ & -0.1333 & $-11.35^{* * *}$ & $10.08 * * *$ & $-0.0043^{* *}$ & $1,734^{* * *}$ & 0.7269 & $3.21^{* *}$ & $59.64^{* * *}$ & $125^{* * *}$ & $110^{* * *}$ & $396^{* * *}$ & $75.76^{* * *}$ & $198^{* * *}$ \\
\hline$D J I \rightarrow N Y E$ & $-0.0419^{* * *}$ & $-99.50^{* * *}$ & -3.80 & $-158 * * *$ & $152^{* * *}$ & $2.81 \mathrm{e}-4$ & $1,698^{* * *}$ & 0.7227 & $2.38^{*}$ & $20.72^{* * *}$ & $183^{* * *}$ & $120^{* * *}$ & $378 * * *$ & $83.17^{* * *}$ & $189^{* * *}$ \\
\hline$D J I \leftarrow N Y E$ & -0.0114 & $-63.88^{* * *}$ & -1.22 & $-116^{* * *}$ & $97.72^{* * *}$ & $-0.0028^{* *}$ & $1,542^{* * *}$ & 0.7030 & $4.60^{* *}$ & $41.05^{* * *}$ & $83.94^{* * *}$ & $94.45^{* * *}$ & $356^{* * *}$ & $65.15^{* * *}$ & $179^{* * *}$ \\
\hline$D J I \rightarrow X A X$ & $-0.0776^{* * *}$ & $-72.38 * *$ & 1.34 & $-119^{* * *}$ & $91.98 * * *$ & $-6.83 \mathrm{e}-4$ & $352^{* * *}$ & 0.3507 & $3.66^{* *}$ & $38.05^{* * *}$ & $15.59^{* * *}$ & $32.36^{* * *}$ & $72.09 * * *$ & $20.25 * * *$ & $36.27^{* * *}$ \\
\hline$D J I \leftarrow X A X$ & $0.0255^{* *}$ & $-9.00^{* * *}$ & 0.5202 & $-20.76^{* * *}$ & $14.50^{* * *}$ & $-7.87 \mathrm{e}-4$ & $345^{* * *}$ & 0.3464 & 1.39 & $89.68^{* * *}$ & 1.67 & $19.26^{* * *}$ & $85.61^{* * *}$ & $12.36^{* * *}$ & $43.93^{* * *}$ \\
\hline$O E X \rightarrow R U I$ & $-0.0335 * * *$ & $-5.25^{* * *}$ & -0.2158 & $-8.93^{* * *}$ & $8.13^{* * *}$ & -0.0019 & $1,514^{* * *}$ & 0.6991 & $58.26^{* * *}$ & $132^{* * *}$ & $123^{* * *}$ & $91.77^{* * *}$ & $343^{* * *}$ & $63.84^{* * *}$ & $172^{* * *}$ \\
\hline$O E X \leftarrow R U I$ & $-0.0502^{* * *}$ & $-5.94 * * *$ & $0.5978^{* * *}$ & $-10.35^{* * *}$ & $9.33^{* * *}$ & $-0.0022^{*}$ & $1,583^{* * *}$ & 0.7084 & $58.87^{* * *}$ & $137^{* * *}$ & $81.35^{* * *}$ & $123^{* * *}$ & $348^{* * *}$ & $76.84^{* * *}$ & $175^{* * *}$ \\
\hline$O E X \rightarrow R U T$ & $-0.0422 * * *$ & $-5.11^{* * *}$ & -0.0731 & $-6.92^{* * *}$ & $6.50^{* * *}$ & $-0.0030^{* * *}$ & $779^{* * *}$ & 0.5446 & $9.26^{* * *}$ & $233^{* * *}$ & $87.42^{* * *}$ & $60.47^{* * *}$ & $148^{* * *}$ & $40.34^{* * *}$ & $73.91^{* * *}$ \\
\hline$O E X \leftarrow R U T$ & $-0.0229 * *$ & $-7.63^{* * *}$ & 0.4118 & $-10.63^{* * *}$ & $9.85^{* * *}$ & $-0.0020^{* * *}$ & $906^{* * *}$ & 0.5817 & 0.9426 & $238^{* * *}$ & $82.16^{* * *}$ & $84.91^{* * *}$ & $172^{* * *}$ & $55.27^{* * *}$ & $86.46^{* * *}$ \\
\hline$O E X \rightarrow R U A$ & $-0.0281^{* * *}$ & $-5.46^{* * *}$ & $-0.2849^{*}$ & $-9.26^{* * *}$ & $8.74^{* * *}$ & $-6.63 \mathrm{e}-4$ & $2,149^{* * *}$ & 0.7674 & $8.81^{* * *}$ & $50.63^{* * *}$ & $200^{* * *}$ & $125^{* * *}$ & $496^{* * *}$ & $88.52^{* * *}$ & $248^{* * *}$ \\
\hline$O E X \leftarrow R U A$ & -0.0072 & $-6.93^{* * *}$ & 0.1408 & $-11.46^{* * *}$ & $10.78^{* * *}$ & -0.0015 & $2,270^{* * *}$ & 0.7770 & $6.46^{* * *}$ & $39.03^{* * *}$ & $184^{* * *}$ & $163^{* * *}$ & $504^{* * *}$ & $110^{* * *}$ & $253^{* * *}$ \\
\hline$O E X \rightarrow N Y E$ & $-0.0466^{* * *}$ & $-5.73^{* * *}$ & -0.2478 & $-8.78 * * *$ & $8.52^{* * *}$ & $-0.0014^{*}$ & $1,581^{* * *}$ & 0.7083 & $5.04 * * *$ & $55.68 * * *$ & $184^{* * *}$ & $115^{* * *}$ & $344^{* * *}$ & $80.48^{* * *}$ & $172^{* * *}$ \\
\hline$O E X \leftarrow N Y E$ & -0.0062 & $-67.77^{* * *}$ & 1.01 & $-111^{* * *}$ & $98.51^{* * *}$ & $-0.0024^{* * *}$ & $1,514^{* * *}$ & 0.6992 & $6.11^{* * *}$ & $53.26^{* * *}$ & $105^{* * *}$ & $113^{* * *}$ & $327^{* * *}$ & $75.88^{* * *}$ & $165^{* * *}$ \\
\hline$O E X \rightarrow X A X$ & $-0.0834^{* * *}$ & $-4.30^{* * *}$ & 0.1590 & $-6.23^{* * *}$ & $4.82^{* * *}$ & $-8.14 \mathrm{e}-4$ & $326^{* * *}$ & 0.3335 & $6.78^{* * *}$ & $122^{* * *}$ & $18.45^{* * *}$ & $35.59^{* * *}$ & $59.31^{* * *}$ & $21.95^{* * *}$ & $29.83^{* * *}$ \\
\hline$O E X \leftarrow X A X$ & $0.0302^{* *}$ & $-10.71^{* * *}$ & 0.5036 & $-18.45^{* * *}$ & $14.04^{* * *}$ & $-0.0013^{* * *}$ & $331^{* * *}$ & 0.3367 & $3.35^{* *}$ & $137^{* * *}$ & $10.67^{* * *}$ & $26.28^{* * *}$ & $68.99^{* * *}$ & $17.22^{* * *}$ & $35.39^{* * *}$ \\
\hline$S P X \rightarrow R U I$ & $-0.0318 * * *$ & $-11.24^{* * *}$ & -0.2667 & $-18.71^{* * *}$ & $16.79^{* * *}$ & $-0.0302 * * *$ & $1,686^{* * *}$ & 0.7213 & $69.54^{* * *}$ & $114^{* * *}$ & $130^{* * *}$ & $109^{* * *}$ & $371^{* * *}$ & $74.39^{* * *}$ & $186^{* * *}$ \\
\hline$S P X \leftarrow R U I$ & $-0.0568^{* * *}$ & $-5.96 * * *$ & $0.4587^{* *}$ & $-10.41^{* * *}$ & $9.31^{* * *}$ & $-0.0242^{* * *}$ & $1,735^{* * *}$ & 0.7271 & $64.94^{* * *}$ & $116^{* * *}$ & $93.83^{* * *}$ & $126^{* * *}$ & $386^{* * *}$ & $79.46^{* * *}$ & $193^{* * *}$ \\
\hline$S P X \rightarrow R U T$ & $-0.0380^{* * *}$ & $-11.01^{* * *}$ & -0.0908 & $-15.78^{* * *}$ & $14.34^{* * *}$ & $-0.0036^{* * *}$ & $1,036^{* * *}$ & 0.6140 & $7.87^{* * *}$ & $150^{* * *}$ & $98.19^{* * *}$ & $77.60^{* * *}$ & $203^{* * *}$ & $51.45^{* * *}$ & $102^{* * *}$ \\
\hline$S P X \leftarrow R U T$ & $-0.0235^{* *}$ & $-7.99^{* * *}$ & 0.1507 & $-11.21^{* * *}$ & $10.11^{* * *}$ & $-0.0030^{* * *}$ & $1,176^{* * *}$ & 0.6436 & 0.6389 & $200^{* * *}$ & $110^{* * *}$ & $102^{* * *}$ & $227^{* * *}$ & $67.65^{* * *}$ & $113^{* * *}$ \\
\hline$S P X \rightarrow R U A$ & $-0.0259^{* * *}$ & $-11.79^{* * *}$ & -0.3847 & $-19.55^{* * *}$ & $18.18^{* * *}$ & 0.0010 & $2,603^{* * *}$ & 0.7998 & $6.60^{* * *}$ & $25.81^{* * *}$ & $230^{* * *}$ & $163^{* * *}$ & $585^{* * *}$ & $113^{* * *}$ & $293^{* * *}$ \\
\hline$S P X \leftarrow R U A$ & $-0.0142^{* *}$ & $-7.02 * * *$ & -0.0419 & $-11.61^{* * *}$ & $10.63^{* * *}$ & -0.0037 & $2,676^{* * *}$ & 0.8043 & $6.91^{* * *}$ & $26.83^{* * *}$ & $217^{* * *}$ & $181^{* * *}$ & $595^{* * *}$ & $123^{* * *}$ & $298 * * *$ \\
\hline$S P X \rightarrow N Y E$ & $-0.0414^{* * *}$ & $-12.13^{* * *}$ & -0.3462 & $-19.10^{* * *}$ & $18.20^{* * *}$ & $-1.47 \mathrm{e}-4$ & $1,995^{* * *}$ & 0.7539 & $5.10^{* * *}$ & $5.10^{* * *}$ & $207^{* * *}$ & $146^{* * *}$ & $438^{* * *}$ & $146^{* * *}$ & $438^{* * *}$ \\
\hline$S P X \leftarrow N Y E$ & -0.0126 & $-67.57^{* * *}$ & 0.1686 & $-114^{* * *}$ & $99.77^{* * *}$ & $-0.0039 * * *$ & $1,801^{* * *}$ & 0.7344 & $5.78^{* * *}$ & $39.14^{* * *}$ & $121^{* * *}$ & $124^{* * *}$ & $397^{* * *}$ & $83.07^{* * *}$ & $199^{* * *}$ \\
\hline$S P X \rightarrow X A X$ & $-0.0824^{* * *}$ & $-9.31^{* * *}$ & 0.3875 & $-14.39^{* * *}$ & $11.07^{* * *}$ & $-3.02 \mathrm{e}-4$ & $410^{* * *}$ & 0.3864 & $6.23^{* * *}$ & $62.54^{* * *}$ & $19.34^{* * *}$ & $42.25^{* * *}$ & $79.01^{* * *}$ & $25.96^{* * *}$ & $39.76^{* * *}$ \\
\hline$S P X \leftarrow X A X$ & $0.0296^{* *}$ & $-10.84^{* * *}$ & 0.5237 & $-19.46^{* * *}$ & $14.77^{* * *}$ & $-0.0013^{* *}$ & $388^{* * *}$ & 0.3733 & 3.31 & $140^{* * *}$ & $11.07^{* * *}$ & $28.62 * * *$ & $83.90^{* * *}$ & $18.45^{* * *}$ & $42.62^{* * *}$ \\
\hline$R U I \rightarrow N Y E$ & $-0.0724^{* * *}$ & $-6.04^{* *}$ & $0.3570^{*}$ & $-10.06^{* * *}$ & $9.30^{* * *}$ & $-2.39 \mathrm{e}-4$ & $1,387^{* * *}$ & 0.6804 & $33.11^{* * *}$ & $110^{* * *}$ & $96.62^{* * *}$ & $110^{* * *}$ & $303^{* * *}$ & $70.03^{* * *}$ & $152^{* * *}$ \\
\hline$R U I \leftarrow N Y E$ & $-0.0247^{* * *}$ & $-64.25^{* * *}$ & 0.0986 & $-109^{* * *}$ & $90.87^{* * *}$ & $-0.0046^{* * *}$ & $1,269^{* * *}$ & 0.6608 & $45.05^{* * *}$ & $83.37^{* * *}$ & $71.16^{* * *}$ & $87.73 * * *$ & $274^{* * *}$ & $58.33 * * *$ & $138^{* * *}$ \\
\hline$R U I \rightarrow X A X$ & $-0.0938^{* * *}$ & $-4.74^{* * *}$ & $0.6250^{* *}$ & $-7.56^{* * *}$ & $5.83^{* * *}$ & $-2.36 \mathrm{e}-4$ & $365^{* * *}$ & 0.3591 & $7.36 * *$ & $77.88^{* * *}$ & $11.17^{* * *}$ & $41.22^{* * *}$ & $69.62^{* * *}$ & $23.88^{* * *}$ & $35.02^{* * *}$ \\
\hline$R U I \leftarrow X A X$ & 0.0198 & $-10.40^{* * *}$ & 0.4887 & $-19.23^{* * *}$ & $12.66^{* * *}$ & $-0.0013^{* *}$ & $336^{* * *}$ & 0.3404 & $12.32^{* * *}$ & $162^{* * *}$ & $3.67^{*}$ & $25.04 * * *$ & $69.91^{* * *}$ & $16.00^{* * * *}$ & $36.37^{* * *}$ \\
\hline$R U T \rightarrow N Y E$ & $-0.0336^{* * *}$ & $-7.87^{* * *}$ & -0.0862 & $-11.75^{* * *}$ & $10.74^{* * *}$ & $-9.57 \mathrm{e}-6$ & $1,154^{* * *}$ & 0.6393 & 1.75 & $234^{* * *}$ & $112^{* * *}$ & $95.00^{* * *}$ & $238 * * *$ & $64.24^{* * *}$ & $119^{* * *}$ \\
\hline$R U T \leftarrow N Y E$ & $-0.0261^{* * *}$ & $-61.01^{* * *}$ & -1.36 & $-100^{* * *}$ & $83.73^{* * *}$ & $-0.0040^{* *}$ & $997^{* * *}$ & 0.6050 & $9.06^{* * *}$ & $126^{* * *}$ & $61.17^{* * *}$ & $64.43^{* * *}$ & $211^{* * *}$ & $43.32^{* * *}$ & $106^{* * *}$ \\
\hline$R U T \rightarrow X A X$ & $-0.0781^{* * *}$ & $-6.38^{* * *}$ & 0.4625 & $-10.45^{* * *}$ & $7.86^{* * *}$ & $4.87 \mathrm{e}-4^{* *}$ & $476^{* * *}$ & 0.4221 & 1.89 & $225^{* * *}$ & $15.11^{* * *}$ & $48.77^{* * *}$ & $94.80^{* * *}$ & $29.35^{* * *}$ & $47.73^{* * *}$ \\
\hline$R U T \leftarrow X A X$ & $0.0248^{* *}$ & $-8.79^{* * *}$ & 0.5188 & $-22.31^{* * *}$ & $15.02^{* * *}$ & $1.81 \mathrm{e}-4$ & $439^{* * *}$ & 0.4025 & $5.74^{* * *}$ & $320^{* * *}$ & 0.36 & $20.14^{* * *}$ & $111^{* * *}$ & $12.58^{* * *}$ & $57.41^{* * *}$ \\
\hline$R U A \rightarrow N Y E$ & $-0.0322^{* * *}$ & $-7.17^{* * *}$ & -0.1893 & $-11.26^{* * *}$ & $10.62^{* * *}$ & $6.27 \mathrm{e}-4$ & $2,015^{* * *}$ & 0.7557 & $3.40^{* *}$ & $30.98^{* * *}$ & $204^{* * *}$ & $149^{* * *}$ & $440^{* * *}$ & $103^{* * *}$ & $220^{* * *}$ \\
\hline$R U A \leftarrow N Y E$ & $-0.0183^{* *}$ & $-67.12^{* * *}$ & -1.63 & $-113^{* * *}$ & $98.69^{* * *}$ & $-0.0036^{* * *}$ & $1,754^{* * *}$ & 0.7292 & $6.18^{* *}$ & $38.91^{* * *}$ & $123^{* * *}$ & $114^{* * *}$ & $388^{* * *}$ & $77.72^{* * *}$ & $195^{* * *}$ \\
\hline$R U A \rightarrow X A X$ & $-0.0752^{* * *}$ & $-5.61^{* * *}$ & 0.2644 & $-8.69 * * *$ & $6.72^{* * *}$ & $-9.31 \mathrm{e}-5$ & $448^{* * * *}$ & 0.4077 & $5.46^{* * *}$ & $65.70^{* * *}$ & $21.03^{* * *}$ & $46.58^{* * *}$ & $86.81^{* * *}$ & $28.51^{* * *}$ & $43.66^{* * *}$ \\
\hline$R U A \leftarrow X A X$ & $0.0249 * *$ & $-10.79 * * *$ & -0.0174 & $-20.36 * * *$ & $14.67^{* * *}$ & $-0.0012^{* *}$ & $408^{* * *}$ & 0.3853 & $2.31^{*}$ & $148^{* * *}$ & $9.34^{* * *}$ & $26.26^{* * *}$ & $90.79 * * *$ & $17.59^{* * *}$ & $46.53^{* * *}$ \\
\hline
\end{tabular}

Notes. Table $2 \mathrm{~A}$ reports the asymmetric response of Index $_{1}$ to Index $x_{2}$ news with the use of an error correction model (ECM) among US stock indices from different groups. The present table concerns the full sample.

$E C=$ Index ${ }_{1}-a_{0}-a_{1} \cdot$ Index 2

$\Delta E C=a_{0}+\beta_{1} \cdot \Delta E R+\beta_{2} \cdot \Delta s^{-}+\beta_{3} \cdot \Delta s^{+}+\beta_{4} \cdot \Delta s^{s}+\beta_{5} \cdot \Delta s^{l}+\beta_{6} \cdot E C+\nu$

Regarding notation look at subsection 3.1. ${ }^{*},{ }^{* *}$ and ${ }^{* * *}$ indicate Newey-West statistical significance at a $10 \%, 5 \%$ and $1 \%$ significance level. 
Table 2B. Asymmetric response of exchange rates to stock market news (ECM) (Lehman crisis sub-sample)

\begin{tabular}{|c|c|c|c|c|c|c|c|c|c|c|c|c|c|c|c|}
\hline \multirow[b]{2}{*}{ L } & \multicolumn{6}{|c|}{ Coefficients } & \multicolumn{4}{|c|}{ Model significance tests } & \multicolumn{5}{|c|}{ Tests on asymmetric tests } \\
\hline & $\Delta E R$ & $\Delta s^{-}$ & $\Delta s^{+}$ & $\Delta s^{S}$ & $\Delta s^{l}$ & $E C$ & $F-s t a t$ & $\operatorname{adj} R^{2}$ & Autocorrelation & Heteroskedasticity & $F_{1}$ & $F_{2}$ & $F_{3}$ & $T_{1}$ & $T_{2}$ \\
\hline$D J A \rightarrow R U I$ & $-0.0463^{* *}$ & $-34.70^{* * *}$ & -2.94 & $-75.46^{* * *}$ & $65.89^{* * *}$ & -0.0203 & $269^{* * *}$ & 0.7408 & $3.01^{*}$ & 0.0075 & $10.73^{* * *}$ & $80.05^{* * *}$ & $64.69^{* * *}$ & $55.33^{* * *}$ & $32.39 * * *$ \\
\hline$D J A \leftarrow R U I$ & $-0.0500^{* *}$ & $-6.16^{* * *}$ & -1.05 & $-13.91^{* * *}$ & $10.56^{* * *}$ & -0.0141 & $250^{* * *}$ & 0.7269 & $7.45^{* * *}$ & 0.6807 & $5.94^{* *}$ & $57.52^{* * *}$ & $58.46^{* * *}$ & $45.58^{* * *}$ & $29.87^{* * *}$ \\
\hline$D J A \rightarrow R U T$ & -0.0317 & $-29.65^{* * *}$ & -1.45 & $-69.07^{* * *}$ & $56.65^{* * *}$ & -0.0237 & $183^{* * *}$ & 0.6607 & $19.86^{* * *}$ & $16.06^{* * *}$ & $3.83^{*}$ & $45.35^{* * *}$ & $41.78^{* * *}$ & $30.06^{* * *}$ & $20.99^{* * *}$ \\
\hline$D J A \leftarrow R U T$ & $-0.0552^{* *}$ & $-8.15^{* * *}$ & -0.47 & $-16.34^{* * *}$ & $12.89^{* * *}$ & -0.0075 & $254^{* * *}$ & 0.7296 & 0.1531 & $18.56^{* * *}$ & $7.16^{* * *}$ & $86.64^{* * *}$ & $55.34^{* * *}$ & $58.59^{* * *}$ & $28.02 * * *$ \\
\hline$D J A \rightarrow R U A$ & $-0.0394^{*}$ & $-34.48^{* * *}$ & -2.40 & $-75.29^{* * *}$ & $66.49^{* * *}$ & -0.0154 & $275^{* * *}$ & 0.7456 & $4.79^{* * *}$ & 0.0033 & $11.05^{* * *}$ & $83.58^{* * *}$ & $66.29^{* * *}$ & $56.17^{* * *}$ & $33.16^{* * *}$ \\
\hline$D J A \leftarrow R U A$ & $-0.0498^{* *}$ & $-6.76^{* * *}$ & -0.9903 & $-14.93^{* * *}$ & $11.49^{* * *}$ & -0.0113 & $264^{* * *}$ & 0.7373 & $6.03^{* * *}$ & 0.4293 & $6.61^{* *}$ & $65.52^{* * *}$ & $60.98^{* * *}$ & $50.03^{* * *}$ & $31.09^{* * *}$ \\
\hline$D J A \rightarrow N Y E$ & $-0.0386^{*}$ & $-31.16^{* * *}$ & -1.88 & $-71.12^{* * *}$ & $58.25^{* * *}$ & 0.0057 & $237^{* * *}$ & 0.7156 & $4.58^{* *}$ & 0.3005 & $5.27^{* *}$ & $58.10^{* * *}$ & $53.56^{* * *}$ & $38.82^{* * *}$ & $26.99^{* * *}$ \\
\hline$D J A \leftarrow N Y E$ & -0.0356 & $-76.38^{* * *}$ & -9.14 & $-174^{* * *}$ & $127^{* * *}$ & $-0.0272^{* * *}$ & $251^{* * *}$ & 0.7276 & $6.46^{* * *}$ & 1.39 & $3.99^{* *}$ & $64.96^{* * *}$ & $57.50^{* * *}$ & $47.53^{* * *}$ & $29.55^{* * *}$ \\
\hline$D J A \rightarrow X A X$ & $-0.0691^{* *}$ & $-26.65^{* * *}$ & -0.6897 & $-65.52^{* * *}$ & $50.97^{* * *}$ & $-0.0247^{* *}$ & $122^{* * *}$ & 0.5646 & $5.42^{* * *}$ & 2.53 & 1.37 & $31.86^{* * *}$ & $27.69^{* * *}$ & $19.32 * * *$ & $13.85^{* * *}$ \\
\hline$D J A \leftarrow X A X$ & 0.0275 & $-12.32^{* * *}$ & 1.47 & $-34.78^{* * *}$ & $24.48^{* * *}$ & -0.0079 & $108^{* * *}$ & 0.5348 & $3.65^{* *}$ & $14.81^{* * *}$ & 0.0091 & $32.10^{* * *}$ & $26.27^{* * *}$ & $18.68^{* * *}$ & $13.43^{* * *}$ \\
\hline$D J I \rightarrow R U I$ & $-0.0572^{* *}$ & $-94.69^{* * *}$ & -11.35 & $-211^{* * *}$ & $186^{* * *}$ & $-0.0407^{*}$ & $251^{* * *}$ & 0.7274 & $4.42^{* *}$ & 1.24 & $10.97^{* * *}$ & $66.10^{* * *}$ & $61.03^{* * *}$ & $47.68^{* * *}$ & $30.57^{* * *}$ \\
\hline$D J I \leftarrow R U I$ & $-0.0416^{*}$ & $-6.08^{* * *}$ & -0.0463 & $-14.37^{* * *}$ & $11.58^{* * *}$ & 0.0067 & $268^{* * *}$ & 0.7402 & $6.03 * * *$ & 1.61 & $4.84^{* *}$ & $91.09^{* * *}$ & $65.45^{* * *}$ & $57.38^{* * *}$ & $32.96^{* * *}$ \\
\hline$D J I \rightarrow R U T$ & $-0.0442^{*}$ & $-74.83^{* * *}$ & -7.15 & $-194^{* * *}$ & $159^{* * *}$ & $-0.0412^{* *}$ & $159^{* * *}$ & 0.6288 & $18.81^{* * *}$ & $21.33^{* * *}$ & $2.81^{*}$ & $30.09^{* * *}$ & $38.16^{* * *}$ & $21.12 * * *$ & $19.23^{* * *}$ \\
\hline$D J I \leftarrow R U T$ & $-0.0484^{* *}$ & $-7.85^{* * *}$ & 0.5850 & $-16.28^{* * *}$ & $13.86^{* * *}$ & -0.0027 & $218^{* * *}$ & 0.6991 & 0.2036 & $71.73^{* * *}$ & $5.83^{* *}$ & $100^{* * *}$ & $49.68^{* * *}$ & $59.26^{* * *}$ & $24.92^{* * *}$ \\
\hline$D J I \rightarrow R U A$ & $-0.0535^{* *}$ & $-92.32 * * *$ & -8.21 & $-211^{* * *}$ & $188^{* * *}$ & $-0.0369^{*}$ & $255^{* * *}$ & 0.7304 & $6.00^{* * *}$ & 1.15 & $10.39^{* * *}$ & $68.37^{* * *}$ & $62.28 * * *$ & $46.93^{* * *}$ & $31.17^{* * *}$ \\
\hline$D J I \leftarrow R U A$ & $-0.0417^{*}$ & $-6.55^{* * *}$ & 0.0903 & $-15.45^{* * *}$ & $12.62^{* * *}$ & 0.0109 & $275^{* * *}$ & 0.7456 & $4.63^{* *}$ & 2.48 & $5.02 * *$ & $96.84^{* * *}$ & $67.14^{* * *}$ & $59.89^{* * *}$ & $33.78^{* * *}$ \\
\hline$D J I \rightarrow N Y E$ & $-0.0573^{* *}$ & $-78.62^{* * *}$ & -6.13 & $-199^{* * *}$ & $171^{* * *}$ & 0.0103 & $219^{* * *}$ & 0.7000 & $6.53^{* * *}$ & 1.40 & $4.95^{* *}$ & $42.61^{* * *}$ & $52.35^{* * *}$ & $29.05 * * *$ & $26.29 * * *$ \\
\hline$D J I \leftarrow N Y E$ & -0.0251 & $-74.92^{* * *}$ & 1.86 & $-183^{* * *}$ & $138^{* * *}$ & $-0.0428^{* * *}$ & $267^{* * *}$ & 0.7395 & $4.48^{* *}$ & 1.66 & 2.22 & $94.63^{* * *}$ & $63.88^{* * *}$ & $57.97^{* * *}$ & $32.54^{* * *}$ \\
\hline$D J I \rightarrow X A X$ & $-0.0867^{* * *}$ & $-64.78^{* * *}$ & 1.34 & $-187^{* * *}$ & $144^{* * *}$ & -0.0125 & $111^{* * *}$ & 0.5412 & $8.03^{* * *}$ & $2.89^{*}$ & 0.4349 & $24.81^{* * *}$ & $26.56^{* * *}$ & $14.49^{* * *}$ & $13.30^{* * *}$ \\
\hline$D J I \leftarrow X A X$ & 0.0306 & $-11.04^{* * *}$ & 3.53 & $-38.83^{* * *}$ & $26.55^{* * *}$ & -0.0172 & $116^{* * *}$ & 0.5532 & $4.19^{* *}$ & 2.27 & 0.7218 & $40.05^{* * *}$ & $31.19^{* * *}$ & $21.17^{* * *}$ & $15.88^{* * *}$ \\
\hline$O E X \rightarrow R U I$ & $-0.0609^{* * *}$ & $-5.05^{* * *}$ & -0.5542 & $-11.18 * * *$ & $9.65^{* * *}$ & $-0.0818 * * *$ & $259^{* * *}$ & 0.7338 & $6.72^{* * *}$ & 1.60 & $10.14^{* * *}$ & $70.01^{* * *}$ & $60.45^{* * *}$ & $49.77^{* * *}$ & $30.27^{* * *}$ \\
\hline$O E X \leftarrow R U I$ & -0.0125 & $-7.13^{* * *}$ & -0.5441 & $-14.41^{* * *}$ & $12.80^{* * *}$ & 0.0109 & $304^{* * *}$ & 0.7636 & $2.83^{*}$ & 1.85 & $15.81^{* * *}$ & $122^{* * *}$ & $72.90^{* * *}$ & $84.11^{* * *}$ & $36.51^{* * *}$ \\
\hline$O E X \rightarrow R U T$ & $-0.0492^{*}$ & $-4.09^{* * *}$ & -0.3939 & $-10.32^{* * *}$ & $8.01^{* * *}$ & $-0.0399^{* * *}$ & $158^{* * * *}$ & 0.6264 & $24.67^{* * *}$ & $24.13^{* * *}$ & 2.17 & $31.72^{* * *}$ & $35.83^{* * *}$ & $22.26^{* * *}$ & $18.17^{* * *}$ \\
\hline$O E X \leftarrow R U T$ & -0.0292 & $-9.08^{* * *}$ & -0.3680 & $-16.81^{* * *}$ & $14.59^{* * *}$ & -0.0082 & $230^{* * *}$ & 0.7099 & 0.2556 & $21.38^{* * *}$ & $12.39^{* * *}$ & $113^{* * *}$ & $52.22^{* * *}$ & $74.88^{* * *}$ & $26.23^{* * *}$ \\
\hline$O E X \rightarrow R U A$ & $-0.0572^{* * *}$ & $-4.97^{* * *}$ & -0.3842 & $-11.20^{* * *}$ & $9.66^{* * *}$ & $-0.0710^{* * *}$ & $263^{* * *}$ & 0.7366 & $8.69^{* * *}$ & 1.51 & $9.13^{* * *}$ & $73.93^{* * *}$ & $61.03^{* * *}$ & $49.99 * * *$ & $30.56^{* * *}$ \\
\hline$O E X \leftarrow R U A$ & -0.0135 & $-7.70^{* * *}$ & -0.4831 & $-15.54^{* * *}$ & $13.87 * * *$ & 0.0086 & $311^{* * *}$ & 0.7679 & 1.94 & 1.66 & $15.97^{* * *}$ & $128^{* * *}$ & $74.68^{* * *}$ & $86.90^{* * *}$ & $37.41^{* * *}$ \\
\hline$O E X \rightarrow N Y E$ & $-0.0647^{* * *}$ & $-4.14^{* * *}$ & -0.3181 & $-10.55^{* * *}$ & $8.95^{* * *}$ & -0.0473 & $219^{* * *}$ & 0.6995 & $8.48^{* * *}$ & 2.14 & $4.47^{* *}$ & $41.86^{* * *}$ & $51.28^{* * *}$ & $28.51^{* * *}$ & $25.72^{* * *}$ \\
\hline$O E X \leftarrow N Y E$ & 0.0019 & $-86.81^{* * *}$ & -4.69 & $-185^{* * *}$ & $152^{* * *}$ & $-0.0259^{* *}$ & $294^{* * *}$ & 0.7576 & $2.65^{*}$ & $2.83^{*}$ & $9.43^{* * *}$ & $120^{* * *}$ & $71.11^{* * *}$ & $80.48^{* * *}$ & $35.99^{* * *}$ \\
\hline$O E X \rightarrow X A X$ & $-0.0974^{* * *}$ & $-3.45^{* * *}$ & 0.0688 & $-10.08 * * *$ & $7.43^{* * *}$ & -0.0070 & $111^{* * *}$ & 0.5419 & $11.05^{* * *}$ & $3.26^{*}$ & 0.1920 & $25.01^{* * *}$ & $26.43^{* * *}$ & $14.62^{* * *}$ & $13.27^{* * *}$ \\
\hline$O E X \leftarrow X A X$ & $0.0589^{* *}$ & $-16.18^{* * *}$ & -0.3179 & $-38.11^{* * *}$ & $27.45^{* * *}$ & $-0.0142^{* *}$ & $123^{* * *}$ & 0.5661 & 2.28 & $20.45^{* * *}$ & 1.03 & $49.83^{* * *}$ & $30.29^{* * *}$ & $32.46^{* * *}$ & $15.50^{* * *}$ \\
\hline$S P X \rightarrow R U I$ & $-0.0518^{* *}$ & $-11.88^{* * *}$ & -1.18 & $-24.70^{* * *}$ & $21.43^{* * *}$ & $-0.3223^{* * *}$ & $300^{* * *}$ & 0.7617 & $5.33^{* * *}$ & 1.21 & $13.36^{* * *}$ & $90.68^{* * *}$ & $67.95^{* * *}$ & $63.63^{* * *}$ & $34.01^{* * *}$ \\
\hline$S P X \leftarrow R U I$ & -0.0301 & $-6.61^{* * *}$ & -0.5506 & $-13.76^{* * *}$ & $11.91^{* * *}$ & $0.2159^{* * *}$ & $312^{* * *}$ & 0.7683 & $5.51^{* * *}$ & 0.6097 & $13.56^{* * *}$ & $101^{* * *}$ & $71.38^{* * *}$ & $69.47^{* * *}$ & $35.73^{* * *}$ \\
\hline$S P X \rightarrow R U T$ & -0.0411 & $-9.95^{* * *}$ & -0.6599 & $-23.45^{* * *}$ & $17.77^{* * *}$ & $-0.0632^{* * *}$ & $187^{* * *}$ & 0.6655 & $24.06^{* * *}$ & $21.30^{* * *}$ & 2.52 & $45.70^{* * *}$ & $41.77^{* * *}$ & $30.94^{* * *}$ & $21.23^{* * *}$ \\
\hline$S P X \leftarrow R U T$ & -0.0324 & $-9.12^{* * *}$ & -0.5694 & $-16.33^{* * *}$ & $14.10^{* * *}$ & -0.0144 & $285^{* * *}$ & 0.7522 & 0.0854 & $34.33^{* * *}$ & $16.65^{* * *}$ & $121^{* * *}$ & $61.71^{* * *}$ & $81.63^{* * *}$ & $30.93 * * *$ \\
\hline$S P X \rightarrow R U A$ & $-0.0480^{* *}$ & $-11.81^{* * *}$ & -0.8374 & $-24.89^{* * *}$ & $21.31^{* * *}$ & $-0.2280^{* * *}$ & $305^{* * *}$ & 0.7641 & $6.58 * * *$ & 0.9034 & $11.78^{* * *}$ & $96.46^{* * *}$ & $68.56^{* * *}$ & $64.77^{* * *}$ & $34.34^{* * *}$ \\
\hline$S P X \leftarrow R U A$ & -0.0288 & $-7.33^{* * *}$ & -0.4502 & $-14.79^{* * *}$ & $12.88^{* * *}$ & $0.1856^{* * *}$ & $330^{* * *}$ & 0.7782 & $3.31^{* *}$ & 0.3473 & $14.93^{* * *}$ & $116^{* * *}$ & $74.32^{* * *}$ & $78.09 * * *$ & $37.20^{* * *}$ \\
\hline$S P X \rightarrow N Y E$ & $-0.0542^{* *}$ & $-9.88^{* * *}$ & -0.6141 & $-24.30^{* * *}$ & $19.15^{* * *}$ & $0.0372^{*}$ & $252^{* * *}$ & 0.7286 & $6.79 * * *$ & 1.92 & $3.58^{*}$ & $55.85^{* * *}$ & $57.89^{* * *}$ & $37.39^{* * *}$ & $29.30^{* * *}$ \\
\hline$S P X \leftarrow N Y E$ & -0.0138 & $-81.61^{* * *}$ & -2.56 & $-178^{* * *}$ & $140^{* * *}$ & $-0.0469^{* * *}$ & $307^{* * *}$ & 0.7654 & $4.60^{* *}$ & 0.7412 & $6.53^{* *}$ & $110^{* * *}$ & $71.25^{* * *}$ & $71.35^{* * *}$ & $36.01^{* * *}$ \\
\hline$S P X \rightarrow X A X$ & $-0.0899^{* * *}$ & $-8.53^{* * *}$ & 0.1323 & $-22.33^{* *}$ & $16.32 * * *$ & -0.0098 & $121^{* * *}$ & 0.5636 & $9.37 * * *$ & $3.37^{*}$ & 0.4387 & $32.50^{* * *}$ & $27.72^{* * *}$ & $19.06^{* * *}$ & $13.93^{* * *}$ \\
\hline$S P X \leftarrow X A X$ & $0.0484^{*}$ & $-16.26^{* * *}$ & 0.4570 & $-34.71^{* * *}$ & $25.40^{* * *}$ & $-0.0182^{*}$ & $119^{* * *}$ & 0.5591 & 2.20 & $15.84^{* * *}$ & 1.34 & $52.33^{* * *}$ & $26.95^{* * *}$ & $32.29^{* * *}$ & $13.63^{* * *}$ \\
\hline$R U I \rightarrow N Y E$ & $-0.0431^{* *}$ & $-5.50^{* * *}$ & -0.4382 & $-13.40^{* * *}$ & $10.39 * * *$ & $0.0405^{* *}$ & $260^{* * *}$ & 0.7347 & $6.13^{* * *}$ & 1.53 & $3.71^{*}$ & $57.01^{* * *}$ & $59.24^{* * *}$ & $38.97 * * *$ & $30.05^{* * *}$ \\
\hline$R U I \leftarrow N Y E$ & -0.0281 & $-81.68^{* * *}$ & -4.29 & $-177^{* * *}$ & $136^{* * *}$ & $-0.0481^{* * *}$ & $293^{* * *}$ & 0.7574 & $3.67^{* *}$ & 0.8457 & $6.10^{* *}$ & $101^{* * *}$ & $66.84^{* * *}$ & $66.96^{* * *}$ & $33.86^{* * *}$ \\
\hline$R U I \rightarrow X A X$ & $-0.0793^{* * *}$ & $-4.84^{* * *}$ & -0.0361 & $-12.29^{* * *}$ & $8.86^{* * *}$ & -0.0103 & $123^{* * *}$ & 0.5670 & $8.63^{* * *}$ & $3.77^{*}$ & 0.5348 & $33.61^{* * *}$ & $27.99^{* * *}$ & $20.07^{* * *}$ & $14.07^{* * *}$ \\
\hline$R U I \leftarrow X A X$ & 0.0365 & $-16.75^{* * *}$ & 0.0963 & $-34.21^{* * *}$ & $23.76^{* * *}$ & $-0.0200^{*}$ & $114^{* * *}$ & 0.5486 & 2.12 & $17.14^{* * *}$ & 1.19 & 51.42 *** & $24.78^{* * *}$ & 32.36 *** & $12.61^{* * *}$ \\
\hline$R U T \rightarrow N Y E$ & $-0.0398^{*}$ & $-8.15^{* * *}$ & -0.5107 & $-15.02^{* * *}$ & $12.45^{* * *}$ & 0.0091 & $237^{* * *}$ & 0.7160 & 1.24 & $81.04^{* * *}$ & $9.81^{* * *}$ & $78.74^{* * *}$ & $48.06^{* * *}$ & $52.78^{* * *}$ & $24.22^{* * *}$ \\
\hline$R U T \leftarrow N Y E$ & -0.0204 & $-69.84^{* * *}$ & -5.81 & $-163^{* * *}$ & $116^{* * *}$ & $-0.0389 * * *$ & $186^{* * *}$ & 0.6644 & $22.09^{* * *}$ & $28.53^{* * *}$ & 1.89 & $47.02^{* * *}$ & $41.24^{* * *}$ & $32.45^{* * *}$ & $21.13^{* * *}$ \\
\hline$R U T \rightarrow X A X$ & $-0.0622^{* *}$ & $-7.83^{* * *}$ & -0.6171 & $-13.31^{* * *}$ & $10.52^{* * *}$ & 0.0029 & $112^{* * *}$ & 0.5432 & $2.96^{*}$ & $110.91^{* * *}$ & $4.97^{* * *}$ & 0.0262 & $22.04^{* * *}$ & $29.94^{* * *}$ & $11.03^{* * *}$ \\
\hline$R U T \leftarrow X A X$ & 0.0387 & $-9.56^{* * *}$ & 3.02 & $-36.10^{* * *}$ & $21.55^{* * *}$ & $-0.0331^{* * *}$ & $94.23^{* * *}$ & 0.4993 & $10.93^{* * *}$ & $76.21^{* * *}$ & 1.88 & $24.38^{* * *}$ & $23.28^{* * *}$ & $12.88^{* * *}$ & $12.06^{* * *}$ \\
\hline$R U A \rightarrow N Y E$ & $-0.0415^{*}$ & $-6.13^{* * *}$ & -0.3772 & $-14.34^{* * *}$ & $11.23^{* * *}$ & $0.0387^{* *}$ & $273^{* * *}$ & 0.7436 & $5.26^{* * *}$ & 2.15 & $304^{* * *}$ & $65.50^{* * *}$ & $60.87^{* * *}$ & $43.82^{* * *}$ & $30.85^{* * *}$ \\
\hline$R U A \leftarrow N Y E$ & -0.0232 & $-80.77^{* * *}$ & -2.95 & $-176^{* * *}$ & $138^{* * *}$ & $-0.0459 * * *$ & $300^{* * *}$ & 0.7615 & $5.60^{* * *}$ & 0.7726 & $6.49^{* *}$ & $104^{* * *}$ & $68.59^{* * *}$ & $67.40^{* * *}$ & $34.66^{* * *}$ \\
\hline$R U A \rightarrow X A X$ & $-0.0774^{* * *}$ & $-5.44^{* * *}$ & -0.0067 & $-13.12^{* * *}$ & $9.56^{* * *}$ & -0.0106 & $126^{* * *}$ & 0.5728 & $7.67^{* * *}$ & $5.51^{* *}$ & 0.7951 & $37.49^{* * *}$ & $28.02^{* * *}$ & $22.27^{* * *}$ & $14.08^{* * *}$ \\
\hline$R U A \leftarrow X A X$ & 0.0413 & $-16.45^{* * *}$ & 0.1280 & $-34.16^{* * *}$ & $24.48^{* * *}$ & $-0.0206^{*}$ & $116^{* * *}$ & 0.5519 & $2.87^{*}$ & $17.13^{* * *}$ & 1.39 & $50.48^{* * *}$ & $25.49^{* * *}$ & $31.43^{* * *}$ & $12.91^{* * *}$ \\
\hline
\end{tabular}

Notes. Table $2 \mathrm{~B}$ reports the asymmetric response of Index $_{1}$ to Index $x_{2}$ news with the use of an error correction model (ECM) among US stock indices from different groups. The present table concerns the Lehman crisis sub-sample.

$E C=\operatorname{Index}_{1}-a_{0}-a_{1} \cdot$ Index $_{2}$

$\Delta E C=a_{0}+\beta_{1} \cdot \Delta E R+\beta_{2} \cdot \Delta s^{-}+\beta_{3} \cdot \Delta s^{+}+\beta_{4} \cdot \Delta s^{s}+\beta_{5} \cdot \Delta s^{l}+\beta_{6} \cdot E C+\nu$

Regarding notation look at subsection 3.1. *, ** and *** indicate Newey-West statistical significance at a $10 \%, 5 \%$ and $1 \%$ significance level. 
Table 2C. Asymmetric response of exchange rates to stock market news (ECM) (EU crisis sub-sample)

\begin{tabular}{|c|c|c|c|c|c|c|c|c|c|c|c|c|c|c|c|}
\hline \multirow[b]{2}{*}{8} & \multicolumn{6}{|c|}{ Coefficients } & \multicolumn{4}{|c|}{ Model significance tests } & \multicolumn{5}{|c|}{ Tests on asymmetric tests } \\
\hline & $\Delta E R$ & $\Delta s^{-}$ & $\Delta s^{+}$ & $\Delta s^{S}$ & $\Delta s^{l}$ & $E C$ & $F-$ stat & $\operatorname{adj} R^{2}$ & Autocorrelation & Heteroskedasticity & $F_{1}$ & $F_{2}$ & $F_{3}$ & $T_{1}$ & $T_{2}$ \\
\hline$D J A \rightarrow R U I$ & $-0.0677^{* *}$ & $-32.21^{* * *}$ & 1.76 & $-63.21^{* * *}$ & $53.07^{* * *}$ & 0.0014 & $159^{* * *}$ & 0.7473 & $6.53^{* * *}$ & 10.49 *** & $4.87^{* *}$ & $88.58^{* * *}$ & $71.12^{* * *}$ & $50.86^{* * *}$ & $89.07^{* * *}$ \\
\hline$D J A \leftarrow R U I$ & $-0.0652^{* *}$ & $-5.61^{* * *}$ & -0.0460 & $-12.21^{* * *}$ & $9.48^{* * *}$ & -0.0244 & $159^{* * *}$ & 0.7474 & $10.76^{* * *}$ & $5.89^{* *}$ & $3.07^{*}$ & $66.63^{* * *}$ & $75.47^{* * *}$ & $42.00^{* * *}$ & $94.62^{* * *}$ \\
\hline$D J A \rightarrow R U T$ & -0.0533 & $-26.62^{* * *}$ & 1.02 & $-49.18^{* * *}$ & $42.83^{* * *}$ & -0.0071 & $97.39^{* * *}$ & 0.6440 & $4.25^{* *}$ & $17.85^{* * *}$ & $3.33^{*}$ & $35.61^{* * *}$ & $36.79^{* * *}$ & $20.46^{* * *}$ & $46.23^{* * *}$ \\
\hline$D J A \leftarrow R U T$ & $-0.0744^{* *}$ & $-9.88^{* * *}$ & -0.2844 & $-15.81^{* * *}$ & $13.55^{* * *}$ & -0.0184 & $132^{* * *}$ & 0.7100 & $4.81^{* * *}$ & $20.93^{* * *}$ & $8.60^{* * *}$ & $76.61^{* * *}$ & $53.11^{* * *}$ & $49.12^{* * *}$ & $66.40^{* * *}$ \\
\hline$D J A \rightarrow R U A$ & $-0.0745^{* * *}$ & $-33.43^{* * *}$ & -0.7837 & $-65.00^{* * *}$ & $52.73^{* * *}$ & 0.0046 & $169^{* * *}$ & 0.7579 & $5.79^{* * *}$ & $6.86^{* * *}$ & $6.01^{* *}$ & $87.60^{* * *}$ & $75.78^{* * *}$ & $52.52 * * *$ & $95.11^{* * *}$ \\
\hline$D J A \leftarrow R U A$ & $-0.0620^{* *}$ & $-6.35^{* * *}$ & -0.0768 & $-13.28^{* * *}$ & $10.42^{* * *}$ & -0.0233 & $163^{* * *}$ & 0.7516 & $10.41^{* * *}$ & $7.05^{* * *}$ & $3.87^{* *}$ & $71.45^{* * *}$ & $75.85^{* * *}$ & $45.20^{* * *}$ & $95.06^{* * *}$ \\
\hline$D J A \rightarrow N Y E$ & $-0.0444^{* *}$ & $-30.84^{* * *}$ & -2.69 & $-62.31^{* * *}$ & $48.95^{* * *}$ & 0.0004 & $151^{* * *}$ & 0.7367 & $6.11^{* * *}$ & $9.77^{* * *}$ & $4.85^{* *}$ & $54.49^{* * *}$ & $67.96^{* * *}$ & $36.45^{* * *}$ & $85.49^{* * *}$ \\
\hline$D J A \leftarrow N Y E$ & -0.0291 & $-72.64^{* * *}$ & -2.05 & $-135^{* * *}$ & $105^{* * *}$ & -0.0086 & $153^{* * *}$ & 0.7400 & $4.32^{* *}$ & $6.37^{* *}$ & $5.26^{* *}$ & $78.13^{* * *}$ & $66.77^{* * *}$ & $50.25^{* * *}$ & $83.79^{* * *}$ \\
\hline$D J A \rightarrow X A X$ & $-0.0852^{* *}$ & $-15.92^{* * *}$ & 8.66 & $-46.16^{* * *}$ & $31.54^{* * *}$ & -0.0154 & $51.61^{* * *}$ & 0.4895 & 0.8573 & $4.61^{* *}$ & 0.3276 & $17.83^{* * *}$ & $19.04^{* * *}$ & $8.92^{* * *}$ & $23.91^{* * *}$ \\
\hline$D J A \leftarrow X A X$ & 0.0024 & $-18.11^{* * *}$ & -0.0163 & $-29.25 * * *$ & $23.09^{* * *}$ & $-0.0627^{* * *}$ & $61.13^{* * *}$ & 0.5317 & 1.87 & $15.70^{* * *}$ & $2.79^{*}$ & $37.46^{* * *}$ & $23.34^{* * *}$ & $23.43^{* * *}$ & $29.25^{* * *}$ \\
\hline$D J I \rightarrow R U I$ & $-0.0713^{* * *}$ & $-89.12^{* * *}$ & 0.7355 & $-183^{* * *}$ & $152^{* * *}$ & -0.0058 & $172^{* * *}$ & 0.7621 & $6.28^{* * *}$ & $11.77^{* * *}$ & $5.19^{* *}$ & $83.93^{* * *}$ & $80.30^{* * *}$ & $49.78^{* * *}$ & $201^{* * *}$ \\
\hline$D J I \leftarrow R U I$ & $-0.0772^{* * *}$ & $-5.47^{* * *}$ & 0.0981 & $-13.43^{* * *}$ & $9.98 * * *$ & -0.0192 & $184^{* * *}$ & 0.7739 & $17.16^{* * *}$ & $14.24^{* * *}$ & 1.40 & $76.15^{* * *}$ & $92.84^{* * *}$ & $47.24^{* * *}$ & $158^{* * *}$ \\
\hline$D J I \rightarrow R U T$ & -0.0492 & $-61.79^{* * *}$ & 4.49 & $-145^{* * *}$ & $123 * * *$ & -0.0107 & $89.39^{* * *}$ & 0.6241 & $2.59^{*}$ & $31.10^{* * *}$ & 1.43 & $24.46^{* * *}$ & $37.65^{* * *}$ & $13.79^{* * *}$ & $47.33^{* * *}$ \\
\hline$D J I \leftarrow R U T$ & $-0.0869^{* * *}$ & $-8.56^{* * *}$ & 0.3454 & $-17.39^{* * *}$ & $14.42^{* * *}$ & -0.0171 & $119^{* * *}$ & 0.6887 & $4.68^{* * *}$ & $28.60^{* * *}$ & $3.42^{*}$ & $62.60^{* * *}$ & $55.17^{* * *}$ & $38.13^{* * *}$ & $69.07^{* * *}$ \\
\hline$D J I \rightarrow R U A$ & $-0.0687^{* *}$ & $-90.25^{* * *}$ & -4.17 & $-187^{* * *}$ & $153^{* * *}$ & -0.0016 & $178^{* * *}$ & 0.7676 & $5.38^{* * *}$ & $7.95^{* * *}$ & $6.18^{* *}$ & $80.93^{* * *}$ & $84.10^{* * *}$ & $49.47^{* * *}$ & $106^{* * *}$ \\
\hline$D J I \leftarrow R U A$ & -0.0736 *** & $-6.21^{* * *}$ & 0.2606 & $-14.43^{* * *}$ & $11.03^{* * *}$ & -0.0250 & $188^{* * *}$ & 0.7771 & $15.85^{* * *}$ & $15.98^{* * *}$ & 2.14 & $85.74^{* * *}$ & $92.73^{* * *}$ & $52.37^{* * *}$ & $117^{* * *}$ \\
\hline$D J I \rightarrow N Y E$ & $-0.0464^{*}$ & $-82.15^{* * *}$ & -7.75 & $-182^{* * *}$ & $144^{* * *}$ & 0.0008 & $174^{* * *}$ & 0.7633 & $6.10^{* * *}$ & $14.72^{* * *}$ & $4.57^{* *}$ & $53.94^{* * *}$ & $82.53^{* * *}$ & $36.42^{* * *}$ & $104^{* * *}$ \\
\hline$D J I \leftarrow N Y E$ & -0.0398 & $-69.58^{* * *}$ & 1.97 & $-151^{* * *}$ & $112^{* * *}$ & -0.0052 & $194^{* * *}$ & 0.7827 & $8.10^{* * *}$ & $13.30^{* * *}$ & 2.55 & $98.18^{* * *}$ & $91.75^{* * *}$ & $60.44^{* * *}$ & $116^{* * *}$ \\
\hline$D J I \rightarrow X A X$ & $-0.0876^{* *}$ & $-46.25^{* * *}$ & 15.99 & $-132^{* * *}$ & $96.73^{* * *}$ & -0.0103 & $56.19^{* * *}$ & 0.5107 & $3.17^{* *}$ & $5.13^{* *}$ & 0.0170 & $15.28^{* * *}$ & $21.91^{* * *}$ & $7.70^{* * *}$ & $27.42^{* * *}$ \\
\hline$D J I \leftarrow X A X$ & -0.0148 & $-18.33^{* * *}$ & -0.1711 & $-34.14^{* * *}$ & $25.97^{* * *}$ & $-0.0565^{* * *}$ & $78.92^{* * *}$ & 0.5945 & $2.49^{*}$ & $19.85^{* * *}$ & 2.25 & $44.65^{* * *}$ & $33.83^{* * *}$ & $28.34^{* * *}$ & $42.50^{* * *}$ \\
\hline$O E X \rightarrow R U I$ & $-0.0817^{* * *}$ & $-4.74^{* * *}$ & -0.2270 & $-9.29^{* * *}$ & $7.66^{* * *}$ & -0.0191 & $199^{* * *}$ & 0.7870 & $13.04^{* * *}$ & $9.14^{* * *}$ & $8.00^{* * *}$ & $94.22^{* * *}$ & $91.07^{* * *}$ & $58.64^{* * *}$ & $114^{* * *}$ \\
\hline$O E X \leftarrow R U I$ & $-0.0676^{* * *}$ & $-7.01^{* * *}$ & -0.3529 & $-13.44^{* * *}$ & $11.43^{* * *}$ & -0.0141 & $222^{* * *}$ & 0.8047 & $15.13^{* * *}$ & $14.52^{* * *}$ & $11.88^{* * *}$ & $140^{* * *}$ & $106^{* * *}$ & $86.91^{* * *}$ & $133^{* * *}$ \\
\hline$O E X \rightarrow R U T$ & $-0.0631^{*}$ & $-3.35^{* * *}$ & -0.1188 & $-7.54^{* * *}$ & $6.17^{* * *}$ & -0.0180 & $104^{* * *}$ & 0.6591 & $5.95^{* * *}$ & $17.97^{* * *}$ & 2.14 & $25.19^{* * *}$ & $43.37^{* * *}$ & $15.52^{* * *}$ & $54.50^{* * *}$ \\
\hline$O E X \leftarrow R U T$ & $-0.0875^{* * *}$ & $-11.27^{* * *}$ & -0.2682 & $-17,20^{* * *}$ & $15.74^{* * *}$ & -0.0202 & $144^{* * *}$ & 0.7285 & $6.45^{* * *}$ & $35.89^{* * *}$ & $12.85^{* * *}$ & $121^{* * *}$ & $58.84^{* * *}$ & $73.48 * * *$ & $73.69^{* * *}$ \\
\hline$O E X \rightarrow R U A$ & $-0.0852^{* * *}$ & $-4.75^{* * *}$ & -0.4425 & $-9.58^{* * *}$ & $7.73^{* * *}$ & $-5.40 \mathrm{e}-4$ & $216^{* * *}$ & 0.8007 & $13.61^{* * *}$ & $5.92^{* *}$ & $8.76^{* * *}$ & $94.16^{* * *}$ & $101^{* * *}$ & $60.18^{* * *}$ & $127^{* * *}$ \\
\hline$O E X \leftarrow R U A$ & $-0.0640^{* * *}$ & $-7.91^{* * *}$ & -0.2856 & $-14.51^{* * *}$ & $12.49^{* * *}$ & -0.0143 & $228^{* * *}$ & 0.8093 & $14.86^{* * *}$ & $15.96^{* * *}$ & $13.35^{* * *}$ & $156^{* * *}$ & $106^{* * *}$ & $95.43^{* * *}$ & $133^{* * *}$ \\
\hline$O E X \rightarrow N Y E$ & $-0.0617^{* *}$ & $-4.39^{* * *}$ & -0.6150 & $-9.10^{* * *}$ & $7.12^{* * *}$ & 0.0045 & $188^{* * *}$ & 0.7775 & $8.78^{* * *}$ & $10.62^{* * *}$ & $6.71^{* * * *}$ & $58.58^{* * *}$ & $86.69^{* * *}$ & $41.89^{* * *}$ & $109^{* * *}$ \\
\hline$O E X \leftarrow N Y E$ & -0.0360 & $-87.43^{* * *}$ & -3.66 & $-150^{* * *}$ & $126^{* * *}$ & -0.0057 & $219^{* * *}$ & 0.8024 & $5.55^{* * *}$ & $12.84^{* * *}$ & $13.77^{* * *}$ & $164^{* * *}$ & $96.34^{* * *}$ & $101^{* * *}$ & $121^{* * *}$ \\
\hline$O E X \rightarrow X A X$ & $-0.1095^{* * *}$ & $-2.47^{* * *}$ & 0.5995 & $-6.88^{* * *}$ & $4.62^{* * *}$ & -0.0089 & $59.46^{* * *}$ & 0.5248 & $3.84^{* *}$ & $5.49^{* *}$ & 0.0503 & $15.21^{* * *}$ & $22.74 * * *$ & $7.80^{* * *}$ & $28.63^{* * *}$ \\
\hline$O E X \leftarrow X A X$ & -0.0193 & $-21.50^{* * *}$ & -2.99 & $-35.40^{* * *}$ & $27.47^{* * *}$ & $-0.0310^{* *}$ & $73.21^{* * *}$ & 0.5763 & 1.98 & $15.48 * * *$ & $5.19 * *$ & $47.51^{* * *}$ & $30.80^{* * *}$ & $32.82^{* * *}$ & $38.99^{* * *}$ \\
\hline$S P X \rightarrow R U I$ & $-0.0801 * * *$ & $-11.03^{* * *}$ & -0.0733 & $-21.44^{* * *}$ & $17.87^{* * *}$ & -0.1080 & $210^{* * *}$ & 0.7956 & $14.29^{* * *}$ & $8.44^{* * *}$ & $7.98^{* * *}$ & $108^{* * *}$ & $94.92^{* * *}$ & $64.54^{* * *}$ & $119^{* * *}$ \\
\hline$S P X \leftarrow R U I$ & $-0.0880^{* * *}$ & $-6.32 * * *$ & 0.0461 & $-12.99 * * *$ & $10.67^{* * *}$ & -0.1708 & $231^{* * *}$ & 0.8113 & $16.78^{* * *}$ & $6.07^{* *}$ & $7.25^{* * *}$ & $129^{* * *}$ & $110^{* * *}$ & $75.57^{* * *}$ & $138^{* * *}$ \\
\hline$S P X \rightarrow R U T$ & $-0.0594^{*}$ & $-7.86^{* * *}$ & 0.2951 & $-17.66^{* * *}$ & $14.69^{* * *}$ & -0.0199 & $118^{* * *}$ & 0.6865 & $6.75^{* * *}$ & $17.12^{* * *}$ & 2.06 & $32.76^{* * *}$ & $48.49 * * *$ & $18.91^{* * *}$ & $61.06^{* * *}$ \\
\hline$S P X \leftarrow R U T$ & $-0.0979 * * *$ & $-10.88^{* * *}$ & 0.0970 & $-16.35^{* * *}$ & $15.10^{* * *}$ & -0.0138 & $167^{* * * *}$ & 0.7567 & $7.48^{* * *}$ & $10.01^{* * *}$ & $14.11^{* * *}$ & $131^{* * *}$ & $66.31^{* * *}$ & $76.65^{* * *}$ & $82.91^{* * *}$ \\
\hline$S P X \rightarrow R U A$ & $-0.0853^{* * *}$ & $-11.10^{* * *}$ & -0.6246 & $-22.20^{* * *}$ & $17.98^{* * *}$ & 0.0636 & $232 * * *$ & 0.8115 & $14.71^{* * *}$ & $5.46^{* *}$ & $8.67^{* * *}$ & $109^{* * *}$ & $107^{* * *}$ & $67.30^{* * *}$ & $135^{* * *}$ \\
\hline$S P X \leftarrow R U A$ & $-0.0810^{* * *}$ & $-7.23^{* * *}$ & 0.1075 & $-14.04 * * *$ & $11.62^{* * *}$ & -0.0457 & $241^{* * *}$ & 0.8173 & $16.78^{* * *}$ & $6.47^{* *}$ & $8.74^{* * *}$ & $146^{* * *}$ & $111^{* * *}$ & $85.29^{* * *}$ & $138^{* * *}$ \\
\hline$S P X \rightarrow N Y E$ & $-0.0592^{* *}$ & $-10.15^{* * *}$ & -1.11 & $-21.09^{* * *}$ & $16.48^{* * *}$ & 0.0051 & $190^{* *}$ & 0.7795 & $8.18^{* * *}$ & $9.38^{* * *}$ & $6.02 * *$ & $63.40^{* * *}$ & $86.18^{* * *}$ & 43.46 *** & $110^{* * *}$ \\
\hline$S P X \leftarrow N Y E$ & $-0.0529^{* *}$ & $-79.44^{* * *}$ & 0.7549 & $-146^{* * *}$ & $116^{* * *}$ & -0.0039 & $221^{* * *}$ & 0.8042 & $7.66^{* * *}$ & $8.82^{* * *}$ & $7.79^{* * *}$ & $148^{* * *}$ & $97.16^{* * *}$ & $86.61^{* * *}$ & $122^{* * *}$ \\
\hline$S P X \rightarrow X A X$ & $-0.1052^{* * *}$ & $-5.80^{* * *}$ & 1.68 & $-16.00^{* * *}$ & $116^{* * *}$ & -0.0122 & $61.76 * * *$ & 0.5343 & $3.09^{* *}$ & $5.56^{* *}$ & 0.0738 & $17.16^{* * *}$ & $23.40^{* * *}$ & $8.72^{* * *}$ & $29.45^{* * *}$ \\
\hline$S P X \leftarrow X A X$ & -0.0339 & $-20.01^{* * *}$ & -0.3333 & $-33.33^{* * *}$ & $25.34^{* * *}$ & $-0.0417^{* *}$ & $77.55^{* * *}$ & 0.5902 & $4.77^{* * *}$ & $16.29^{* * *}$ & $3.18^{*}$ & $54.59^{* * *}$ & $30.58^{* * *}$ & $32.70^{* * *}$ & $38.43^{* * *}$ \\
\hline$R U I \rightarrow N Y E$ & $-0.0579^{* *}$ & $-5.57^{* * *}$ & -0.6751 & $-11.97^{* * *}$ & $9.39^{* * *}$ & 0.0037 & $181^{* * *}$ & 0.7704 & $8.52^{* * *}$ & $9.47^{* * *}$ & $5.45^{* *}$ & $55.79 * * *$ & $84.56^{* * *}$ & $38.80 * * *$ & $106^{* * *}$ \\
\hline$R U I \leftarrow N Y E$ & $-0.0490^{*}$ & $-76.32 * * *$ & -0.3540 & $-137^{* * *}$ & $110^{* * *}$ & -0.0097 & $192^{* * *}$ & 0.7809 & $5.15 * * *$ & $11.26^{* * *}$ & $7.61^{* * *}$ & $113^{* * *}$ & $81.63^{* * *}$ & $67.76^{* * *}$ & $103^{* * *}$ \\
\hline$R U I \rightarrow X A X$ & $-0.1009^{* * *}$ & $-3.41^{* * *}$ & 0.9697 & $-8.77^{* * *}$ & $6.11^{* * *}$ & -0.0125 & $60.12^{* * *}$ & 0.5276 & $2.78^{*}$ & $5.80^{* *}$ & 0.0093 & $18.11^{* * *}$ & $22.26^{* * *}$ & $9.21^{* * *}$ & $27.95^{* * *}$ \\
\hline$R U I \leftarrow X A X$ & -0.0338 & $-19.86^{* * *}$ & 0.4030 & $-30.54^{* * *}$ & $23.09^{* * *}$ & $-0.0408^{* *}$ & $73.21^{* * *}$ & 0.5763 & 2.09 & $16.47^{* * *}$ & $2.97^{*}$ & $53.99^{* * *}$ & $26.22^{* * *}$ & $31.74^{* * *}$ & $33.10^{* * *}$ \\
\hline$R U T \rightarrow N Y E$ & $-0.0692^{* *}$ & $-9.49^{* * *}$ & -0.6600 & $-15.28^{* * *}$ & $14.10^{* * *}$ & -0.0391 & $148^{* * *}$ & 0.7329 & $2.81^{*}$ & $12.69^{* * *}$ & $12.59 * * *$ & $69.12^{* * *}$ & $60.59^{* * *}$ & $45.24^{* * *}$ & $75.74^{* * *}$ \\
\hline$R U T \leftarrow N Y E$ & -0.0259 & $-53.66^{* * *}$ & 2.72 & $-117^{* * *}$ & $91.05^{* * *}$ & $-0.0435^{*}$ & $124^{* * *}$ & 0.6975 & $2.48^{*}$ & $18.73^{* * *}$ & 1.44 & $38.32^{* * *}$ & $49.10^{* * *}$ & $21.85^{* * *}$ & $62.22^{* * *}$ \\
\hline$R U T \rightarrow X A X$ & $-0.1287^{* * *}$ & $-5.56 * * *$ & 0.9622 & $-12.83^{* * *}$ & $8.83^{* * *}$ & -0.0087 & $60.33^{* * *}$ & 0.5284 & 1.64 & $13.31^{* * * *}$ & 0.0312 & $17.41^{* * *}$ & $20.82^{* * *}$ & $9.19^{* * *}$ & $26.16^{* * *}$ \\
\hline$R U T \leftarrow X A X$ & -0.0169 & $-11.18^{* * *}$ & 2.14 & $-27.78^{* * *}$ & $23.74^{* * *}$ & $-0.0253^{*}$ & $61.05^{* * *}$ & 0.5314 & 1.73 & $30.56^{* * *}$ & 0.4821 & $18.20^{* * *}$ & $25.68 * * *$ & $9.66^{* * *}$ & $32.25^{* * *}$ \\
\hline$R U A \rightarrow N Y E$ & $-0.0530^{* *}$ & $-6.39^{* * *}$ & -0.6437 & $-12.91^{* * *}$ & $10.22^{* * *}$ & 0.0040 & $189^{* * *}$ & 0.7780 & $7.77^{* * *}$ & $10.07 * * *$ & $6.85^{* * *}$ & $66.02^{* * *}$ & $85.45^{* * *}$ & $44.78^{* * *}$ & $107^{* * *}$ \\
\hline$R U A \leftarrow N Y E$ & $-0.0479^{*}$ & $-77.40^{* * *}$ & -4.98 & $-143^{* * *}$ & $110^{* * *}$ & -0.0134 & $214^{* * *}$ & 0.7989 & $5.74^{* * *}$ & $8.41^{* * *}$ & $8.20^{* * *}$ & $115^{* * *}$ & $93.14^{* * *}$ & $71.36^{* *}$ & $118^{* * *}$ \\
\hline$R U A \rightarrow X A X$ & $-0.1013^{* * *}$ & $-3.72^{* * *}$ & 1.04 & $-9.93^{* * *}$ & $6.73^{* * *}$ & -0.0131 & $63.02 * * *$ & 0.5393 & $2.87^{*}$ & $7.10^{* * *}$ & 0.0449 & $18.12^{* * *}$ & $23.68^{* * *}$ & $9.22^{* * *}$ & $29.78^{* * *}$ \\
\hline$R U A \leftarrow X A X$ & -0.0312 & $-18.76^{* * *}$ & 0.1912 & $-32.13^{* * *}$ & $24.27^{* * *}$ & $-0.0349^{* *}$ & $74.86^{* * *}$ & 0.5817 & $2.62^{*}$ & $17.44^{* * *}$ & 2.42 & $48.58^{* * *}$ & $29.21^{* * *}$ & $28.43^{* * *}$ & $36.91^{* * *}$ \\
\hline
\end{tabular}

Notes. Table $2 \mathrm{C}$ reports the asymmetric response of Index 1 to Index $x_{2}$ news with the use of an error correction model (ECM) among US stock indices from different groups. The present table concerns the EU crisis sub-sample.

$E C=$ Index ${ }_{1}-a_{0}-a_{1} \cdot$ Index 2

$\Delta E C=a_{0}+\beta_{1} \cdot \Delta E R+\beta_{2} \cdot \Delta s^{-}+\beta_{3} \cdot \Delta s^{+}+\beta_{4} \cdot \Delta s^{s}+\beta_{5} \cdot \Delta s^{l}+\beta_{6} \cdot E C+\nu$

Regarding notation look at subsection 3.1. ${ }^{*},{ }^{* *}$ and ${ }^{* * *}$ indicate Newey-West statistical significance at a $10 \%, 5 \%$ and $1 \%$ significance level. 


\begin{tabular}{|c|c|c|c|c|c|c|c|c|c|c|c|c|c|c|c|}
\hline \multirow[b]{2}{*}{ 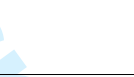 } & \multicolumn{6}{|c|}{ Coefficients } & \multicolumn{4}{|c|}{ Model significance tests } & \multicolumn{5}{|c|}{ Tests on asymmetric tests } \\
\hline & $\Delta E R$ & $\Delta s^{-}$ & $\Delta s^{+}$ & $\Delta s^{S}$ & $\Delta s^{l}$ & $E C$ & $F-$ stat & adj $R^{2}$ & Autocorrelation & Heteroskedasticity & $F_{1}$ & $F_{2}$ & $F_{3}$ & $T_{1}$ & $T_{2}$ \\
\hline$D J A \rightarrow R U I$ & -0.0318 & $-25.43^{* * *}$ & 1.41 & $-38.55^{* * *}$ & $27.63^{* * *}$ & $-0.0184^{* *}$ & $95.71^{* * *}$ & 0.4098 & $88.53^{* * *}$ & $92.04^{* * *}$ & $3.26^{*}$ & $92.82^{* * *}$ & $87.45^{* * *}$ & $28.87^{* * *}$ & $44.17^{* * *}$ \\
\hline$D J A \leftarrow R U I$ & $-0.1622^{* * *}$ & $-3.79^{* * *}$ & $2.20^{* * *}$ & $-7.17^{* * *}$ & $5.59^{* * *}$ & -0.0053 & $117^{* * *}$ & 0.4593 & 21.96 *** & $64.01^{* * *}$ & $9.14 \mathrm{e}-5$ & $149^{* * *}$ & $109^{* * *}$ & $37.92^{* * *}$ & $54.84^{* * *}$ \\
\hline$D J A \rightarrow R U T$ & -0.0219 & $-26.63^{* * *}$ & 3.41 & $-41.22^{* * *}$ & $31.33^{* * *}$ & -0.0030 & $212^{* * *}$ & 0.6062 & $2.76^{*}$ & 0.7218 & $5.65^{* *}$ & $161^{* * *}$ & $189 * * *$ & $46.38 * * *$ & $95.61^{* * *}$ \\
\hline$D J A \leftarrow R U T$ & -0.0069 & $-7.98 * * *$ & -0.5415 & $-11.98^{* * *}$ & $9.16^{* * *}$ & $-0.0079^{*}$ & $216^{* * *}$ & 0.6102 & 0.9442 & 1.78 & $14.44^{* * *}$ & $162^{* * *}$ & $213^{* * *}$ & $55.17^{* * *}$ & $107^{* * *}$ \\
\hline$D J A \rightarrow R U A$ & -0.0042 & $-35.41^{* * *}$ & -1.29 & $-49.29 * * *$ & $45.86^{* * *}$ & 0.0019 & $509^{* * *}$ & 0.7870 & 1.44 & 0.6223 & $58.67^{* * *}$ & $408^{* * *}$ & $507^{* * *}$ & $141^{* * *}$ & $253^{* * *}$ \\
\hline$D J A \leftarrow R U A$ & $0.0275^{*}$ & $-6.74^{* * *}$ & -0.5423 & $-10.25^{* * *}$ & $8.95^{* * *}$ & $-5.63 \mathrm{e}-4$ & $524^{* * *}$ & 0.7916 & 1.34 & $12.26^{* * *}$ & $49.98^{* * *}$ & $354^{* * *}$ & $552^{* * *}$ & $122^{* * *}$ & $276^{* * *}$ \\
\hline$D J A \rightarrow N Y E$ & -0.0163 & $-37.34^{* * *}$ & -1.51 & $-49.80^{* * *}$ & $49.08^{* * *}$ & -0.0042 & $435^{* * *}$ & 0.7593 & 0.9462 & 0.5250 & $63.78^{* * *}$ & $409^{* * *}$ & $428^{* * *}$ & $145^{* * *}$ & $214^{* * *}$ \\
\hline$D J A \leftarrow N Y E$ & 0.0212 & $-65.27^{* * *}$ & -5.37 & $-87.84^{* * *}$ & $79.39^{* * *}$ & -0.0047 & $452^{* * *}$ & 0.7663 & 0.6727 & $3.94^{* *}$ & $56.41^{* * *}$ & $347^{* * *}$ & $440^{* * *}$ & $120^{* * *}$ & $220^{* * *}$ \\
\hline$D J A \rightarrow X A X$ & -0.0415 & $-25.29 * * *$ & -2.22 & $-39.56^{* * *}$ & $25.69 * * *$ & $-9.07 e-4$ & $97.73 * * *$ & 0.4149 & 0.8570 & 1.37 & $3.78^{*}$ & $62.57^{* * *}$ & $92.63^{* * *}$ & $24.50^{* * *}$ & $48.61^{* * *}$ \\
\hline$D J A \leftarrow X A X$ & 0.0178 & $-11.85^{* * *}$ & 0.8166 & $-18.68^{* * *}$ & $14.21^{* * *}$ & $-8.33 \mathrm{e}-4$ & $90.59^{* * *}$ & 0.3966 & 0.7937 & 0.4513 & $3.17^{*}$ & $79.69^{* * *}$ & $87.60^{* * *}$ & $24.02^{* * *}$ & $44.05^{* * * *}$ \\
\hline$D J I \rightarrow R U I$ & -0.0299 & $-71.15^{* * *}$ & 2.40 & $-109^{* * *}$ & $75.79^{* * *}$ & $-0.0331^{* * *}$ & $93.16^{* * *}$ & 0.4033 & $72.20^{* * *}$ & $90.73^{* * *}$ & $2.93^{*}$ & $86.28^{* * *}$ & $84.57^{* * *}$ & $27.32^{* * *}$ & $42.85^{* * *}$ \\
\hline$D J I \leftarrow R U I$ & $-0.1534^{* * *}$ & $-3.88^{* * *}$ & $2.46^{* * *}$ & $-6.74 * * *$ & $5.59^{* * *}$ & -0.0104 & $104^{* * *}$ & 0.4310 & $24.94 * * *$ & $44.78^{* * *}$ & 0.0480 & $158^{* * *}$ & $92.01^{* * *}$ & $40.15^{* * *}$ & $46.13^{* * *}$ \\
\hline$D J I \rightarrow R U T$ & -0.0198 & $-77.17^{* * *}$ & 5.15 & $-111^{* * *}$ & $83.95^{* * *}$ & -0.0126 & $181^{* * *}$ & 0.5674 & 2.29 & $13.60^{* * *}$ & $7.47^{* * *}$ & $137^{* * *}$ & $155^{* * *}$ & $41.26^{* * *}$ & $78.17^{* * *}$ \\
\hline$D J I \leftarrow R U T$ & -0.0067 & $-7.60^{* * *}$ & 0.1498 & $-11.96^{* * *}$ & $8.71^{* * *}$ & -0.0069 & $180^{* * *}$ & 0.5661 & 0.1652 & $19.35^{* * *}$ & $7.24^{* * *}$ & $156^{* * *}$ & $176^{* * *}$ & $50.57^{* * *}$ & $88.94^{* * *}$ \\
\hline$D J I \rightarrow R U A$ & -0.0026 & $-98.95^{* * *}$ & -7.43 & $-142^{* * *}$ & $129^{* * *}$ & -0.0066 & $471^{* * *}$ & 0.7736 & 0.7963 & 2.12 & $54.32 * * *$ & $345^{* * *}$ & $483^{* * *}$ & $124^{* * *}$ & $242^{* * *}$ \\
\hline$D J I \leftarrow R U A$ & 0.0262 & $-6.68^{* * *}$ & 0.1152 & $-10.42^{* * *}$ & $8.75^{* * *}$ & -0.0016 & $484^{* * *}$ & 0.7783 & 0.0669 & $13.17^{* * *}$ & $32.39 * * *$ & $394^{* * *}$ & $497^{* * *}$ & $129^{* * *}$ & $249^{* * *}$ \\
\hline$D J I \rightarrow N Y E$ & -0.0149 & $-105.22^{* * *}$ & -5.40 & $-142^{* * *}$ & $141^{* * *}$ & -0.0085 & $451^{* * *}$ & 0.7659 & 0.6457 & 0.0015 & $68.47^{* * *}$ & $408^{* * *}$ & $453^{* * *}$ & $146^{* * *}$ & $226^{* * *}$ \\
\hline$D J I \leftarrow N Y E$ & 0.0173 & $-62.83^{* * *}$ & 1.05 & $-93.00^{* * *}$ & $78.75^{* * *}$ & -0.0031 & $447^{* * *}$ & 0.7644 & 0.5072 & 1.77 & $33.64^{* * *}$ & $383^{* * *}$ & $441^{* * *}$ & $125^{* * *}$ & $221^{* * *}$ \\
\hline$D J I \rightarrow X A X$ & -0.0403 & $-72.53^{* * *}$ & -4.52 & $-109^{* * *}$ & $78.54^{* * *}$ & $-9.24 \mathrm{e}-4$ & $104^{* * *}$ & 0.4298 & 0.4530 & $6.09^{* * *}$ & $5.56^{* *}$ & $69.77^{* * *}$ & $98.66^{* * *}$ & $26.44^{* * *}$ & $50.83^{* * *}$ \\
\hline$D J I \leftarrow X A X$ & 0.0226 & $-11.51^{* * *}$ & 1.39 & $-19.18^{* * *}$ & $15.26 * * *$ & $-3.16 \mathrm{e}-4$ & $90.74 * * *$ & 0.3970 & 0.7593 & 0.0732 & $2.95^{*}$ & $81.59 * * *$ & $92.10^{* * *}$ & $24.55^{* * *}$ & $46.26^{* * *}$ \\
\hline$O E X \rightarrow R U I$ & 0.0032 & $-3.86^{* * *}$ & 0.0219 & $-5.70^{* * *}$ & $4.28^{* * *}$ & $-0.1939 * * *$ & $137^{* * *}$ & 0.4977 & $51.30^{* * *}$ & $81.33^{* * *}$ & $6.15^{* *}$ & $109^{* * *}$ & $111^{* * *}$ & $35.22^{* * *}$ & $55.87^{* * *}$ \\
\hline$O E X \leftarrow R U I$ & $-0.1782^{* * *}$ & $-4.94^{* * *}$ & $2.61^{* * *}$ & $-8.00^{* * *}$ & $6.01^{* * *}$ & $-0.0341^{* *}$ & $137^{* * *}$ & 0.4994 & $27.44^{* * *}$ & $85.26^{* * *}$ & 0.0731 & $265^{* * *}$ & $111^{* * *}$ & $69.14^{* * *}$ & $55.83^{* * *}$ \\
\hline$O E X \rightarrow R U T$ & 0.0054 & $-3.89 * * *$ & 0.2486 & $-5.99^{* * *}$ & $4.79^{* * *}$ & -0.0013 & $216^{* * *}$ & 0.6110 & 1.83 & $20.97^{* * *}$ & $9.07^{* * *}$ & $147^{* * *}$ & $201^{* * *}$ & $44.16^{* * *}$ & $101^{* * *}$ \\
\hline$O E X \leftarrow R U T$ & -0.0149 & $-8.70^{* * *}$ & 0.5758 & $-12.93^{* * *}$ & $10.10^{* * *}$ & $-0.0096^{*}$ & $216^{* * *}$ & 0.6100 & 0.9123 & $31.21^{* * *}$ & $11.19 * * *$ & $260^{* * *}$ & $201^{* * *}$ & $82.79^{* * *}$ & $101^{* * *}$ \\
\hline$O E X \rightarrow R U A$ & 0.0193 & $-5.12 * * *$ & -0.3372 & $-7.59^{* * *}$ & $7.03^{* * *}$ & -0.0074 & $682^{* * *}$ & 0.8319 & 0.2663 & $10.22^{* * *}$ & $76.03^{* * *}$ & $483^{* * *}$ & $720^{* * *}$ & $172^{* * *}$ & $360^{* * *}$ \\
\hline$O E X \leftarrow R U A$ & 0.0095 & $-7.57^{* * *}$ & 0.2014 & $-11.65^{* * *}$ & $10.06^{* * *}$ & -0.0034 & $679^{* * *}$ & 0.8313 & 0.2222 & $29.41^{* * *}$ & $51.71^{* * *}$ & $711^{* * *}$ & $696^{* * *}$ & $234^{* * *}$ & $348^{* * *}$ \\
\hline$O E X \rightarrow N Y E$ & 0.0072 & $-5.34^{* * *}$ & -0.2791 & $-7.66^{* * *}$ & $7.36^{* * *}$ & -0.0019 & $507^{* * *}$ & 0.7863 & 0.1495 & $3.79^{*}$ & $67.29^{* * *}$ & $437^{* * *}$ & $531^{* * * *}$ & $156^{* * *}$ & $265^{* * *}$ \\
\hline$O E X \leftarrow N Y E$ & 0.0071 & $-71.46^{* * *}$ & 0.0485 & $-102^{* * *}$ & $88.96 * * *$ & $9.97 \mathrm{e}-5$ & $533^{* * *}$ & 0.7944 & 0.9080 & $10.16^{* * *}$ & $51.36 * * *$ & $579^{* * *}$ & $517^{* * *}$ & $195^{* * *}$ & $258^{* * *}$ \\
\hline$O E X \rightarrow X A X$ & -0.0194 & $-3.91^{* * *}$ & -0.2659 & $-5.75^{* * *}$ & $4.16^{* * *}$ & $-7.11 \mathrm{e}-5$ & $117^{* * *}$ & 0.4586 & 0.3334 & $9.11^{* * *}$ & $6.94^{* * *}$ & $80.01 * * *$ & $110^{* * *}$ & $30.53^{* * *}$ & $56.49^{* * *}$ \\
\hline$O E X \leftarrow X A X$ & 0.0208 & $-14.53^{* * *}$ & 1.33 & $-19.37^{* * *}$ & $16.69^{* * *}$ & -0.0012 & $101^{* * *}$ & 0.4234 & 0.8237 & 0.1211 & $7.74^{* * *}$ & $134^{* * *}$ & $87.72^{* * *}$ & $42.13^{* * *}$ & $43.86^{* * *}$ \\
\hline$S P X \rightarrow R U I$ & 0.0088 & $-9.23^{* * *}$ & 0.2780 & $-12.28^{* * *}$ & $10.44^{* * *}$ & $-0.5817^{* * *}$ & $219^{* * *}$ & 0.6135 & $20.19^{* * *}$ & $61.93^{* * *}$ & $13.50^{* * *}$ & $165^{* * *}$ & $146^{* * *}$ & $52.32 * * *$ & $72.88^{* * *}$ \\
\hline$S P X \leftarrow R U I$ & $-0.0890 * * *$ & $-5.09 * * *$ & $2.06^{* * *}$ & $-8.68^{* * *}$ & $6.86^{* * *}$ & $-0.4055^{* * *}$ & $174^{* * *}$ & 0.5583 & $5.97^{* * *}$ & $56.37^{* * *}$ & 1.10 & $258^{* * *}$ & $171^{* * *}$ & $68.44^{* * *}$ & $85.72^{* * *}$ \\
\hline$S P X \rightarrow R U T$ & 0.0026 & $-9.26 * * *$ & 0.6244 & $-14.08^{* * *}$ & $11.07 * * *$ & -0.0015 & $264^{* * *}$ & 0.6572 & 2.13 & $17.00^{* * *}$ & $10.67 * * *$ & $185^{* * *}$ & $241^{* * *}$ & $55.45^{* * *}$ & $121^{* * *}$ \\
\hline$S P X \leftarrow R U T$ & -0.0096 & $-9.26^{* * *}$ & -0.2101 & $-12.37^{* * *}$ & $9.25^{* * *}$ & -0.0062 & $272^{* * *}$ & 0.6640 & 0.8138 & $4.78^{* *}$ & $19.88^{* * *}$ & $276^{* * *}$ & $239^{* * *}$ & $94.11^{* * *}$ & $120^{* * *}$ \\
\hline$S P X \rightarrow R U A$ & 0.0150 & $-11.86^{* * *}$ & -0.5210 & $-17.45^{* * *}$ & $15.78^{* * *}$ & 0.0014 & $810^{* * *}$ & 0.8546 & 0.2207 & $16.82^{* * *}$ & $81.90^{* * *}$ & $610^{* * *}$ & $837^{* * *}$ & $212^{* * *}$ & $418^{* * *}$ \\
\hline$S P X \leftarrow R U A$ & 0.0172 & $-7.53^{* * *}$ & -0.3716 & $-10.85^{* * *}$ & $9.46^{* * *}$ & 0.0016 & $820^{* * *}$ & 0.8560 & 0.1945 & $17.41^{* * *}$ & $81.92^{* * *}$ & $677^{* * *}$ & $828^{* * *}$ & $238^{* * *}$ & $414^{* * *}$ \\
\hline$S P X \rightarrow N Y E$ & 0.0033 & $-12.42^{* * *}$ & -0.4564 & $-17.61^{* * *}$ & $16.53^{* * *}$ & -0.0019 & $593^{* * *}$ & 0.8113 & 0.0963 & $7.69^{* * *}$ & $72.80^{* * *}$ & $538^{* * *}$ & $603^{* * *}$ & $189^{* * *}$ & $302^{* * *}$ \\
\hline$S P X \leftarrow N Y E$ & 0.0114 & $-71.20^{* * *}$ & -4.14 & $-94.39^{* * *}$ & $83.25^{* * *}$ & -0.0020 & $628^{* * *}$ & 0.8201 & 0.2402 & $8.27^{* * *}$ & $74.72^{* * *}$ & $558 * * *$ & $596 * *$ & $198 * * *$ & $298^{* * *}$ \\
\hline$S P X \rightarrow X A X$ & -0.0201 & $-9.07^{* * *}$ & -0.6560 & $-13.26^{* * *}$ & $9.44^{* * *}$ & $-1.47 \mathrm{e}-4$ & $124^{* * *}$ & 0.4727 & 0.4106 & $9.95^{* * *}$ & $7.25^{* * *}$ & $85.30^{* * *}$ & $115^{* * *}$ & $32.72^{* * *}$ & $59.33^{* * *}$ \\
\hline$S P X \leftarrow X A X$ & 0.0240 & $-14.18^{* * *}$ & 0.8481 & $-18.48^{* * *}$ & $15.89^{* * *}$ & $-6.88 \mathrm{e}-4$ & $110^{* * *}$ & 0.4431 & 0.9446 & $3.65 \mathrm{e}-4$ & $8.97^{* * *}$ & $120^{* * *}$ & $95.79 * * *$ & $38.17^{* * *}$ & $47.90^{* * *}$ \\
\hline$R U I \rightarrow N Y E$ & $-0.1705^{* * *}$ & $-4.43^{* * *}$ & $2.39^{* * *}$ & $-7.42^{* * *}$ & $6.42^{* * *}$ & -0.0059 & $127^{* * *}$ & 0.4798 & $22.52 * * *$ & $93.00^{* * *}$ & 0.6426 & $204^{* * *}$ & $112^{* * *}$ & $53.00^{* * *}$ & $56.22^{* * *}$ \\
\hline$R U I \leftarrow N Y E$ & -0.0146 & $-54.54^{* * *}$ & 2.20 & $-73.50^{* * *}$ & $48.33^{* * *}$ & $-0.0186^{* * *}$ & $121^{* * *}$ & 0.4665 & $83.76^{* * *}$ & $70.19^{* * *}$ & $4.56^{* *}$ & $136 * * *$ & $97,24^{* * *}$ & $42.69 * * *$ & $49.61^{* * *}$ \\
\hline$R U I \rightarrow X A X$ & $-0.1059^{* * *}$ & $-3.16^{* * *}$ & $1.43^{* *}$ & $-6.01 * * *$ & $4.03^{* * *}$ & $-5.87 \mathrm{e}-4$ & $57.52 * * *$ & 0.2945 & $2.37^{*}$ & $49.40^{* * *}$ & 0.0315 & $60.81^{* * *}$ & 53.06 *** & $16.38^{* * *}$ & $27.65^{* * *}$ \\
\hline$R U I \leftarrow X A X$ & 0.0087 & $-11.20^{* * *}$ & 1.90 & $-16.02^{* * *}$ & $7.70^{* * *}$ & -0.0011 & $50.83^{* * *}$ & 0.2694 & $15.75^{* * *}$ & $11.14^{* * *}$ & 0.0575 & $70.29^{* * *}$ & $35.77^{* * *}$ & $20.27^{* * *}$ & $19.28^{* * *}$ \\
\hline$R U T \rightarrow N Y E$ & -0.0215 & $-9.44^{* * *}$ & -0.3653 & $-12.74^{* * *}$ & $9.88^{* * *}$ & -0.0088 & $263^{* * *}$ & 0.6559 & 0.5197 & 0.0817 & $22.43^{* * *}$ & $274^{* * *}$ & $234^{* * *}$ & $96.51^{* * *}$ & $119^{* * *}$ \\
\hline$R U T \leftarrow N Y E$ & -0.0048 & $-54.53^{* * *}$ & 4.09 & $-78.57^{* * *}$ & $57.35^{* * *}$ & -0.0093 & $271^{* * *}$ & 0.6631 & $3.28 * * *$ & $6.57^{* * *}$ & $9.38^{* * *}$ & $211^{* * *}$ & $229^{* * *}$ & $62.86^{* * *}$ & $116^{* * *}$ \\
\hline$R U T \rightarrow X A X$ & -0.0355 & $-6.63^{* * *}$ & -0.4132 & $-9.74^{* * *}$ & $6.48^{* * *}$ & -0.0030 & $93.99 * * *$ & 0.4054 & 0.1730 & 0.8601 & $4.27^{* *}$ & $66.74^{* * *}$ & $83.70^{* * *}$ & $25.25^{* * *}$ & $43.79^{* * *}$ \\
\hline$R U T \leftarrow X A X$ & 0.0179 & $-10.27^{* * *}$ & 0.9899 & $-20.18^{* * *}$ & $11.67^{* * *}$ & $-4.33 \mathrm{e}-4$ & $100^{* * *}$ & 0.4205 & $3.3110^{* *}$ & $1.28 \mathrm{e}-4$ & 0.0496 & $60.15^{* * *}$ & $97,13^{* * *}$ & $17.70^{* * *}$ & $51.02^{* * *}$ \\
\hline$R U A \rightarrow N Y E$ & 0.0049 & $-7.63^{* * *}$ & -0.2735 & $-10.78^{* * *}$ & $9.74^{* * *}$ & -0.0020 & $604^{* * *}$ & 0.8142 & 0.1227 & $6.57^{* *}$ & $68.09^{* * *}$ & $562^{* * *}$ & $602^{* * *}$ & $198^{* * *}$ & $302^{* * *}$ \\
\hline$R U A \leftarrow N Y E$ & 0.0091 & $-68.80^{* * *}$ & -2.42 & $-92.57^{* * *}$ & $81,28^{* * *}$ & -0.0019 & $620^{* * *}$ & 0.8182 & 0.2792 & $9.43^{* * *}$ & $65.42 * * *$ & $534^{* * *}$ & $587^{* * *}$ & $184^{* * *}$ & $294^{* * *}$ \\
\hline$R U A \rightarrow X A X$ & -0.0174 & $-5.53^{* * *}$ & -0.3766 & $-8.07^{* * *}$ & $5.70^{* * *}$ & $-2.46 \mathrm{e}-4$ & $125^{* * *}$ & 0.4765 & 0.4934 & $8.84^{* * *}$ & $7.15^{* * *}$ & $87.88^{* * *}$ & $116^{* * *}$ & $33.52^{* * *}$ & $59.92^{* * *}$ \\
\hline$R U A \leftarrow X A X$ & 0.0208 & $-13.59^{* * *}$ & 1.12 & $-20.01^{* * *}$ & $13.89^{* * *}$ & $-5.39 \mathrm{e}-4$ & $110^{* * *}$ & 0.4441 & 1.16 & 0.1001 & $3.18^{*}$ & $114^{* * *}$ & $97.01 * * *$ & $35.31^{* * *}$ & $49.10^{* * *}$ \\
\hline
\end{tabular}

Notes. Table 2D reports the asymmetric response of Index 1 to Index 2 news with the use of an error correction model (ECM) among US stock indices from different groups. The present table concerns the post-crisis sub-sample.

$E C=\operatorname{Index}_{1}-a_{0}-a_{1} \cdot$ Index $_{2}$

$\Delta E C=a_{0}+\beta_{1} \cdot \Delta E R+\beta_{2} \cdot \Delta s^{-}+\beta_{3} \cdot \Delta s^{+}+\beta_{4} \cdot \Delta s^{s}+\beta_{5} \cdot \Delta s^{l}+\beta_{6} \cdot E C+\nu$

Regarding notation look at subsection 3.1. $*$, ** and *** indicate Newey-West statistical significance at a $10 \%, 5 \%$ and $1 \%$ significance level. 
Table 3A. Breitung's non-linear cointegration (Full sample and Lehman crisis sub-sample)

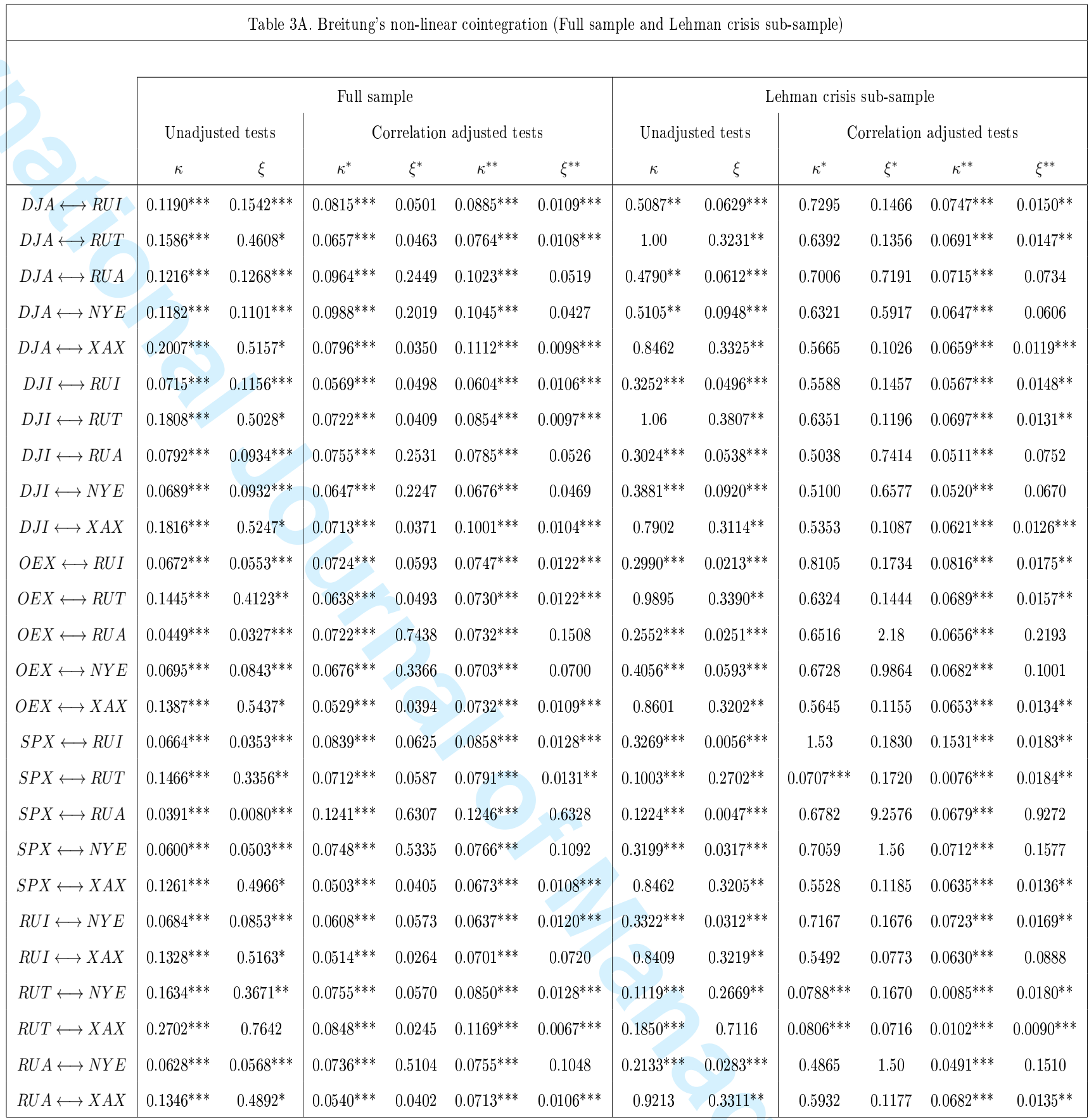

Notes. Table 3A concerns the Breitung's non-linear bivariate cointegration relationships between the US stock indices from a different publishing group. The present table provides results for the full sample and the Lehman crisis sub-sample.

\section{$10 \%: \quad 0.6442 \quad 0.0573 \quad 0.3940 \quad 0.0232 \quad 0.3940 \quad 0.0232$}

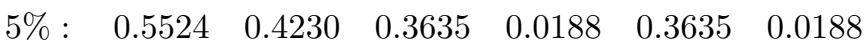

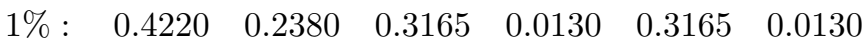

$\kappa^{*}$ and $\xi^{*}$ have the same critical values as $\kappa^{* *}$ and $\xi^{* *}$, respectively. Regarding notation look at subsection 2.1. * ** and $* * *$ indicate Newey-West statistical significance at a $10 \%, 5 \%$ and $1 \%$ significance level. 


\section{Table 3B. Breitung's non-linear cointegration (EU crisis sub-sample and post-crisis sub-sample)}

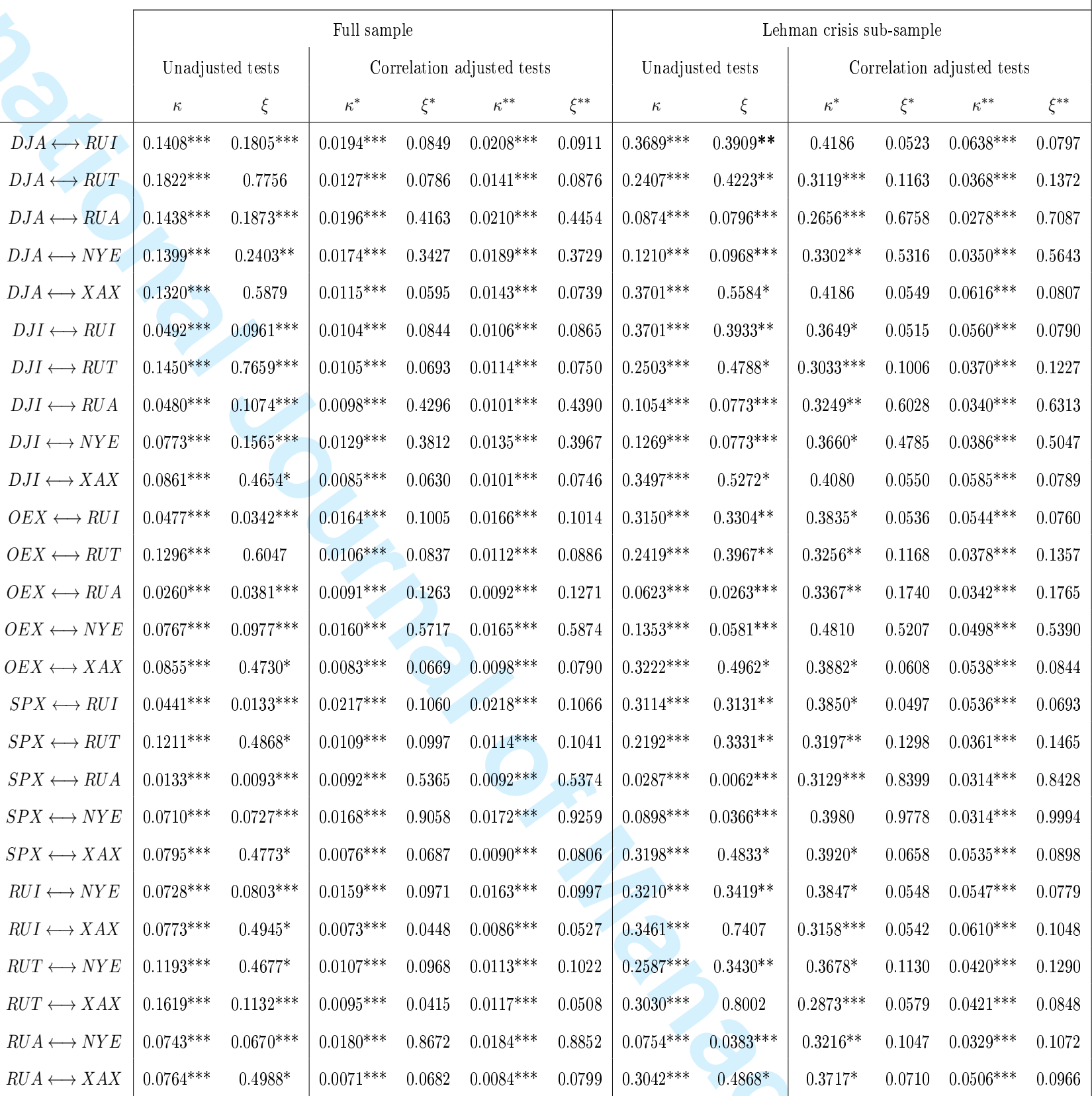

Notes. Table 3B concerns the Breitung's non-linear bivariate cointegration relationships between the US stock indices from a different publishing group. The present table provides results for the EU crisis subsample and the post-crisis sub-sample.

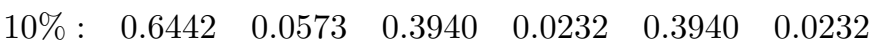

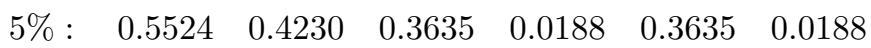

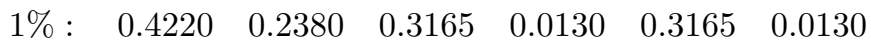

$\xi^{* *}$, respectively. Regarding notation look at subsection $2.1 .^{*}, * *$ and $* * *$ indicate Newey-West statistical significance at a $10 \%, 5 \%$ and $1 \%$ significance level. 
Table 4. Symmetric non-linear relationships from a M-G model

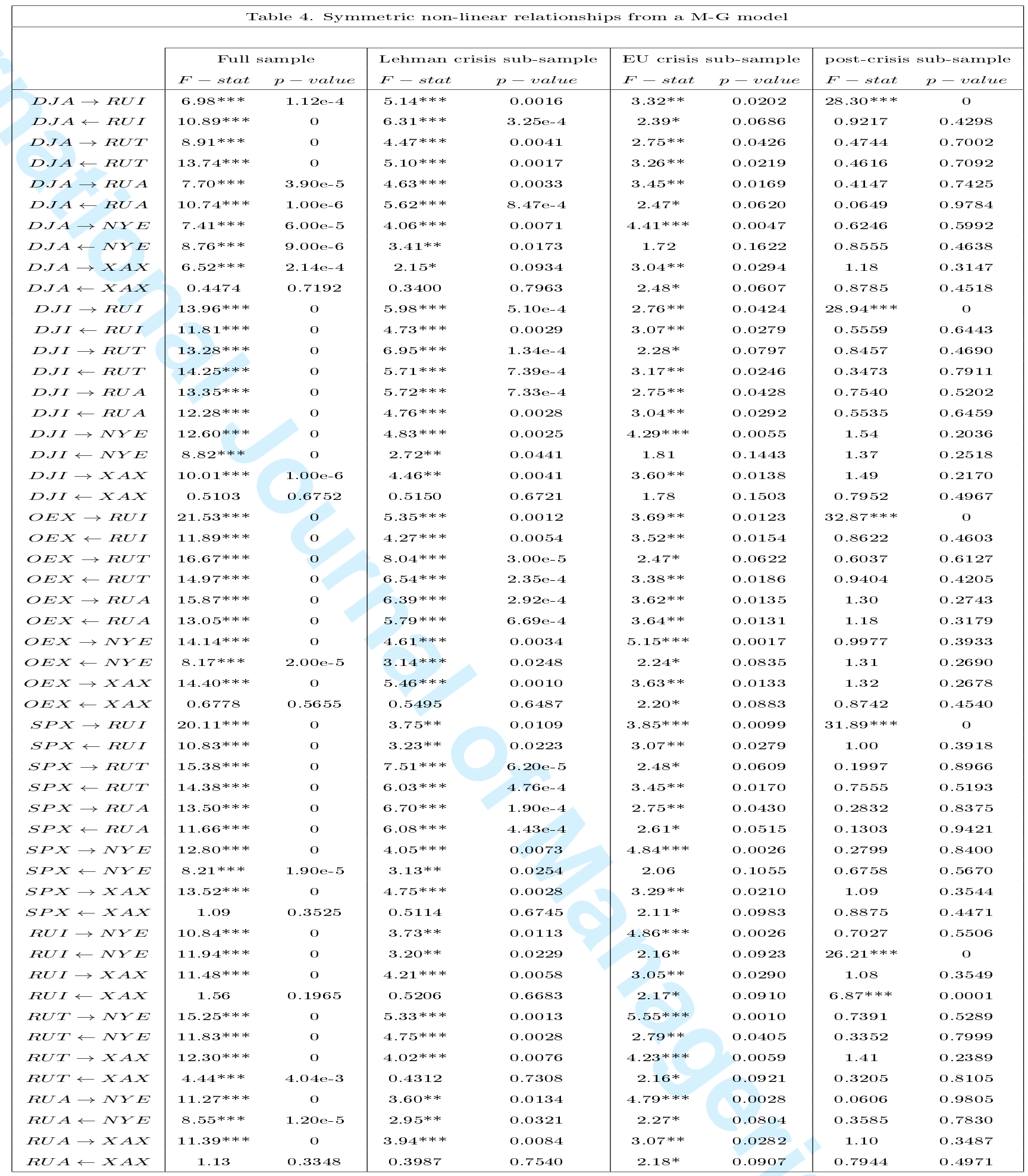

Notes. Table 4 concerns the symmetric non-linear relationships from a M-G model, between the US stock indices from a different publishing group. Input parameters for all tests have been selected on the basis of Akaike information criterion (AIC). The arrow indicates the direction of non-linear causality relationship between US stock indices from a different publisher. Regarding notation, look at subsection 2.1. *, ** and *** indicate Newey-West statistical significance at a $10 \%, 5 \%$ and $1 \%$ significance level. 
Table 5. US stock indices and total forecast error variance (TFEV)

\begin{tabular}{|c|c|c|c|c|c|c|c|c|}
\hline & \multicolumn{4}{|c|}{ Return } & \multicolumn{4}{|c|}{ Volatility } \\
\hline & Full sample & Lehman crisis & EU crisis & post-crisis & Full sample & Lehman crisis & EU crisis & post-crisis \\
\hline$D J A \rightarrow R U I$ & 0.2034 & 1.18 & 1.38 & 0.7648 & 0.8555 & 1.12 & 0.3262 & 0.3944 \\
\hline$D J A \leftarrow R U I$ & 0.2079 & 1.44 & 0.9607 & 0.8273 & 0.6515 & 0.4988 & 0.6246 & 0.7807 \\
\hline$D J A \rightarrow R U T$ & 0.2506 & 0.8324 & 0.9801 & 0.2385 & 0.8590 & 0.8722 & 0.5441 & 0.5588 \\
\hline$D J A \leftarrow R U T$ & 0.0337 & 0.3377 & 0.3354 & 0.0969 & 0.5592 & 0.7088 & 0.3382 & 0.4225 \\
\hline$D J A \rightarrow R U A$ & 0.0587 & 0.8102 & 1.51 & 0.1748 & 0.8864 & 1.12 & 0.3839 & 0.4646 \\
\hline$D J A \leftarrow R U A$ & 0.2652 & 1.08 & 1.04 & 0.0984 & 0.6144 & 0.4977 & 0.4966 & 0.6424 \\
\hline$D \cdot J A \rightarrow N Y E$ & 0.1271 & 0.4711 & 1.14 & 0.2394 & 0.8232 & 1.21 & 0.8343 & 0.6545 \\
\hline$D J A \leftarrow N Y E$ & 0.3099 & 0.7188 & 0.7569 & 0.1533 & 0.7629 & 0.4806 & 0.6337 & 0.8143 \\
\hline$D J A \rightarrow X A X$ & 0.1098 & 0.3927 & 0.2280 & 0.2167 & 0.8384 & 1.01 & 0.5065 & 0.6104 \\
\hline$D J A \leftarrow X A X$ & 0.0655 & 0.1966 & 0.0093 & 0.1925 & 0.7943 & 1.05 & 0.4356 & 0.5716 \\
\hline$D J I \rightarrow R U I$ & 0.2198 & 0.3868 & 0.5578 & 0.7770 & 0.7236 & 1.09 & 0.7810 & 0.3151 \\
\hline$D J I \leftarrow R U I$ & 0.1860 & 0.1041 & 0.2127 & 0.8229 & 0.7391 & 0.4629 & 0.4539 & 0.9704 \\
\hline$D J I \rightarrow R U T$ & 0.2924 & 1.14 & 0.4062 & 0.2412 & 0.8457 & 0.9001 & 0.7357 & 0.4232 \\
\hline$D J I \leftarrow R U T$ & 0.0195 & 0.4964 & 0.1008 & 0.0938 & 0.6036 & 0.7121 & 0.4164 & 0.4967 \\
\hline$D J I \rightarrow R U A$ & 0.0755 & 1.00 & 0.5967 & 0.2902 & 0.8057 & 1.14 & 0.9370 & 0.3579 \\
\hline$D J I \leftarrow R U A$ & 0.1665 & 0.4980 & 0.2296 & 0.2005 & 0.6517 & 0.4131 & 0.4858 & 0.6979 \\
\hline$D J I \rightarrow N Y E$ & 0.0252 & 0.7000 & 0.7798 & 0.3715 & 0.6719 & 0.9415 & 0.8937 & 0.5556 \\
\hline$D J I \leftarrow N Y E$ & 0.2406 & 0.2328 & 0.4303 & 0.2697 & 0.8858 & 0.6341 & 0.7439 & 0.8686 \\
\hline$D J I \rightarrow X A X$ & 0.1392 & 0.6204 & 0.1286 & 0.2267 & 0.8375 & 1.25 & 0.7000 & 0.4371 \\
\hline$D J I \leftarrow X A X$ & 0.0719 & 0.3635 & 0.0861 & 0.1909 & 0.8190 & 1.09 & 0.5079 & 0.7202 \\
\hline$O E X \rightarrow R U I$ & 0.7435 & 2.05 & 2.32 & 0.9770 & 0.4177 & 0.9865 & 0.7468 & 0.4025 \\
\hline$O E X \leftarrow R U I$ & 0.4848 & 1.53 & 1.84 & 1.00 & 0.9445 & 0.4472 & 0.5618 & 1.09 \\
\hline$O E X \rightarrow R U T$ & 0.3945 & 1.33 & 0.7119 & 0.3104 & 0.7518 & 0.8013 & 0.7438 & 0.5048 \\
\hline$O E X \leftarrow R U T$ & 0.0863 & 0.6686 & 0.1621 & 0.1566 & 0.6011 & 0.6690 & 0.3814 & 0.4545 \\
\hline$O E X \rightarrow R U A$ & 0.5764 & 2.91 & 2.36 & 0.9115 & 0.6131 & 1.08 & 0.9703 & 0.4830 \\
\hline$O E X \leftarrow R U A$ & 0.3079 & 2.31 & 1.82 & 0.8216 & 0.7471 & 0.3618 & 0.5079 & 0.6950 \\
\hline$O E X \rightarrow N Y E$ & 0.1494 & 1.51 & 1.40 & 0.6214 & 0.6316 & 0.9377 & 0.9062 & 0.6792 \\
\hline$O E X \leftarrow N Y E$ & 0.0907 & 0.9667 & 1.00 & 0.5321 & 0.8622 & 0.5476 & 0.6805 & 0.8734 \\
\hline$O E X \rightarrow X A X$ & 0.1551 & 0.6585 & 0.1382 & 0.2340 & 0.7509 & 0.9447 & 0.6749 & 0.5465 \\
\hline$O E X \leftarrow X A X$ & 0.0646 & 0.4209 & 0.0959 & 0.2176 & 0.8165 & 1.07 & 0.5302 & 0.7034 \\
\hline$S P X \rightarrow R U I$ & 0.9727 & 1.62 & 1.87 & 1.01 & 0.3257 & 0.4025 & 0.8933 & 0.3664 \\
\hline$S P X \leftarrow R U I$ & 0.8867 & 1.21 & 1.53 & 1.09 & 1.29 & 0.9714 & 0.6017 & 1.15 \\
\hline$S P X \rightarrow R U T$ & 0.4258 & 1.38 & 0.5366 & 0.2685 & 0.7401 & 0.6193 & 0.8001 & 0.4962 \\
\hline$S P X \leftarrow R U T$ & 0.1264 & 0.7712 & 0.1515 & 0.1399 & 0.6037 & 0.8012 & 0.3811 & 0.4401 \\
\hline$S P X \rightarrow R U A$ & 1.28 & 7.65 & 3.04 & 1.02 & 0.4304 & 0.4622 & 1.25 & 0.5690 \\
\hline$S P X \leftarrow R U A$ & 1.01 & 7.09 & 2.59 & 0.9521 & 1.03 & 0.9136 & 0.5592 & 0.7792 \\
\hline$S P X \rightarrow N Y E$ & 0.0856 & 1.39 & 0.8716 & 0.5694 & 0.5854 & 0.6755 & 0.8885 & 0.7210 \\
\hline$S P X \leftarrow N Y E$ & 0.1516 & 0.9393 & 0.5782 & 0.5026 & 0.9030 & 0.7590 & 0.6928 & 0.8895 \\
\hline$S P X \rightarrow X A X$ & 0.1386 & 0.5772 & 0.0873 & 0.2109 & 0.7667 & 0.9864 & 0.6342 & 0.5205 \\
\hline$S P X \leftarrow X A X$ & 0.0579 & 0.3788 & 0.1722 & 0.2058 & 0.8212 & 1.08 & 0.4811 & 0.6980 \\
\hline$R U I \rightarrow N Y E$ & 0.3594 & 1.07 & 0.6206 & 0.9627 & 0.6663 & 0.7267 & 0.7870 & 0.5804 \\
\hline$R U I \leftarrow N Y E$ & 0.4003 & 0.6583 & 0.3657 & 0.8604 & 0.8523 & 0.7241 & 0.7137 & 0.7706 \\
\hline$R U I \rightarrow X A X$ & 0.1387 & 0.5421 & 0.0897 & 0.3690 & 0.7840 & 1.04 & 0.5235 & 0.6950 \\
\hline$R U I \leftarrow X A X$ & 0.0211 & 0.3628 & 0.1517 & 0.3690 & 0.8245 & 1.09 & 0.4664 & 0.6064 \\
\hline$R U T \rightarrow N Y E$ & 0.1355 & 0.5319 & 0.2110 & 0.0489 & 0.6202 & 0.9326 & 0.3682 & 0.5438 \\
\hline$R U T \leftarrow N Y E$ & 0.4027 & 0.9656 & 0.1215 & 0.1330 & 0.8469 & 0.5903 & 0.7489 & 0.8509 \\
\hline$R U T \rightarrow X A X$ & 0.1302 & 0.2142 & 0.2005 & 0.0829 & 0.5891 & 0.7242 & 0.3639 & 0.4193 \\
\hline$R U T \leftarrow X A X$ & 0.0913 & 0.0840 & 0.2372 & 0.0960 & 0.8080 & 1.04 & 0.4706 & 0.7161 \\
\hline$R U A \rightarrow N Y E$ & 0.0964 & 0.1247 & 0.5104 & 0.4583 & 0.6237 & 0.7448 & 0.6984 & 0.8151 \\
\hline$R U A \leftarrow N Y E$ & 0.3111 & 0.2262 & 0.2694 & 0.4135 & 0.8780 & 0.7097 & 0.7256 & 0.8657 \\
\hline$R U A \rightarrow X A X$ & 0.1048 & 0.4800 & 0.0952 & 0.1928 & 0.7719 & 1.05 & 0.5025 & 0.5912 \\
\hline$R U A \leftarrow X A X$ & 0.0492 & 0.3062 & 0.2081 & 0.2015 & 0.8240 & 1.09 & 0.4539 & 0.6262 \\
\hline
\end{tabular}

Notes. Table 5 reports results on the importance of US stock index return (or volatility) shocks in explaining the forecast error variance of returns of any other US stock index belonging a different group (publisher) and importance of US stock return shocks in explaining the forecast error variance of US stock index return (volatility). A 30-day-ahead error in forecasting is computed. The arrow indicates the direction of nonlinear causality relationship between US stock indices from a different publisher. Regarding notation, look at subsection 2.1. * ** and *** indicate Newey-West statistical significance at a $10 \%, 5 \%$ and $1 \%$ significance level. 


\begin{tabular}{|c|c|c|c|c|c|c|c|c|}
\hline & \multirow[b]{2}{*}{ Full sample } & \multicolumn{2}{|c|}{ Return } & \multirow[b]{2}{*}{ post-crisis } & \multirow[b]{2}{*}{ Full sample } & \multicolumn{2}{|c|}{ Volatility } & \multirow[b]{2}{*}{ post-crisis } \\
\hline & & Lehman crisis & EU crisis & & & Lehman crisis & EU crisis & \\
\hline$D J A \longleftrightarrow R U I$ & 5.80 & 5.90 & 3.55 & 5.37 & 4.26 & 2.11 & 7.19 & 7.42 \\
\hline$D J A \longleftrightarrow R U T$ & 0.1775 & 1.89 & 1.58 & 1.40 & 3.61 & 4.29 & 2.60 & 3.81 \\
\hline$D J A \longleftrightarrow R U A$ & 9.45 & 6.27 & 3.44 & 2.62 & 3.95 & 2.14 & 5.77 & 6.16 \\
\hline$D J A \longleftrightarrow N Y E$ & 7.87 & 6.92 & 3.26 & 2.92 & 5.20 & 1.95 & 3.77 & 6.99 \\
\hline$D J A \longleftrightarrow X A X$ & 2.40 & 1.86 & 0.0219 & 4.36 & 5.61 & 6.28 & 5.01 & 5.30 \\
\hline$D J I \longleftrightarrow R U I$ & 2.89 & 0.7377 & 1.36 & 5.26 & 5.05 & 1.80 & 2.43 & 9.03 \\
\hline$D J I \longleftrightarrow R U T$ & 0.0509 & 1.71 & 0.6427 & 1.36 & 3.57 & 4.00 & 1.82 & 5.40 \\
\hline$D J I \longleftrightarrow R U A$ & 7.60 & 1.99 & 1.37 & 3.28 & 4.12 & 1.51 & 1.63 & 7.49 \\
\hline$D J I \longleftrightarrow N Y E$ & 9.81 & 1.02 & 2.38 & 3.46 & 5.92 & 3.39 & 3.75 & 7.82 \\
\hline$D J I \longleftrightarrow X A X$ & 1.96 & 2.40 & 3.08 & 4.14 & 5.57 & 5.80 & 2.94 & 6.94 \\
\hline$O E X \longleftrightarrow R U I$ & 3.64 & 3.57 & 3.87 & 5.25 & 7.72 & 1.99 & 2.89 & 8.85 \\
\hline$O E X \longleftrightarrow R U T$ & 0.4728 & 2.08 & 0.6671 & 1.94 & 4.11 & 4.45 & 1.73 & 4.12 \\
\hline$O E X \longleftrightarrow R U A$ & 2.25 & 3.87 & 3.73 & 4.49 & 5.77 & 1.44 & 1.65 & 6.47 \\
\hline$O E X \longleftrightarrow N Y E$ & 2.48 & 2.93 & 3.39 & 4.23 & 6.17 & 3.00 & 3.28 & 7.08 \\
\hline$O E X \longleftrightarrow X A X$ & 1.37 & 2.74 & 2.63 & 4.64 & 5.97 & 6.77 & 3.44 & 5.86 \\
\hline$S P X \longleftrightarrow R U I$ & 4.28 & 3.69 & 4.16 & 5.33 & 9.42 & 8.41 & 2.31 & 9.10 \\
\hline$S P X \longleftrightarrow R U T$ & 0.8678 & 2.48 & 0.8742 & 2.05 & 4.15 & 6.12 & 1.50 & 4.26 \\
\hline$S P X \longleftrightarrow R U A$ & 3.85 & 4.62 & 4.20 & 4.67 & 8.18 & 7.82 & 1.69 & 7.08 \\
\hline$S P X \longleftrightarrow N Y E$ & 6.61 & 3.12 & 3.14 & 4.38 & 6.48 & 5.66 & 3.47 & 7.16 \\
\hline$S P X \longleftrightarrow X A X$ & 1.32 & 2.84 & 7.43 & 4.91 & 5.98 & 6.77 & 3.49 & 6.12 \\
\hline$R U I \longleftrightarrow N Y E$ & 6.16 & 2.79 & 3.11 & 4.38 & 5.95 & 5.03 & 4.11 & 6.45 \\
\hline$R U I \longleftrightarrow X A X$ & 0.1773 & 2.93 & 6.46 & 1.62 & 5.84 & 6.58 & 4.28 & 4.68 \\
\hline$R U T \longleftrightarrow N Y E$ & 8.89 & 7.41 & 2.60 & 8.19 & 6.42 & 3.41 & 8.16 & 7.83 \\
\hline$R U T \longleftrightarrow X A X$ & 3.55 & 0.9014 & 5.62 & 6.17 & 6.45 & 6.92 & 6.49 & 7.04 \\
\hline$R U A \longleftrightarrow N Y E$ & 8.68 & 6.71 & 2.68 & 4.51 & 6.19 & 4.81 & 4.87 & 6.46 \\
\hline$R U A \longleftrightarrow X A X$ & 1.15 & 2.72 & 8.24 & 5.26 & 5.88 & 6.54 & 5.11 & 5.08 \\
\hline
\end{tabular}

Notes. Table 6 reports total shock spillover index (\%) from the US stock index returns to other US stock index return; also, results based on the US stock index return volatility to US stock index returns, where $\mathrm{h}$ $=30$. The arrow indicates the direction of non-linear causality relationship between US stock indices from a different publisher. Regarding notation, look at subsection 2.1. ${ }^{*}, * *$ and ${ }^{* * *}$ indicate Newey-West statistical significance at a $10 \%, 5 \%$ and $1 \%$ significance level. 
Table 7A. VAR(1)-ABEKK(1,1,1) model estimates (Full sample, and Lehman crisis sub-sample)

\begin{tabular}{|c|c|c|c|c|c|c|c|c|c|c|c|c|c|c|c|c|c|c|}
\hline & \multicolumn{2}{|c|}{ Mean Equation } & \multicolumn{7}{|c|}{ Varianoe Equation } & \multicolumn{2}{|c|}{ Mean Equation } & \multicolumn{7}{|c|}{ Varianoe Equation } \\
\hline & $\Phi_{11} / \Phi_{21}$ & $\Phi_{12} / \Phi_{22}$ & $1 / C_{22}$ & $A_{11} / A_{22}$ & $A_{12} / A_{21}$ & $B_{11} / B_{22}$ & $B_{12} / B_{21}$ & $G_{11} / G_{22}$ & $G_{12} / G_{21}$ & $\Phi_{11} / \Phi_{21}$ & $\Phi_{12} / \Phi_{2}$ & $C_{11} / C_{22}$ & $A_{11} / A_{22}$ & $A_{12} / A_{21}$ & $B_{11} / B_{22}$ & $B_{12} / B_{21}$ & $G_{11} / G_{22}$ & $G_{12} / G_{21}$ \\
\hline$D J A \leftrightarrow R U I$ & 0.0203 & $-0.0660^{*}$ & $0.0012^{* * *}$ & $-0.2508 * * *$ & $0.2782^{* * *}$ & -0.1588 & $1.0265^{* * *}$ & -0.0265 & -0.4366 & 0.2242 & $-0.3126^{*}$ & -0.0090 & -0.4309 & $0.7370^{* *}$ & -0.2262 & 0.8992 & -0.7777 & $1.0134^{* * *}$ \\
\hline$R U I \leftrightarrow D J A$ & $0.0558 *$ & $-0.1059^{* * *}$ & 0.0014 & $-0.1499 * * *$ & $0.1286^{* * *}$ & 0.2701 & $0.6999^{* * *}$ & $-0.2700^{* * *}$ & $0.1286^{* * *}$ & $0.3485^{* *}$ & $-0.4328^{* * *}$ & $9.06 \mathrm{E}-05$ & 0.7291 & -0.3928 & 1.0626 & -0.2749 & $1.7993^{* * *}$ & -0.3928 \\
\hline$D J A \leftrightarrow R U T$ & $-0.0465^{*}$ & -0.0151 & -0.0019 & $0.3090^{* * *}$ & $-0.0907^{* * *}$ & $-0.9191^{* * *}$ & $0.0091^{* * *}$ & $0.2143^{* * *}$ & $0.1871^{* * *}$ & -0.0485 & 0.0113 & -0.0006 & $0.7699^{* * *}$ & $-0.7351^{* * *}$ & $-2.2390^{* * *}$ & $1.4265^{* * *}$ & 0.3851 & 0.1424 \\
\hline$R U T \leftrightarrow D J A$ & -0.0128 & -0.0358 & $-6.81 \mathrm{E}-06$ & $0.1760^{* * * *}$ & $0.0881^{* *}$ & $-0.9250^{* * *}$ & -0.0039 & $0.4459^{* * *}$ & $0.0881^{* *}$ & 0.0237 & -0.1067 & $0.0037^{* * *}$ & $-0.9137^{* * *}$ & $0.7195^{* * *}$ & $1.5332 * * *$ & $-2.8186^{* * *}$ & 0.1066 & $0.7195^{* * *}$ \\
\hline$D J A \leftrightarrow R U A$ & 0.0300 & $-0.0842^{* *}$ & 0.0051 & $0.4398^{* * *}$ & $-0.5181^{* * *}$ & $-0.2287^{* * *}$ & $-0.4619^{* * *}$ & $0.4693^{* * *}$ & $0.2375 * *$ & 0.2151 & $-0.2852^{*}$ & $0.0012^{* * *}$ & 0.7937 & -0.6840 & 1.5336 & -0.6195 & $\mathrm{NA}$ & $\mathrm{NA}$ \\
\hline$R U A \leftrightarrow D J A$ & 0.0429 & $-0.0935^{* *}$ & 1.64E-05 & $-0.1622^{* *}$ & $0.1439^{*}$ & $-1.3564^{* * *}$ & $0.6783^{* * *}$ & $0.3705^{* * *}$ & $0.1439^{*}$ & $0.3244^{*}$ & $-0.3905^{* *}$ & -0.0021 & $\mathrm{NA}$ & $\mathrm{NA}$ & $\mathrm{NA}$ & $\mathrm{NA}$ & $\mathrm{NA}$ & $\mathrm{NA}$ \\
\hline$D J A \leftrightarrow N Y E$ & -0.0082 & -0.0525 & -0.0050 & $-0.7516^{* * *}$ & $0.7336^{* * *}$ & 0.0776 & 0.6485 & $-0.3262^{* * *}$ & $0.8973^{* * *}$ & 0.0791 & -0.1438 & 0.0012 & -0.1213 & 0.1009 & 0.2588 & 0.5681 & $0.9700^{* * *}$ & $-0.4071^{* *}$ \\
\hline$N Y E \leftrightarrow D J A$ & 0.0106 & $-0.0659^{*}$ & $3.67 \mathrm{E}-05$ & $0.4646^{* * *}$ & $-0.4097 * * *$ & 0.8121 & 0.0886 & $0.6549^{* * *}$ & $-0.4097 * * *$ & 0.0979 & -0.1685 & $0.0039^{* * *}$ & 0.4066 & -0.3369 & $0.5894^{* * *}$ & $0.3569^{* * * *}$ & $-0.8933 * * *$ & -0.3369 \\
\hline$D J A \leftrightarrow X A X$ & $0.0408^{* *}$ & 0.0024 & $-4.64 \mathrm{E}-08$ & $0.1970^{* * *}$ & $-0.1938^{* * *}$ & $0.8702^{* * *}$ & $0.0998^{* * *}$ & $-0.5410^{* * *}$ & $0.1624^{* * *}$ & $-0.1151^{*}$ & -0.0395 & 0.0012 & $0.4075^{* * *}$ & $-0.3532^{* * *}$ & $-0.8187^{* * *}$ & $-0.1268^{* * *}$ & $-0.4976 * *$ & 0.1405 \\
\hline$X A X \leftrightarrow D J A$ & 0.0261 & $-0.0545 * * *$ & $-0.0036^{* * *}$ & $-0.2093^{* * *}$ & -0.0433 & $0.8270^{* * *}$ & $0.0402^{* * *}$ & $-0.2937^{* * *}$ & -0.0433 & -0.0733 & 0.0174 & 3.43E-07 & $-0.5319^{* * *}$ & $0.3414^{* *}$ & $-0.8387^{* * *}$ & 0.0286 & $0.3055^{*}$ & $0.3414^{* *}$ \\
\hline$D J I \leftrightarrow R U I$ & $-0.1559^{* * *}$ & $0.1015^{* *}$ & 0.0068 & $1.3376^{* * *}$ & -1.0853 & $-0.6176^{* * *}$ & 0.0734 & $-1.3313^{* * *}$ & $1.6766^{* * *}$ & 0.0118 & -0.0083 & $0.0014^{*}$ & -0.2623 & 0.1160 & 0.1122 & $0.6919^{* * *}$ & 0.4371 & $-0.9250^{* *}$ \\
\hline$R U I \leftrightarrow D J J I$ & $-0.1779^{* * *}$ & $0.1295^{* * *}$ & $6.21 \mathrm{E}-05$ & $-1.5379^{* * *}$ & $1.7713^{* * *}$ & -0.4081 & 0.0847 & $1.2754^{* * *}$ & $1.7713^{* * *}$ & 0.0644 & -0.1235 & $0.0022^{* * *}$ & 0.4675 & $-0.7445^{*}$ & $0.7746^{* * *}$ & 0.1276 & $-1.0288^{* *}$ & $-0.7445^{*}$ \\
\hline$D J I \leftrightarrow R U T$ & $-0.0417^{*}$ & -0.0160 & $-0.0006^{* * *}$ & $-0.4343^{* * *}$ & $0.3060^{* * *}$ & $0.8915^{* * *}$ & $0.0335^{*}$ & $-0.3422^{* * *}$ & -0.0303 & -0.1441 & 0.0350 & $-0.0111^{* * *}$ & $1.4681^{* * *}$ & $-0.8597^{* * *}$ & -0.1089 & $-0.0982^{* *}$ & -0.2275 & $-0.4480^{* *}$ \\
\hline$R U T \leftrightarrow D J I$ & -0.0357 & -0.0357 & $0.0018^{* * *}$ & $0.4094^{* * *}$ & $-0.3113^{* * *}$ & $0.8813^{* * *}$ & 0.0180 & 0.2921 & $-0.3113^{* * *}$ & 0.1201 & 0.0221 & 0.0024 & $-1.1356^{* * *}$ & $1.7387^{* * *}$ & -0.3190 & 0.4844 & -0.1184 & $1.7387^{* * *}$ \\
\hline$D J I \leftrightarrow R U A$ & 0.0084 & -0.0650 & 0.0054 & $0.4875^{* * *}$ & 0.0204 & -1.2498 & 0.6954 & $1.6614^{* * *}$ & $-1.9572^{* * *}$ & -0.1873 & 0.0975 & $0.0127^{* * *}$ & $2.1647^{* * *}$ & $-2.1217^{* * *}$ & 0.1274 & $-0.1913^{* * *}$ & $-2.6084^{* * *}$ & $1.5405^{* * *}$ \\
\hline$R U A \leftrightarrow D J I$ & -0.0273 & -0.0322 & -0.0014 & 0.4887 & 0.0243 & 0.0737 & -0.6635 & $-2.1371^{* * *}$ & 0.0243 & -0.1743 & 0.0903 & $1.21 \mathrm{E}-0.5$ & $-2.6649^{* * *}$ & $2.8021^{* * *}$ & $-0.4884^{* * *}$ & 0.2926 & $1.6935^{* * *}$ & $2.8021^{* * *}$ \\
\hline$D J I \leftrightarrow N Y E$ & -0.0182 & -0.0189 & 0.0059 & $0.4818^{* * *}$ & -0.1465 & 0.0999 & $0.5737^{* * *}$ & $-08252^{* * *}$ & $1.1318^{* * *}$ & -0.1511 & 0.0702 & 0.0034 & $1.1316^{* * *}$ & $-0.7132^{* * *}$ & $-0.9463^{* * *}$ & $0.1013^{*}$ & 0.1133 & $0.4061^{*}$ \\
\hline$N Y E \leftrightarrow D J I$ & -0.0294 & 0.0073 & $-7.24 \mathrm{E}-05$ & 0.1871 & 0.1110 & $0.6894^{* * *}$ & 0.1451 & $1.4351^{* * *}$ & 0.1110 & -0.1966 & 0.1047 & $-0.0008^{* * *}$ & $-1.1317^{* * *}$ & $1.5387^{* * *}$ & $0.5865^{* * *}$ & $-1.5945^{* * *}$ & 0.2038 & $1.5387^{* * *}$ \\
\hline$D J I \leftrightarrow X A X$ & $-0.0584^{* *}$ & 0.0168 & $0.0012^{* * *}$ & 0.0879 & 0.1114 & $0.9160^{* * *}$ & 0.0117 & $0.5438^{* * *}$ & -0.1573 & $-0.1792^{* *}$ & 0.0873 & 0.0012 & $-0.3482^{* * *}$ & $0.4583^{* * *}$ & $-1.2646^{* * *}$ & 0.4807 & $-0.4579^{* * *}$ & -0.0464 \\
\hline$X A X \leftrightarrow D J I$ & -0.0083 & $0.0508^{*}$ & $0.0022^{* * *}$ & 0.3340 & 0.0190 & $0.8566^{* * *}$ & 0.0062 & 0.1347 & 0.0190 & -0.1106 & 0.0522 & $9.57 \mathrm{E}-06$ & $0.4831^{* * *}$ & $-0.6832^{* * *}$ & $-0.2070^{* * *}$ & $-0.6554^{* * *}$ & $-0.4493^{* *}$ & $-0.6832^{* * *}$ \\
\hline$O E X \leftrightarrow R U I$ & $-0.2700^{* * *}$ & $0.2277^{* * *}$ & $0.0009^{* * *}$ & $-0.2955^{* * *}$ & $0.6219^{* * *}$ & $1.1650^{* * *}$ & $0.9541^{1 * *}$ & $1.142^{* * *}$ & $1.7799^{* * *}$ & 0.2226 & -0.3006 & $-0.0050^{* * *}$ & $-0.4967^{*}$ & $0.7583^{* * *}$ & -0.7955 & -0.0299 & 0.6802 & -0.0896 \\
\hline$R U I \leftrightarrow O E X$ & -0.2866 *** & $0.2609^{* * *}$ & $-0.0012^{* * *}$ & $-0.4525 * * *$ & $0.3943^{* * *}$ & -0.0103 & $-0.2487^{* * *}$ & $-0.4957^{* * *}$ & $-1.2772^{* * *}$ & 0.2301 & -0.3009 & $0.0019^{* * *}$ & $1.2242^{* * *}$ & $-1.0451^{* * *}$ & 0.0717 & -0.9424 & -0.2820 & $-1.0451^{* * *}$ \\
\hline$O E X \leftrightarrow R U T$ & $-0.0758^{* * *}$ & -0.0005 & $7.75 \mathrm{E}-05$ & $0.4684^{* * *}$ & -0.0823 & $0.7965^{* * *}$ & $-1.1008^{* * *}$ & $0.5226^{* * *}$ & $-0.4657^{* * *}$ & -0.1552 & 0.0544 & $0.0030^{* * *}$ & -0.1066 & 0.0935 & $-1.4273^{* * *}$ & $0.4449^{* * *}$ & $-0.5447^{* * *}$ & $0.7273^{* * *}$ \\
\hline$R U T \leftrightarrow O E X$ & $-0.0758^{* *}$ & -0.0124 & $-0.0027^{* * *}$ & $-0.3703^{* * *}$ & $0.8574^{* * *}$ & $-1.6804^{* * *}$ & $1.8794^{* * *}$ & $-0.5288^{* * *}$ & $0.8574^{* * *}$ & -0.1799 & 0.0242 & 4.25E- -05 & $0.5772^{* * *}$ & $-0.8200^{* *}$ & -0.1127 & $-1.0198^{* * *}$ & $1.0663^{* * *}$ & $-0.8200^{* *}$ \\
\hline$O E X \leftrightarrow R U A$ & -0.0894 & 0.0368 & $-0.0104^{* * *}$ & $2.2575^{* * *}$ & $-2.0935^{* * *}$ & -1.0519 & 1.1.1392 & $-1.5728^{* *}$ & $2.1358^{* * *}$ & -0.2842 & 0.1929 & $-0.0088^{* * *}$ & $3.4356^{* * *}$ & $-2.9369^{* * *}$ & $0.8261^{* *}$ & -0.3141 & $2.4809^{* *}$ & $-3.0167^{* * *}$ \\
\hline$R U A \leftrightarrow O E X$ & $-0.1310^{* *}$ & 0.0901 & $0.0001^{* *}$ & $-1.8930^{* * *}$ & $2.0940^{* * *}$ & 0.9712 & -0.7487 & $2.8819^{* * *}$ & $2.0940^{* * *}$ & -0.3241 & 0.2274 & $-6.33 \mathrm{E}-06$ & $-2.9266^{* * *}$ & $3.4400^{* * *}$ & 0.3528 & 0.2251 & $-3.4000^{* * *}$ & $3.4400^{* * *}$ \\
\hline$O E X \leftrightarrow N Y E$ & 0.0255 & -0.0336 & 0.0001 & $0.1926^{*}$ & $-0.5214^{* * *}$ & $1.7634^{* * *}$ & $-0.9623^{* * *}$ & $0.6182^{* * *}$ & -0.2253 & 0.0547 & -0.1248 & $-0.0017^{* * *}$ & 1.1258 & $-0.9090^{* * *}$ & $-0.6017^{* * *}$ & $-0.2682^{* *}$ & 0.6603 & -0.1720 \\
\hline$N Y E \leftrightarrow O E X$ & 0.0237 & -0.0551 & $0.0030^{* * *}$ & $-0.9310^{* * *}$ & $0.5860^{* * *}$ & $-0.9336^{* * *}$ & $1.6989^{* * *}$ & -0.0477 & $0.5860^{* * *}$ & 0.0491 & -0.1153 & $0.0029^{* * *}$ & $-1.3471^{* * *}$ & $1.7275^{* * *}$ & $-0.2926^{* *}$ & $-0.6573^{* * *}$ & 0.1112 & $1.7275^{* * *}$ \\
\hline$O E X \leftrightarrow X A X$ & $-0.0730^{* * *}$ & 0.0196 & $0.0005^{* * *}$ & $0.2706^{* * *}$ & $-0.2043^{* * *}$ & $0.8738^{* * *}$ & $0.0876^{* * *}$ & $0.5037^{* * *}$ & $-0.0778^{* *}$ & $-0.1701^{* *}$ & 0.0833 & -0.0005 & $0.3221^{* *}$ & -0.0290 & $-1.5997^{* * *}$ & $1.2514^{* * *}$ & $-0.5128^{* *}$ & $0.9333^{* * *}$ \\
\hline$X A X \leftrightarrow O E X$ & -0.0102 & $0.0534^{* *}$ & $0.0034^{* * *}$ & $-0.0920 * * *$ & $-0.0524^{* *}$ & $0.826 g^{* * *}$ & $0.0486^{* * *}$ & $0.3957^{* * *}$ & $-0.0520^{* *}$ & -0.0848 & 0.0356 & $-7.85 \mathrm{E}-05$ & $0.4542^{* * *}$ & -0.1674 & $0.6845^{* * *}$ & $-1.3662^{* * *}$ & $0.8622^{* * *}$ & -0.1674 \\
\hline$S P X \leftrightarrow R U I$ & $0.3214^{* * *}$ & $-0.3275^{* * *}$ & $-0.0061^{1 * *}$ & $1.1409^{* * *}$ & $-1.6368^{* * *}$ & -0.0464 & $-0.6473^{* * *}$ & $-1.3567^{* * *}$ & $1.8945^{* * *}$ & -0.0743 & -0.0389 & $0.0054^{* * *}$ & 2.7897 & -2.3180 & 0.7006 & -1.5059 & 0.9280 & -1.0233 \\
\hline$R U I \leftrightarrow S P X$ & $0.2798^{* * *}$ & $-0.2973^{* *}$ & $0.0003^{* * *}$ & $-0.9107^{* * *}$ & 0.4153 & $-0.5438^{* * *}$ & -0.1648 & $2.7727^{* * *}$ & 0.4153 & 0.1846 & -0.3073 & $-0.0004^{* * *}$ & -2.9305 & $3.4151^{*}$ & -0.9553 & 0.1309 & -0.7073 & $3.4151^{*}$ \\
\hline$S P X \leftrightarrow R U T$ & -0.0152 & $-0.0714^{* *}$ & $0.0019^{* * *}$ & 0.0073 & $-0.1881^{* * *}$ & $1.6440^{* * *}$ & $-0.8535^{* * *}$ & $-0.7110^{* * *}$ & $0.3707^{* * *}$ & 0.0331 & -0.1947 & $0.0045^{* * *}$ & $0.9788^{* * *}$ & $-0.5712^{* * *}$ & $-1.8158^{* * *}$ & $0.9532^{* * *}$ & $-0.8475^{* * *}$ & $1.0744^{* * *}$ \\
\hline$R U T \leftrightarrow S P X$ & 0.0105 & $-0.0857^{* *}$ & $0.0003^{* * *}$ & 0.0434 & $-0.4265^{* * *}$ & $-0.3255^{* * *}$ & $1.5996^{* * *}$ & $0.6123^{* * *}$ & $-0.4265^{* * *}$ & 0.0679 & $-0.1871^{*}$ & $9.88 \mathrm{E}-05$ & $-0.4167^{*}$ & $0.9675^{* * *}$ & $0.4726^{* * *}$ & $-1.5569^{* * *}$ & $1.6938^{* * *}$ & $0.9675^{* * *}$ \\
\hline$S P X \leftrightarrow R U A$ & 0.0958 & -0.1489 & $0.0026^{* * *}$ & $1.4839^{* * *}$ & $-1.2266^{* * *}$ & 0.3403 & -1.2056 & -2.5091 & 2.9992 & $1.2773^{* *}$ & $-1.3978^{* * *}$ & 0.0001 & $4.4814^{* * *}$ & $-4.4988^{* * *}$ & $-0.5266^{* * *}$ & $-0.3612^{* * *}$ & 2.0593 & -1.4669 \\
\hline$R U A \leftrightarrow S P X$ & 0.0926 & -0.1534 & $0.0003^{* * *}$ & $-1.7688^{* * *}$ & $2.1148^{* * * *}$ & -0.5665 & -0.3028 & 2.3723 & 0.2255 & $1.2664^{* * *}$ & $-1.3896^{* * *}$ & $-0.0003^{* * *}$ & $-4.3851^{* * *}$ & $4.3617^{* * *}$ & $-0.3611^{* * *}$ & $-0.5569^{* * *}$ & -1.2820 & $4.3617^{* * *}$ \\
\hline$S P X \leftrightarrow N Y E$ & -0.0341 & 0.0079 & -0.0028 & $-1.3300^{* * *}$ & $1.5690^{* * *}$ & 2.6662 & -2.9453 & 1.9782 & $-1.6656 * *$ & 0.0401 & -0.0936 & -0.0004 & -1.3012 & 2.1066 & 0.2383 & 0.3599 & $-5.3579^{* * *}$ & $5.1516^{* * *}$ \\
\hline$N Y E \leftrightarrow S P X$ & -0.0057 & -0.0028 & 0.0006 & $1.6713^{* * *}$ & $-1.3430^{* * *}$ & -2.7596 & 2.2884 & $-0.9050^{* * *}$ & $-1.3430^{* * *}$ & 0.0698 & -0.1265 & -0.0020 & 2.0546 & -1.0851 & 0.7677 & -0.1789 & $6.2745^{* * *}$ & -1.0851 \\
\hline$S P X \leftrightarrow X A X$ & $-0.0671^{* * *}$ & 0.0239 & -0.0001 & $0.3571^{* * *}$ & $-0.2770^{* * *}$ & $0.8803^{* * *}$ & $0.0779^{* * *}$ & $0.3909 * *$ & 0.0215 & $0.1772^{* *}$ & 0.0957 & -0.0006 & 0.1934 & $-0.4901^{* * *}$ & $0.8475^{* * *}$ & $-1.4971^{* * *}$ & $1.1184^{* * *}$ & $-0.8077^{* * *}$ \\
\hline$X A X \leftrightarrow S P X$ & -0.0056 & $0.0528^{* * *}$ & -0.0010 & $-0.0525^{*}$ & $-0.0675^{* * *}$ & $0.8409^{* * *}$ & $0.0625^{* * *}$ & $0.3407^{* * *}$ & $-0.0675^{* * *}$ & -0.0873 & 0.0436 & $-0.0031^{* * *}$ & -0.1492 & -0.2096 & $-1.5200^{* * *}$ & $1.2807^{* * *}$ & $-0.9783^{* * *}$ & -0.2096 \\
\hline$R U I \leftrightarrow N Y E$ & $-0.1685^{* * *}$ & $0.1635^{* * *}$ & $-0.0010^{* * *}$ & $0.6156^{* * *}$ & $-0.4724^{* * *}$ & $-0.3276^{* * *}$ & $1.2137^{* * *}$ & 0.0824 & $0.3579^{* * *}$ & 0.2359 & -0.3069 & $-0.0094^{* * *}$ & $-6.0288^{* * *}$ & $5.4163^{* * *}$ & $1.3027^{* * *}$ & $-0.9871^{* * *}$ & 0.4771 & 0.2387 \\
\hline$N Y E \leftrightarrow R U I$ & $-0.1228^{* *}$ & $0.1096^{*}$ & -0.0016 & $0.1677^{* * *}$ & -0.0474 & $0.6577^{* * *}$ & $0.2668^{* * *}$ & $0.1140^{* *}$ & -0.0474 & 0.2689 & -0.3365 & $-9.48 \mathrm{E}-05$ & $5.5212^{* * *}$ & $-6.1041^{* * *}$ & -0.4751 & $0.7948^{* *}$ & -0.3763 & $-6.1041 * * *$ \\
\hline$R U I \leftrightarrow X A X$ & $-0.0492^{* *}$ & 0.0186 & -0.0019 & $-0.1219^{* * *}$ & $-0.1707^{* * *}$ & $0.9251^{* * *}$ & -0.0197 & $0.3857^{* * *}$ & 0.0171 & $-0.1966^{* * *}$ & $0.1206^{*}$ & -0.0010 & 0.0310 & 0.2637 & $1.2896 * * *$ & $-0.5386^{* * *}$ & $-0.8326^{* * *}$ & $0.7182^{* *}$ \\
\hline$X A X \leftrightarrow R U I$ & 0.0197 & $0.0345^{*}$ & $0.0021^{* * *}$ & $-0.1964^{* * *}$ & $0.2249^{* * *}$ & $0.6889^{* * *}$ & $0.2629^{* * *}$ & $0.5297^{* * *}$ & $0.2249^{* * *}$ & -0.1107 & 0.0644 & $0.0035^{* * *}$ & -0.1203 & $0.4651^{*}$ & $0.1981^{* * *}$ & $0.6146^{* * *}$ & $0.8856^{* * *}$ & $0.4651^{*}$ \\
\hline$R U T \leftrightarrow N Y E$ & $-0.0599^{* *}$ & 0.0107 & $-0.0031^{* * *}$ & $0.3165^{* * *}$ & $-0.5432^{* * *}$ & -0.5491 & -0.5085 & 0.1822 & 0.3650 & $-0.1752^{*}$ & 0.0808 & $-0.0059^{* * *}$ & -0.2463 & -0.2035 & $-0.7783^{* * *}$ & -0.0643 & $1.1874^{* * *}$ & $-1.3182^{* * *}$ \\
\hline$N Y E \leftrightarrow R U T$ & -0.0496 & -0.0259 & -0.0013 & 0.0495 & $-0.0662^{* * *}$ & 0.5150 & -1.0023 & 0.3067 & $-0.0662^{* * *}$ & -0.1808 & 0.0491 & $1.35 \mathrm{E}-06$ & -0.3251 & 0.0894 & $-0.6711^{* * *}$ & $-0.2016^{* * *}$ & $-1.4285^{* * *}$ & 0.0894 \\
\hline$R U T \leftrightarrow X A X$ & $-0.0575^{* * *}$ & 0.0254 & $0.0041^{* * *}$ & $0.1603^{* * *}$ & $0.2745^{* * *}$ & $-0.8419^{* * *}$ & $0.0823^{* * *}$ & 0.3643 & 0.0197 & -0.0973 & 0.0159 & $-0.0069^{* * *}$ & 0.1504 & $0.3244^{* *}$ & -0.3482 & $1.4545^{* * *}$ & $0.8022^{* * *}$ & $-0.8237^{* * *}$ \\
\hline$X A X \leftrightarrow R U T$ & 0.0002 & $0.0496^{* *}$ & $0.0015^{* * *}$ & $0.3309^{* * *}$ & $-0.1736^{* * *}$ & $-0.8285^{* * *}$ & $-0.2146^{* * *}$ & 0.4271 & $-0.1736^{* * *}$ & -0.0346 & -0.0023 & $2.74 \mathrm{E}-0.5$ & $0.5379^{* * *}$ & $-0.2537^{* * *}$ & 0.4215 & 0.3328 & $-0.2942^{* *}$ & $-0.2537^{* * *}$ \\
\hline$R U A \leftrightarrow N Y E$ & -0.0231 & 0.0042 & 0.2903 & 0.3179 & 0.0322 & -0.2935 & -0.1895 & 0.1010 & 0.0997 & -0.0201 & -0.0254 & $-0.0156^{* * *}$ & $-3.9127^{* * *}$ & $3.5819^{* * *}$ & -0.0030 & 0.0124 & -0.8202 & 1.3908 \\
\hline$N Y E \leftrightarrow R U A$ & -0.0046 & -0.0237 & $-0.0026^{* * *}$ & 0.3039 & 0.0134 & $-0.4121^{* * *}$ & -0.0426 & 0.0897 & 0.0134 & 0.0175 & -0.0642 & -0.0001 & $3.4740^{* * *}$ & $-3.8517^{* * *}$ & -0.0093 & -0.0966 & 1.8101 & $-3.8517^{* * *}$ \\
\hline$R U A \leftrightarrow X A X$ & $-0.0572^{* * *}$ & 0.0254 & $0.0005^{* * *}$ & $0.1629^{* * *}$ & 0.0314 & $-0.8749^{* * *}$ & $-0.0923^{* * *}$ & $0.5998^{* * *}$ & $-0.3274^{* * *}$ & $-0.1691^{* *}$ & 0.0939 & 0.0018 & $-0.2964^{*}$ & $0.5866^{* * *}$ & $-0.9174^{* * *}$ & $1.6138^{* * *}$ & $1.0447^{* * *}$ & $-0.6690^{* * *}$ \\
\hline$X A X \leftrightarrow R U A$ & 0.0002 & $0.0496^{* *}$ & $0.0033^{* * *}$ & $0.2408^{* * *}$ & $0.1539^{* * *}$ & $-0.8430^{* * *}$ & -0.0062 & -0.0253 & $0.1539^{* * *}$ & -0.0868 & 0.0427 & $-0.0032^{* * *}$ & $0.2578^{*}$ & 0.0994 & $1.5910^{* * *}$ & $-1.2913^{* * *}$ & $-0.8913^{* * *}$ & 0.0994 \\
\hline
\end{tabular}

Notes. Table 7A reports the mean and volatility spillovers from Index1 to Index2 via an assymetric VAR(1)

-ABEKK(1,1,1) model. The present table concerns the Full sample, and Lehman crisis sub-sample. Regarding notation look at subsection 3.1. ${ }^{*}, * *$ and $* * *$ indicate Newey-West statistical significance at a $10 \%, 5 \%$ and $1 \%$ significance level. 
Table 7B. VAR(1)-A BEKK(1,1,1) model estimates (EU crisis sub-sample, and post-crisis sub-sample)

\begin{tabular}{|c|c|c|c|c|c|c|c|c|c|c|c|c|c|c|c|c|c|c|}
\hline & \multicolumn{2}{|c|}{ Mean Equation } & \multicolumn{7}{|c|}{ Variance Equation } & \multicolumn{2}{|c|}{ Mean Equation } & \multicolumn{7}{|c|}{ Variance Equation } \\
\hline & $\Phi_{11} / \Phi_{21}$ & $\Phi_{12} / \Phi_{2}$ & $C_{11} / C_{22}$ & $A_{11} / A_{22}$ & $A_{12} / A_{21}$ & $B_{11} / B_{22}$ & $B_{12} / B_{21}$ & $G_{11} / G_{22}$ & $G_{12} / G_{21}$ & $\Phi_{11} / \Phi_{21}$ & $\Phi_{12} / \Phi_{2}$ & $C_{11} / C_{22}$ & $A_{11} / A_{22}$ & $A_{12} / A_{21}$ & $B_{11} / B_{22}$ & $B_{12} / B_{21}$ & $G_{11} / G_{22}$ & $G_{12} / G_{21}$ \\
\hline$D J A \leftrightarrow R U I$ & $-0.3216^{* *}$ & $0.2798^{* *}$ & $0.0105 * * *$ & $1.5172^{* * *}$ & $-1.0381^{* * *}$ & -0.0001 & -0.0001 & -0.6643 & 0.4781 & $-0.2654 * *$ & $0.4188^{* * *}$ & $-0.0064^{* * *}$ & -0.0078 & $-0.2235^{* * *}$ & $0.2269 * * *$ & $-0.2320^{* * *}$ & -0.2375 & 0.1776 \\
\hline$R U I \leftrightarrow D J A$ & -0.2125 & 0.2001 & $0.0039 * * *$ & $-1.1929^{* *}$ & $1.7037^{* * *}$ & -0.0002 & -0.0002 & 0.1175 & $1.7037^{* * *}$ & $-0.1557 * *$ & $0.3202^{* * *}$ & -0.0019 & $0.2709^{* * *}$ & $-0.5607^{* * *}$ & $0.3270^{* * *}$ & $-0.3606^{* * *}$ & $-0.5176^{* * *}$ & $-0.5607^{* * *}$ \\
\hline$D J A \leftrightarrow R U T$ & -0.1268 & 0.0319 & $0.0033^{* * *}$ & -0.0358 & $-0.3091^{* *}$ & 0.1432 & $0.3039^{* * *}$ & $1.7236^{* * *}$ & $-0.7231^{* * *}$ & -0.0456 & 0.0221 & $-0.0072^{* * *}$ & -0.1691 & 0.1001 & -0.0241 & 0.0155 & 0.3153 & -0.1320 \\
\hline$R U T \leftrightarrow D J A$ & -0.0825 & -0.0355 & $0.0067^{* * *}$ & $-0.6386^{* * *}$ & 0.2873 & $0.4229 * * *$ & 0.2036 & -0.6034 & 0.2873 & -0.0279 & -0.0015 & $-0.0053^{* * *}$ & $0.2810^{* *}$ & -0.3914 & 0.0027 & $-0.0373^{* *}$ & -0.2915 & -0.3914 \\
\hline$D J A \leftrightarrow R U A$ & $-0.4042^{* *}$ & $0.3450^{* *}$ & $0.0051 * * *$ & $\begin{array}{ll}-0.0173 \\
\end{array}$ & $\begin{array}{ll}-0.3028 \\
\end{array}$ & $0.2480^{* *}$ & $0.3026^{* * *}$ & $1.3234^{* * *}$ & $\begin{array}{ll}-0.3578 \\
\end{array}$ & $\begin{array}{ll}-0.0318 \\
\end{array}$ & 0.0121 & -0.0076 & $\begin{array}{ll}-0.2038 \\
\end{array}$ & $0.3940^{*}$ & 0.0548 & 0.1302 & 0.0669 & -0.1068 \\
\hline$R U A \leftrightarrow D J A$ & $-0.3625^{*}$ & $0.3252^{*}$ & $0.0039 * * *$ & -0.1515 & -0.2086 & $0.3437^{* * *}$ & $0.2823^{* *}$ & -0.1172 & -0.2086 & -0.0325 & 0.0269 & -0.0022 & $0.5471 * *$ & -0.3120 & 0.1117 & -0.0455 & 0.0755 & -0.3120 \\
\hline$D J A \leftrightarrow N Y E$ & $-0.3694^{* *}$ & $0.2628^{* *}$ & $0.0046^{* * *}$ & $0.7779^{* * *}$ & -0.1946 & $0.2320^{* *}$ & $0.3396 * *$ & 0.1879 & $0.4253^{* *}$ & -0.0649 & 0.0335 & $-0.0072^{* * *}$ & -0.0298 & 0.1436 & $0.3349^{* * *}$ & -0.1379 & $-0.8222^{* *}$ & $0.9337^{* * *}$ \\
\hline$N Y E \leftrightarrow D J A$ & $-0.4532^{* *}$ & $0.3324^{* *}$ & $0.0042^{* * *}$ & 0.2058 & $0.4536^{*}$ & $0.3621^{* * *}$ & $0.2483^{* *}$ & $0.3974 *$ & $0.4536^{*}$ & -0.0414 & 0.0134 & $-0.0025^{* * *}$ & 0.3675 & -0.2469 & -0.1041 & 0.2291 & $0.9547^{* *}$ & -0.2469 \\
\hline$D J A \leftrightarrow X A X$ & -0.1349 & 0.0529 & $0.0043^{* * *}$ & $-0.6764^{* * *}$ & $0.3810^{* *}$ & 0.4670 & 0.0931 & $0.6099^{*}$ & $0.4958^{* *}$ & -0.0713 & 0.0574 & $-0.0072^{* * *}$ & 0.1036 & -0.0565 & -0.0201 & $-0.0252^{* * *}$ & -0.1096 & $0.2657^{* *}$ \\
\hline$X A X \leftrightarrow D J A$ & -0.0679 & 0.0507 & $0.0068 * *$ & 0.1660 & -0.2536 & 0.0934 & 0.4742 & 0.0011 & -0.2536 & -0.0431 & 0.0495 & $-0.0058^{* * *}$ & -0.0362 & 0.2066 & -0.0453 & -0.0278 & 0.0099 & 0.2066 \\
\hline$D . J I \leftrightarrow R U I$ & 0.0244 & 0.0581 & $0.0103^{* * *}$ & -0.3887 & 0.0728 & 0.0013 & -0.0010 & $-2.1477^{* * *}$ & $2.1482^{* * *}$ & $0.2761^{* * *}$ & $0.3571^{* * *}$ & -0.0064 & 0.1673 & -0.1794 & $0.1096^{* * *}$ & -0.3332 & -0.0558 & $0.3935^{* * *}$ \\
\hline$R U I \leftrightarrow D J I$ & 0.0125 & 0.0507 & $0.0026^{* * *}$ & 0.5163 & $-0.8486^{*}$ & -0.0004 & 0.0023 & $2.5573^{* * *}$ & $-0.8486^{*}$ & $0.2047^{* * *}$ & $0.3144^{* * *}$ & -0.0015 & 0.3199 & -0.2525 & 0.2284 & -0.4853 & -0.4121 & -02525 \\
\hline$D . J I \leftrightarrow R U T$ & -0.0136 & -0.0161 & $5.13 \mathrm{E}-06$ & -0.8969 & 0.2163 & 0.1186 & $0.3768^{* * *}$ & -0.5899 & 0.7396 & -0.0891 & 0.0431 & $-0.0066^{* * *}$ & 0.1593 & 0.0542 & -0.1449 & $-0.0978^{* * *}$ & -0.3577 & 0.1000 \\
\hline$R U T \leftrightarrow D J I$ & -0.0744 & -0.0191 & 0.0062 & 0.4655 & -1.4745 & $0.5146^{* * *}$ & 0.1573 & 1.2673 & -1.4745 & -0.0685 & 0.0257 & -0.0050 & -0.1658 & 0.4963 & -0.0050 & 0.0050 & 0.1960 & 0.4963 \\
\hline$D J I \leftrightarrow R U A$ & -0.1875 & 0.1126 & $0.0110^{* * *}$ & -0.5983 & $0.777^{* *}$ & $0.1241^{* * *}$ & 0.0374 & $0.7412^{*}$ & $-0.9270^{* *}$ & -0.0953 & 0.0363 & $-0.0074^{* * *}$ & 0.0397 & -0.0359 & 0.4731 & -0.2724 & $0.2477^{*}$ & -0.04527 \\
\hline$R U A \leftrightarrow D J I$ & -0.2897 & 0.1869 & $0.0029^{* * *}$ & 0.7446 & -0.5914 & 0.0309 & 0.1580 & $-1.3457^{* * *}$ & -0.5914 & -0.0946 & 0.0511 & $-0.0026^{* * *}$ & -0.0125 & 0.0047 & -0.2843 & 0.4955 & -0.0420 & 0.0047 \\
\hline$D J I \leftrightarrow N Y E$ & $-0.3100^{*}$ & 0.2137 & $0.0106 * *$ & -0.3720 & 0.4530 & $-0.0507^{* * *}$ & -0.0546 & $-1.4479^{* * *}$ & $1.5625^{* * *}$ & -0.0644 & 0.0071 & $-0.0074^{* * *}$ & 0.1234 & -0.0471 & 0.4529 & -0.2217 & -0.3817 & 0.4829 \\
\hline$N Y E \leftrightarrow D J I$ & $-0.4162^{* *}$ & $0.2917^{*}$ & 0.0009 & 0.6330 & -0.6764 & $0.0514^{* * *}$ & 0.0426 & $1.7906^{* * *}$ & -0.6764 & -0.0827 & 0.0281 & $-0.0026^{* * *}$ & -0.0402 & 0.1036 & -0.2422 & 0.4888 & 0.6932 & 0.1036 \\
\hline$D J I \leftrightarrow X A X$ & $-0.1388^{*}$ & 0.0911 & 0.0007 & -0.1702 & $0.4097^{* * *}$ & $0.3358^{* * *}$ & $0.3605^{* * *}$ & $1.1073^{* * *}$ & -0.0604 & -0.0695 & 0.0411 & $-0.0066^{* * *}$ & $0.3131^{* *}$ & -0.0975 & -0.0087 & -0.0018 & $0.6313^{* * *}$ & $-0.5554 * * *$ \\
\hline$X A X \leftrightarrow D J I$ & -0.1211 & 0.1183 & $0.0066^{* * *}$ & $0.4686 * *$ & -0.0722 & $0.3277^{* * *}$ & $0.3051 * *$ & -0.2204 & -0.0722 & -0.0476 & 0.0446 & $-0.0057^{* * *}$ & -0.1597 & $0.4370^{* * *}$ & -0.0050 & -0.0168 & -0.2411 & $0.4370^{* * *}$ \\
\hline$O E X \leftrightarrow R U I$ & $0.8674 * *$ & $-0.8140^{* * *}$ & 0.0119 & 0.3120 & 0.0716 & $0.0339^{* * *}$ & 0.0204 & -0.1623 & 0.3976 & $-0.3004^{* * *}$ & $0.4535^{* * *}$ & $-0.0080^{* * *}$ & 0.1886 & $0.2901 * * *$ & $-0.2848^{* * *}$ & $0.1721^{* * *}$ & -0.0781 & 0.0787 \\
\hline$R U I \leftrightarrow O E X$ & $0.8393 * * *$ & $-0.7896^{* * *}$ & 0.0013 & 0.6297 & -0.2268 & 0.0408 & 0.0524 & -0.0769 & -0.2268 & $-0.2451^{* * *}$ & $0.4122^{* * *}$ & $-3.88 \mathrm{E}-05$ & $0.6426^{* * *}$ & $-0.7929^{* * *}$ & $-0.2797^{* * *}$ & $0.2500^{* * *}$ & $0.6317^{* * *}$ & $-0.7929^{* * *}$ \\
\hline$O E X \leftrightarrow R U T$ & 0.0467 & -0.0347 & 0.0005 & $-0.7357^{*}$ & $0.6185^{* * *}$ & 0.1038 & $0.4615^{* * *}$ & $0.7990^{* *}$ & -0.0515 & $-0.1245^{* *}$ & $0.0815^{* *}$ & $-0.0072^{* * *}$ & $0.2681^{* * *}$ & -0.0103 & -0.0135 & -0.0004 & 0.4296 & -0.2798 \\
\hline$R U T \leftrightarrow O E X$ & -0.0004 & -0.0287 & -0.0011 & $0.983 * * *$ & $-0.8952^{*}$ & $0.6195 * *$ & 0.1373 & 0.2672 & $-0.8952^{*}$ & $-0.1238^{*}$ & 0.0701 & $-0.0048^{* * *}$ & $-0.3362^{* *}$ & $0.6593^{* * *}$ & -0.0025 & -0.0227 & -0.1087 & $0.6593^{* * *}$ \\
\hline$O E X \leftrightarrow R U A$ & 0.0059 & -0.03479 & $0.0122 * * *$ & -1.0262 & 1.0724 & -0.0042 & 0.0128 & 1.4386 & $-1.8286^{*}$ & -0.1711 & 0.1404 & $-0.0078^{* * *}$ & -0.2443 & 0.4546 & $0.7211^{* * *}$ & $-0.4205^{*} * *$ & 0.1214 & 0.1316 \\
\hline$R U A \leftrightarrow O E X$ & -0.0841 & 0.0426 & $0.0018 * * *$ & 1.4162 & -1.3602 & 0.0180 & -0.0064 & -2.0015 & -1.3602 & -0.2298 & 0.1996 & -0.0016 & 0.4524 & -0.2256 & $-0.4743^{* * *}$ & $0.8135^{* * *}$ & 0.0450 & -0.2256 \\
\hline$O E X \leftrightarrow N Y E$ & $0.4156^{*}$ & -0.4236 & 0.0110 & 0.2153 & -0.0332 & 0.3120 & -0.0797 & 0.7382 & $-1.0927^{* * *}$ & $-0.1758^{*}$ & $0.1698^{*}$ & $-0.0064^{* * *}$ & -0.2775 & 0.2423 & -0.0447 & 0.4480 & $1.1501^{* * *}$ & $-0.6668^{*}$ \\
\hline$N Y E \leftrightarrow O E X$ & 0.2859 & -0.2898 & $0.0022^{* * *}$ & -0.0604 & 0.1342 & -0.0802 & 0.3140 & $-0.9485 * * *$ & 0.1342 & $-0.1954^{* *}$ & $0.1853^{*}$ & $-0.0005^{* * *}$ & 0.2437 & -0.2749 & 0.3406 & -0.1547 & -0.2437 & -0.2749 \\
\hline$O E X \leftrightarrow X A X$ & -0.0692 & 0.0346 & 0.0016 & -0.0155 & $-0.4339^{* * *}$ & $0.2920^{*}$ & $0.4162^{* *}$ & $1.2594^{* * *}$ & $-0.5054^{* *}$ & -0.0656 & 0.0558 & $-0.0068^{* * *}$ & 0.1756 & 0.0901 & -0.0099 & 0.0027 & $0.5815^{* * *}$ & $-0.4210^{* * *}$ \\
\hline$X A X \leftrightarrow O E X$ & -0.0395 & 0.0613 & $0.0062^{* * *}$ & $-0.5784 * * *$ & 0.3082 & $0.3554 * *$ & $0.2493^{*}$ & -0.1942 & 0.3082 & -0.0471 & 0.0508 & $-0.0055^{* * *}$ & -0.1112 & 0.2816 & 0.0032 & -0.0194 & -0.1049 & 0.2816 \\
\hline$S P X \leftrightarrow R U I$ & -0.1910 & 0.0844 & 0.0129 & 0.2204 & -0.1907 & 0.0936 & $0.1530^{* *}$ & 0.4095 & 0.3172 & $-0.3011^{* * *}$ & $0.5223^{* * *}$ & -0.0083 & 0.0324 & $-0.1672^{*}$ & $-0.1440^{* *}$ & $0.1997^{* * *}$ & 0.04441 & -0.1672 \\
\hline$R U I \leftrightarrow S P X$ & 0.2420 & -0.3599 & -0.0011 & 0.0608 & -0.0243 & $0.1520^{* *}$ & 0.0930 & 0.9827 & -0.0243 & $-0.2217^{* * *}$ & $0.4566^{* * *}$ & $-1.27 \mathrm{E}-05$ & $0.4740^{* * *}$ & $-0.6121^{* * *}$ & $-0.4442^{* * *}$ & $0.4932^{* * *}$ & $0.4692^{* * *}$ & $-0.6121^{* * *}$ \\
\hline$S P X \leftrightarrow R U T$ & -0.0125 & -0.0306 & $0.0031 * * *$ & 0.5118 & 0.0590 & -1.1368 & $-0.4130^{* * *}$ & 0.0855 & 0.2826 & $-0.1402^{* *}$ & $0.0881^{* *}$ & -0.0061 & $0.3863^{* *}$ & -0.1671 & $-0.1367^{* *}$ & -0.2110 & $0.9105^{* * *}$ & $-0.3476^{*}$ \\
\hline$R U T \leftrightarrow S P X$ & -0.0023 & -0.0168 & $-0.0043^{* * *}$ & 0.4307 & 0.2176 & $-0.5441^{* * *}$ & -0.1679 & -0.5370 & 0.2176 & -0.1251 & 0.0635 & -0.0037 & $-0.5018^{* * *}$ & $0.8128^{* * *}$ & -0.0886 & -0.0654 & -0.4197 & $0.8128^{* * *}$ \\
\hline$S P X \leftrightarrow R U A$ & 0.0458 & -0.0879 & $0.0101^{* * *}$ & 0.3997 & 0.0997 & -0.0259 & 0.0022 & 0.0999 & 0.0999 & -0.3407 & 0.3323 & $-0.0093^{* * *}$ & 0.2257 & -0.3176 & 0.5499 & -0.1331 & -0.3836 & -0.0708 \\
\hline$R U A \leftrightarrow S P X$ & 0.0305 & -0.0740 & 0.0010 & 0.3997 & 0.0997 & -0.0259 & 0.0022 & 0.0999 & 0.0997 & -0.3471 & 0.3443 & $5.19 \mathrm{E}-05$ & 0.0527 & -0.1386 & -0.0457 & 0.4227 & -0.0453 & -0.1386 \\
\hline$S P X \leftrightarrow N Y E$ & $0.5248^{*}$ & -0.5374 & $0.0134^{* * *}$ & 0.0664 & 0.0503 & 0.0446 & -0.0023 & -0.6270 & $0.8055^{* * *}$ & -0.1440 & 0.1135 & $-0.0087^{* * *}$ & -0.1702 & 0.2995 & $0.2000^{*}$ & -0.0518 & 0.7181 & -0.3187 \\
\hline$N Y E \leftrightarrow S P X$ & 0.3774 & -0.3896 & $0.0018 * * *$ & 0.0497 & -0.0373 & -0.0032 & 0.0492 & $0.5779^{*}$ & -0.0373 & -0.1388 & 0.1082 & -0.0017 & 0.3159 & -0.2030 & -0.0150 & 0.1099 & -0.0237 & -0.2030 \\
\hline$S P X \leftrightarrow X A X$ & -0.0853 & 0.0434 & 0.0027 & 0.0679 & $0.3432^{*}$ & $0.3066 *$ & $0.4252 * * *$ & $-1.2794^{* * *}$ & $0.5381^{* *}$ & -0.0637 & 0.0511 & $-0.0070^{* * *}$ & $0.2535^{*}$ & -0.0043 & -0.0176 & 0.0045 & $0.6467^{* * *}$ & $-0.4601^{* * *}$ \\
\hline$X A X \leftrightarrow S P X$ & -0.0406 & 0.0586 & $0.0063^{* * *}$ & 0.1685 & 0.3448 & $0.3346^{* * *}$ & $0.2409^{* *}$ & 0.4204 & 0.3448 & -0.0552 & 0.0567 & $-0.0055^{* * *}$ & -0.1526 & $0.3356^{* *}$ & 0.0009 & -0.0255 & -0.1496 & $0.3356^{* *}$ \\
\hline$R U I \leftrightarrow N Y E$ & 0.3860 & -0.3889 & $0.0135 * * *$ & 0.8295 & $-0.5892^{* * *}$ & -0.0188 & -0.0029 & 0.2831 & 0.0478 & $0.3142^{* * *}$ & $-0.1801 * * *$ & -0.0075 & $0.6593^{* * *}$ & $-0.4872^{* * *}$ & $0.4705 * * *$ & $-0.2422^{* *}$ & $-0.7986^{* * *}$ & $0.6829^{* * *}$ \\
\hline$N Y E \leftrightarrow R U I$ & 0.3879 & -0.3950 & 0.0017 & -0.2997 & 0.4045 & -0.0031 & -0.0207 & 0.2209 & 0.4045 & $0.4449^{* * *}$ & $-0.3113^{* * *}$ & $5.83 \mathrm{E}-05$ & 0.1516 & -0.0271 & 0.1141 & -0.0426 & $-0.4256 * * *$ & -0.0271 \\
\hline$R U I \leftrightarrow X A X$ & $-0.1419^{*}$ & 0.0724 & $0.0113^{* * *}$ & -0.0323 & 0.2968 & 0.0001 & 0.0002 & $1.1554^{* * *}$ & $-0.8644^{* * *}$ & 0.0274 & 0.0169 & $-0.0072^{* * *}$ & -0.0197 & $0.2644^{* * *}$ & -0.0099 & 0.0005 & $-0.3900^{* *}$ & 0.2735 \\
\hline$X A X \leftrightarrow R U I$ & -0.0761 & 0.0719 & $0.0060^{* * *}$ & $0.3326^{*}$ & -0.2884 & 0.0003 & 0.0001 & -0.3913 & -0.2884 & $0.1734^{* * *}$ & $0.0770^{*}$ & $-0.0056^{* * *}$ & -0.1130 & $0.4472 * *$ & 0.0007 & -0.0186 & -0.1514 & $0.4472^{* * *}$ \\
\hline$R U T \leftrightarrow N Y E$ & 0.0634 & -0.0639 & $0.0153^{* * *}$ & 0.9986 & -0.8623 & 0.0522 & -0.0371 & 1.2320 & $-1.5485^{*}$ & $-0.1168^{*}$ & 0.0722 & -0.0036 & -0.1610 & 0.4852 & $0.8947^{*}$ & $-1.8947^{* * *}$ & $0.7693^{* * *}$ & $-1.2353^{* * *}$ \\
\hline$N Y E \leftrightarrow R U T$ & 0.0886 & -0.1194 & $0.0038^{* * *}$ & -0.6383 & 0.6438 & -0.0140 & 0.0140 & -1.0170 & 0.6438 & $-0.0622^{* *}$ & $0.0169^{*}$ & $-0.0038^{* * *}$ & 0.2528 & -0.0001 & $-1.2629^{* * *}$ & $0.5958^{* *}$ & $-0.8880^{* * *}$ & -0.0001 \\
\hline$R U T \leftrightarrow X A X$ & -0.1164 & 0.0821 & $0.0083^{* * *}$ & -0.0401 & $0.5036^{*}$ & $0.4461^{* * *}$ & 0.1872 & $1.4452^{* * *}$ & $-0.9666^{* * *}$ & -0.0383 & 7.09E-05 & -0.0090 & -0.1083 & 0.3352 & -0.0726 & -0.2768 & 02384 & -0.1846 \\
\hline$X A X \leftrightarrow R U T$ & 0.0015 & 0.0217 & $0.0065^{* * *}$ & $0.3081^{*}$ & -0.2081 & 0.1093 & $0.2586^{* * *}$ & $-0.4792^{*}$ & -0.2081 & -0.0144 & 0.0221 & $-0.0058^{* * *}$ & $0.0747^{* *}$ & -0.0087 & -0.1852 & -0.0448 & -0.0549 & -0.0087 \\
\hline$R U A \leftrightarrow N Y E$ & 0.2981 & -0.2795 & 0.0119 & 2.3945 & -2.3922 & 0.0767 & 0.0028 & 0.0169 & 0.4115 & -0.1207 & 0.1061 & $-0.0080^{* * *}$ & -0.2314 & 0.3493 & 0.2384 & -0.1842 & 0.0092 & 0.2945 \\
\hline$N Y E \leftrightarrow R U A$ & 0.2253 & -0.2099 & 0.0019 & -2.2055 & 2.1417 & 0.0019 & 0.0612 & 0.6041 & 2.1417 & -0.0750 & 0.0548 & $-0.0019^{* * *}$ & 0.4446 & -0.3087 & -0.2046 & 0.2255 & 0.2846 & -0.3087 \\
\hline$R U A \leftrightarrow X A X$ & -0.1017 & 0.0562 & 0.0032 & 0.0461 & $0.3220^{*}$ & $0.3444^{* *}$ & $0.3984^{* *}$ & $1.3514^{* * *}$ & $-0.5995^{* *}$ & -0.0588 & 0.0513 & $-0.0073^{* * *}$ & $0.3923^{* * *}$ & -0.1469 & -0.0089 & -0.0004 & -0.2200 & $0.2524^{*}$ \\
\hline$X A X \leftrightarrow R U A$ & -0.0411 & 0.0565 & $0.0056 * * *$ & $0.4383^{* *}$ & -0.2702 & $0.2964^{* *}$ & $0.2552^{* *}$ & -0.2647 & -0.2702 & -0.0542 & 0.0561 & $-0.0054^{* * *}$ & -0.1108 & 0.2802 & 0.0007 & -0.0133 & 0.1054 & $0.2802^{*}$ \\
\hline
\end{tabular}

Notes. Table 7B reports the mean and volatility spillovers from Index1 to Index2 via an assymetric VAR(1)

-ABEKK $(1,1,1)$ model. The present table concerns the EU crisis sub-sample and post-crisis sub-sample. Regarding notation look at subsection 3.1. ${ }^{*},{ }^{* *}$ and ${ }^{* * *}$ indicate Newey-West statistical significance at a $10 \%, 5 \%$ and $1 \%$ significance level. 